\title{
Doppler ultrasound and duplex scanning in the diagnosis of aortoiliac obstructive disease
}

Citation for published version (APA):

de Smet, A. A. E. A. (1997). Doppler ultrasound and duplex scanning in the diagnosis of aortoiliac obstructive disease. [Doctoral Thesis, Maastricht University]. Universiteit Maastricht. https://doi.org/10.26481/dis.19970905as

Document status and date:

Published: 01/01/1997

DOI:

10.26481/dis.19970905as

Document Version:

Publisher's PDF, also known as Version of record

\section{Please check the document version of this publication:}

- A submitted manuscript is the version of the article upon submission and before peer-review. There can be important differences between the submitted version and the official published version of record. People interested in the research are advised to contact the author for the final version of the publication, or visit the DOI to the publisher's website.

- The final author version and the galley proof are versions of the publication after peer review.

- The final published version features the final layout of the paper including the volume, issue and page numbers.

Link to publication

\footnotetext{
General rights rights.

- You may freely distribute the URL identifying the publication in the public portal. please follow below link for the End User Agreement:

www.umlib.nl/taverne-license

Take down policy

If you believe that this document breaches copyright please contact us at:

repository@maastrichtuniversity.nl

providing details and we will investigate your claim.
}

Copyright and moral rights for the publications made accessible in the public portal are retained by the authors and/or other copyright owners and it is a condition of accessing publications that users recognise and abide by the legal requirements associated with these

- Users may download and print one copy of any publication from the public portal for the purpose of private study or research.

- You may not further distribute the material or use it for any profit-making activity or commercial gain

If the publication is distributed under the terms of Article $25 \mathrm{fa}$ of the Dutch Copyright Act, indicated by the "Taverne" license above, 
DOPPLER ULTRASOUND AND DUPLEX

SCANNING IN THE DIAGNOSIS OF AORTOILIAC

OBSTRUCTIVE DISEASE 


\section{DOPPLER ULTRASOUND AND DUPLEX SCANNING IN THE DIAGNOSIS OF AORTOILIAC OBSTRUCTIVE DISEASE}

DOPPLER ULTRAGELUID EN DUPLEX SCANNING BIJ DE DIAGNOSE VAN AORTO-ILLACALE VERNAUWINGEN OF OBSTRUCTIES

\section{PROEFSCHRIFT}

ter verkrijging van de graad van doctor aan de Universiteit Maastricht

op gezag van de Rector Magnificus, Prof. Mr. M.J. Cohen ingevolge het besluit van het College van Decanen in het openbaar te verdedigen

op vrijdag 5 september 1997 des namiddags te 16.00 uur

door 
Promotores:

Prof Dr. P.JEH.M. Kitslaar

Prof. Dr. Ir. A.P.G. Hoeks

Beoordelingscommissie: Prof. Dr. J.M.A. van Engelshoven (voonzitter)

Prof. Dr. Ir. T. Arts

Dr. F.L. Moll (St. Antonius Ziekenhuis, Nieuwegein)

Prof Dr. R.S. Reneman

Financial support by the Netherlands Heart Foundation and the van Puyvelde Foundation for the publication of this thesis is gratefully acknowledged.

The publication of this thesis was also financially supported by Advanced Technology Laboratories Nederland B.V., Bard Benelux N.V., Baxter B.V., Boston Scientific Corporation, Medtronic B.V., Sigma Medical B.V., TD Medical B.V., and W.L. Gore \& Associates B.V. 
Voor wie er wat aan heeft 
ISBN 90-9010770-3

Printed by Haveka B.V., Alblasserdam 


\section{Contents}

Chapter 1 Introduction

Chapter 2 Theory, methods, and instrumentation of Doppler ultrasound and duplex scanning.

Chapter 3 Development of ultrasound techniques for assessment of aortoiliac obstructive disease.

Vascular Surgery 1996;30:311-321.

Chapter 4 A duplex criterion for aortoiliac stenosis.

Eur J Vasc Surg 1990;4:275-278.

Chapter 5 Duplex velocity characteristics of aortoiliac stenoses.

$J$ Vasc Surg 1996:23:628-636.

Chapter 6 Duplex scanning for grading aortoiliac obstructive disease and guiding treatment.

Eur J Vasc Surg 1994:8:711-715.

Chapter 7 Is there still a place for common femoral Doppler sonography in the noninvasive evaluation of aortoiliac obstructive arterial disease? Submitted

Chapter 8 Noninvasive evaluation before and after percutaneous therapy of iliac artery stenoses: the value of the Bernoulli predicted pressure gradient. Submitted

Chapter 9 General discussion and conclusions

Chapter 10 Summary - samenvatting

List of abbreviations

Dankwoord 
CHAPTER 1

Introduction 
Accurate assessment of the degree of obstructive disease in the aortoiliac arteries is a difficult clinical problem. Arteriography combined with intraarterial pressure measurements is generally considered to be essential to provide detailed anatomic and hemodynamic information necessary to formulate optimal plans for operative and/or endovascular treatment of lower extremity atherosclerotic occlusive disease. Noninvasive indirect methods, e.g. Doppler ultrasound analysis of femoral velocity waveforms, have been applied for hemodynamic assessment of obstructive disease in the aortoiliac segment, but dissatisfaction with these indirect methods led to the application of duplex scanning to the aortoiliac segment. The development of duplex scanners with low-frequency ultrasound transducers allowed acquisition of velocity information directly from the aortoiliac segments. In 1985, Jager and colleagues reported their experience using a duplex scanner to interrogate the vascular tree from the abdominal aorta to the popliteal arteries. The technique of aortoiliac duplex scanning has been systematically evaluated in only a small number of patients in a few centers and many important questions remained unanswered concerning its potential clinical usefulness.

The objectives of this study were:

- to establish the diagnostic value of duplex scanning to predict hemodynamically significant aortoiliac obstructive disease

- to determine criteria for grading aortoiliac stenoses

- to investigate the value of aortoiliac duplex scanning as tool in the noninvasive work-up of patients with peripheral arterial occlusive disease

- to compare the clinical value of other diagnostic tests such as invasive femoral artery pressure measurements and common femoral Doppler sonography to duplex scanning in the analysis of aortoiliac obstructive disease

- to validate the Doppler ultrasound assessment of pressure gradients across iliac artery stenosis with the use of the modified Bernoulli equation

To answer these questions, a prospective study was started comparing the results of duplex scanning with the results of intraarterial pressure measurements, intraarterial arteriography, and common femoral Doppler sonography in patients with peripheral arterial insufficiency of the lower limbs. The results of these tests were also analyzed in relation to the clinical decision making process. The clinical research has been done in the Department of Surgery of the Uniwersity Hospital Maastricht between December 1988 and July 1992. Velocity and pressure data for investigation of the Bernoulli calculated pressure gradient of iliac artery stenosis were obtained from the Dutch Iliac Stent Trial in the period from November 1993 through August 1996. 
CHAPTER 2

Theory, methods, and instrumentation of Doppler ultrasound and duplex scanning 


\section{The Doppler principle and ultrasound}

Christian Johann Doppler (1803-1853), an Austrian mathematician and physicist, in a paper of 1842, , called attention to the fact that the electro-magnetic frequency of a luminuous body must be changed by the relative motion of the body and the observer. This frequency shift for lights, or Doppler shift, finds many applications in astronomy, where it is used to deternine the speeds at which luminuous heavenly bodies are moving toward or away from us. In 1845 the Dutch physicist Christophorus Buijs Ballot (1817-1890) proved that this Doppler effect also occurs in sound waves; the Doppler shift principle applies to waves in general. ${ }^{2}$ The detection of the motion of blood by means of an ultrasonic Doppler device was first mentioned in a report of Satomura, a Japanese physicist. ${ }^{3}$ Shortly thereafter, it was proved that the amount of frequency shift of ultrasound, backscattered from red blood cells in the flowing blood, is proportional to the velocity of the bloodcells. ${ }^{4}$ The Doppler shift $\delta f$ when an ultrasonic beam is backscattered from moving red blood cells and emitter and receiver are at the same position is given by the Doppler formula $\delta f=2 f v \cos \theta / c$. This equation relates the Doppler shifted frequency $\delta f$ (measured in $\mathrm{Hz}$ ) to the velocity $v$ of the moving blood (in $\mathrm{m} / \mathrm{s}$ ), the frequency $f$ of transmitted ultrasound (in $\mathrm{Hz}$ ), the velocity of the sound $c$ in the medium (in $\mathrm{m} / \mathrm{s}$ ), and the cosine of the angle $\theta$ between the direction of motion and the axis of the ultrasonic beam (Figure 1). ${ }^{5}$ Based on the Doppler principle, ultrasonic flowmeters were constructed and used to record blood flow through vessels.

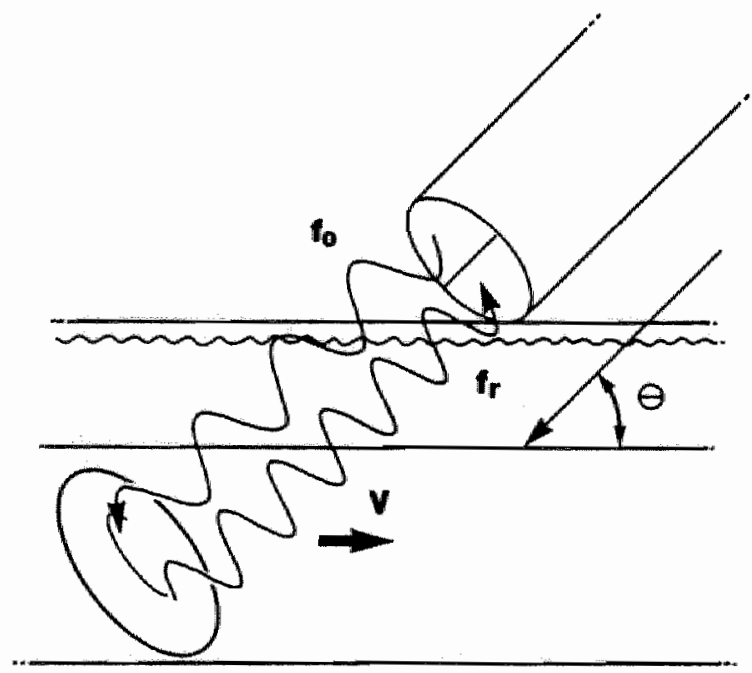

Figure 1. The Doppler shift produced by red blood cells moving toward the probe. The transmitting frequency $\left(f_{0}\right)$ is emitted and backscattered from red blood cells. The backscattered frequency $(f)$ is increased when the cells move toward the probe. The velocity of red blood cells is represented by and the angle at which the sound beam intersects the velocity vector is indicated by $\theta$. From Sumner ${ }^{18}$ 


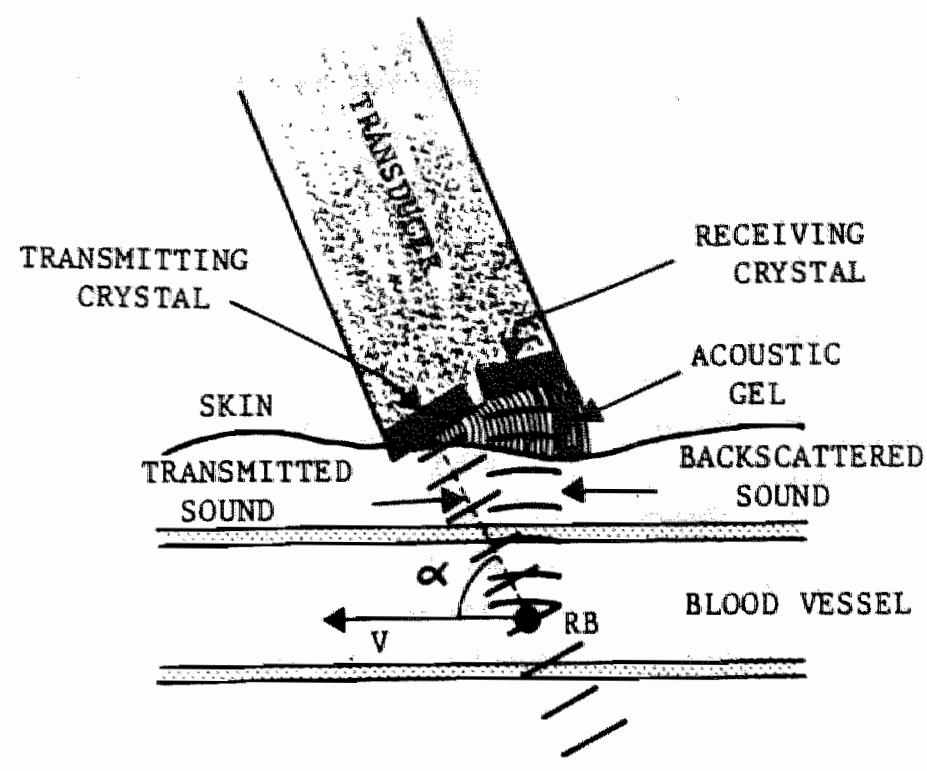

Figure 2. The principle of continuous wave Doppler flowmetry. The arrow indicates the flow velocity (v) direction. $R B=$ red blood cell and $\alpha=$ the angle between the transmitted sound beam and the direction of flow. From Rereman et al."

\section{Continuous wave Doppler}

The simplest Doppler instrument is the continuous wave (CW) Doppler shift detector (Figure 2). In a continuous wave Doppler instrument an oscillator causes a sinusoidal electrical waveform to drive a transmitting piezoelectric cristal at its resonant frequency to emit a continuous beam of ultrasound into the tissues through an acoustic gel coupling with the skin. With the use of a CW system, everything in the path of the beam is insonated and the transmitting ultrasound is reflected from various acoustic interfaces within the body. Moving structures such as red blood cells provide a reflective interface, which causes backscattered ultrasound to be shifted in frequency by an amount proportional to the velocity of these blood cells, according to the Doppler formula. The backscattered signal is received by a second piezoelectrical crystal in the Doppler probe. This received signal is referenced to the transmission frequency, and the frequency difference is detected and amplified as an audible signal. The signal may be processed further for graphic recording employing analog or sound spectrum analysis to obtain a velocity signal as a function of time (sonogram). ${ }^{6}$ The method of choice for Doppler signal processing is real-time spectral analysis of the Doppler signal. ${ }^{7}$ The transmission frequency in most devices used for clinical evaluation of peripheral arterial disease ranges between 5 and $10 \mathrm{Mhz}$.

Simple nondirectional CW Doppler equipment is incapable of determining the direction 
of bloodflow relative to the Doppler probe. Directional flow information is possible by the identification and separation of positive and negative Doppler frequency shifts using special signal analysis techniques. ${ }^{-12}$

\section{Pulsed Doppler}

The pulsed Doppler system was devised to obtain Doppler data of a single vessel without the superimposed Doppler signal of another nearby vessel (Figure 3). In pulsed Doppler systems a single crystal is used for alternately transmission and reception. The ultrasonic pulsed Doppler instrument consists of a radiofrequency oscillator operating in the range of 1 to $20 \mathrm{Mhz}$. The Doppler pulse consists of a series of cycles at the ultrasonic carrier frequency. These pulses are emitted at a high repetition frequency and the returned signals are received during the intervals between two pulses. In pulsed Doppler systems single-gate and multi-gate instruments can be distinguished. In single-gate pulsed Doppler systems an electronic gate selects the returned Doppler shifted signal from a single depth in the tissue while rejecting the signals from all other depths. ${ }^{13-16}$ In this way, Doppler data of a sample volume with a choosen size can be obtained from a desired region in a single artery. The audio signal generated by the pulsed Doppler unit is similar to the CW Doppler signal and can be analyzed likewise to obtain an analog velocity recording or sonograms. The multi-gate pulsed Doppler systems allow the online recording of the mean velocity as an instantaneous function of time simultanously at various sites along the ultrasonic beam. With these multi-gate systems a velocity distribution along the cross section of the vessel at discrete time intervals during the cardiac cycle can be obtained. ${ }^{17}$

A major limitation of pulsed Doppler over CW Doppler devices is that the Doppler velocity range of the system is limited. The maximum Doppler velocity that can be detected unambiguously depends on the distance between probe and vessel, the angle of observation, and the transmitter frequency. If the Doppler frequency shift exceeds the limiting audio frequency (the Nyquist frequency) the frequency will not be measured correctly and a phenomena called "aliasing" occurs. Aliasing can be easily recognized on a Doppler velocity waveform tracing or from the sonogram. In a directional Doppler recording, the frequencies exceeding the Nyquist frequency are cut off at this level and plotted in the reverse direction. ${ }^{18}$

A good anatomic insight and experience is needed to place the sample volume in the desired region of the vessel and to aim the ultrasonic beam at the right angle with the vessel. This can only be achieved at readily accessible vessels. The need for an ultrasound system that combines the visualization of a vessel with Doppler flow information led to the development of the duplex system. 


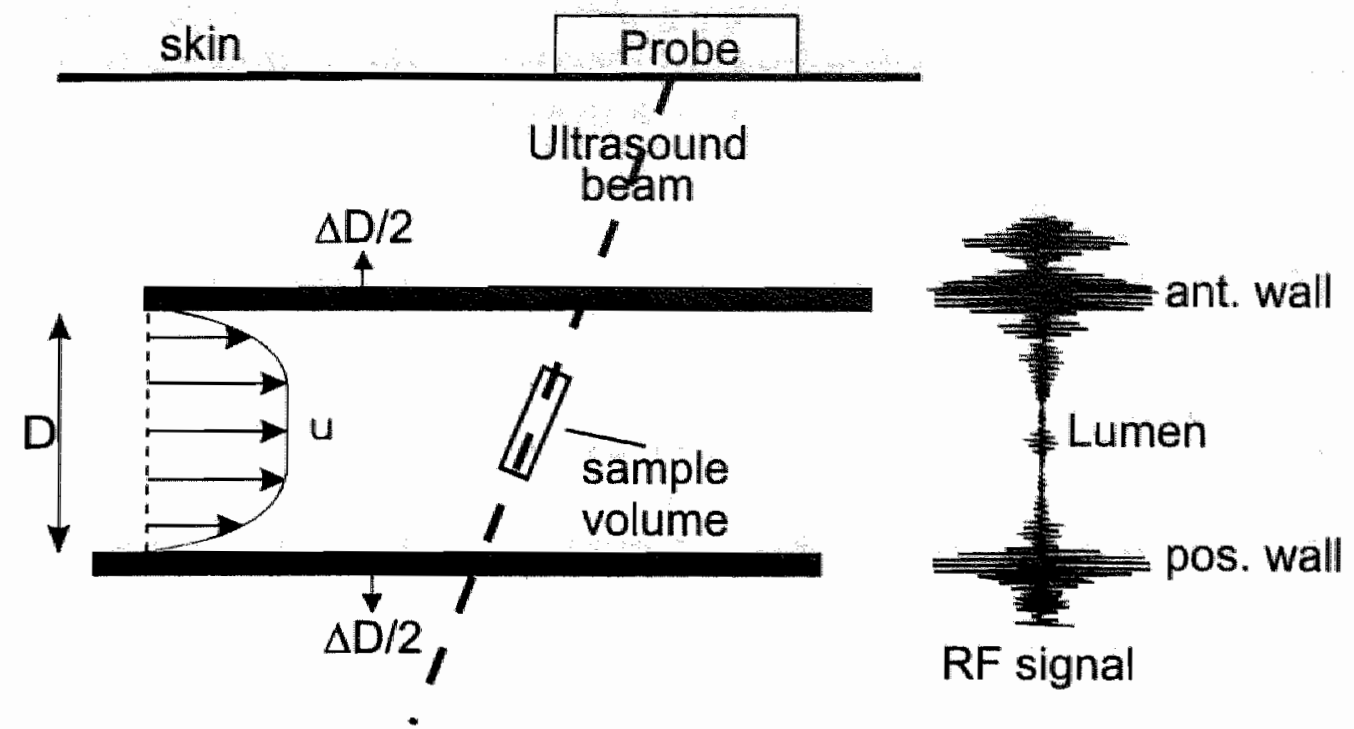

Figure 3. The principle of single-channel pulsed Doppler flowmetry. The arrows indicate the flow direction. The ultrasonic power is backscattered from the walls of the vessel and the moving red blood cells. The sample volume is choosen so that mainly the signal that contains the flow velocity information is processed.

\section{Black and white duplex seanning}

The duplex scanner is an ultrasound system which combines real time B-mode $(\mathrm{B}=$ Brightness) imaging with single-gate pulsed Doppler ultrasound. Olinger appears to have made the first two-dimensional images of peripheral blood vessels using a pulsed echo system. ${ }^{19}$ Nowadays real-time B-mode instruments are widely used for noninvasive imaging. The integration of B-mode echo and pulsed Doppler into one system was firstly described by Barber. ${ }^{20}$ The duplex system allows the visualization of a blood vessel in the longitudinal section and the positioning of the Doppler sample volume under visual control. The basic elements of a mechanical duplex system for vascular applications includes pulsed echo electronics, pulsed Doppler electronics, the scanhead, a master oscillator and control logic, and associated display and recording instrumentation. The scanhead consists of rotating echo transducer and a pulsed Doppler transducer. The transmitted and received echo and Doppler signals are controlled and processed by the pulse echo and pulse Doppler electronics. After processing, a real time B-mode image of the insonated vessel is displayed on a monitor, and the sampled pulsed Doppler data of blood flow is sent to a fast Fourier spectrum analyzer providing an online display of the sonogram. ${ }^{21}$ Next to the mechanical sector scanners, several different types of phased array systems have been designed. The phased array 
transducers are composed of many transducer crystals mounted close to each other in the scan head in either a flat or a convex linear format. In contrast to the mechanical sector probes, the phased array systems potentially allow for simultaneous display of images and Doppler spectra.

\section{Color-flow duplex scanning}

More recently color flow duplex scanners have become available. Color flow instruments present pulsed echo gray scale image of tissue and vessel structures in the conventional form but also include circuitry that allows rapid detection of mean Doppler frequency shift distribution along each scan line and the representation of these in color at the appropriate locations in the cross sectional image. The color-flow imaging instrument is therefore a combined pulsed echo gray-scale imaging instrument and pulsed Doppler multi-gate instrument. The color-flow instrument consists of a pulser, receiver, memory, and the display. The instrument uses a scanhead that contains a transducer array operating at a certain transmitting frequency for both the B-mode and Doppler functions. An ultrasound beam in rectangular or sector format is focussed through the tissue cross section. Echoes returning from the tissue are processed conventionally as in any ultrasonic instrument. To obtain short segments of the Doppler signal at each location along the beam in a specific direction a series of ultrasound bursts are emitted. From the available Doppler segments the mean of the Doppler shift frequency over depth is estimated and converted to a color. When a significant Doppler frequency shift is detected, a color is assigned at the corresponding depth along the scan line. Shades of red and blue indicate the flow direction relative to the ultrasound probe. Subsequently the line of observation is shifted to the next position. Because repetitive observations along the same line are required to obtain an estimate for the velocity the attainable image frame rate in color Doppler mode is substantially lower than in conventional B-mode. $22-26$

The duplex scanners have gradually improved considerably in imaging quality and display capabilities. A variety of scanhead configurations and transducer operating frequencies enables a single instrument to be used for multiple clinical applications, including the abdominal and peripheral arterial vessels. The addition of color flow imaging provides a new method for displaying Doppler information but does not supplant the need for Doppler spectral analysis. 


\section{References}

1. Doppler C. Ueber das farbige Licht der Dopplersterne und einiger anderer Gestime des Himmels. Prag 1842.

2. Buijs Ballot $C$. Akustüsche Versuche auf der Niederländischen Eisenbahn, nebst gelegentlichen Bemerkungen zur Theorie des Hrn. Prof. Doppler. Annalen der Physik and Chemie 1845;66:321351.

3. Satomura S. Study of the flow patterns in peripheral arteries by uitrasonics. J Acoust Soe Jpn 1959;15:151-158.

4. Franklin DL, Schegel W, Rushmer RF. Blood flow measured by Doppler frequency shitt of backscattered ultrasound. Science 1961;93:564-565.

5. Burns PN. The physical principles of Doppler and spectral analysis. J Clin Ultrasound 1987;15:567-590.

6. Barnes RW. Continuous-wave Doppler ultrasound. In Bernstein EF ed. Noninvasive diagnostic techniques in vascular disease. St Louis: The CV Mosby Co, 1985;19-24.

7. Coghlan BA, Taylor MG, King DH. On-line display of Doppler-shift spectra by a new timecompression analyser. In Reneman $\mathrm{RS}$ ed. Cardiovasculair applications of ultrasound. Amsterdam: North-Holland, 1974;55-65.

8. Mcleod FD. A directional Doppler flowmeter. Dig Int Conf Med Biol Eng 1967;7:213.

9. Nippa JH, et all. Phase rotation for seperating forward and reverse blood velocity signals. IEEE Trans Sonics Ultrasonics 1975;22:340-346.

10. Gosling RG. Extraction of physiological information from spectrum-analysed Doppler-shifted continuous-wave ultrasound signals obtained non-invasively from the arterial system. In Hill, Watson eds. IEE Medical Electronics Monographs. Stevenage: Peter Peregrinus, 1976;4:73-125.

11. Woodcock JP. Analysis of Doppler-shift signals in ultrasonic flowmeters. In Taylor D, Whanond J eds. Noninvasive Clinical Measurement. Turnbridge Wells: Pitman Medical, 1977;82-97.

12. Coghlan BA, Taylor MG. On methods for preprocessing direction Doppler signals to allow display of directional blood-velocity waveforms by spectrum analysers. Med Biol Eng Comput $1978 ; 16: 549-553$

13. Felix WR Jr, Sigel B, Gibson RJ, et al. Pulsed Doppler ultrasound detection of flow disturbances in arteriosclerosis. JCU 1976;4:275-282.

14. Reneman RS, Hoeks A, Spencer MP. Doppler ultrasound in the evaluation of the peripheral arterial circulation. Angiology 1979;30:526-538.

15. Reneman RS, Spencer MP. Local Doppler audio spectra in normal and stenosed carotid arteries in man. Ultrasound Med Bioll 1979;5:1-11.

16. Beach KW, Strandness DE Jr. Pulsed Doppler ultrasound for blood velocity measurements. In Bernstein EF ed. Noninvasive diagnostic techniques in vascular disease. St Louis: The C.V. Mosby Company, 1985;25-32.

17. Reneman RS, van Merode T, Hick P, Hoeks APG. Cardiovascular applications of multi-gate pulsed Doppler systems. Ultrasound Med Biol 1986;12:357-370.

18. Sumner DS. Ultrasound. In Kempczinski RF, Yao JST eds. Practical noninwasive vascular diagnosis. Chicago: Year Book Medical Publishers, 1987;44-79.

19. Olinger CP. Ultrasonic carotid echoarteriography. Am J Roentgenol 1969;106:282-295.

20. Barber FE, Baker DW, Natio AWC, Strandness DE Jr, Reid JM. Ultrasonic duplex echo-Doppler 
scanner. IEEE Tramsactions on Biomedical Engineering 1974;21:109-113.

21. Phillips DJ, Powers JE, Eyer MK, et al. Detection of peripheral vascular disease using the duplex scanner III. Ultrasound Med Biol 1980;6:205-218.

22. Merritt CRB. Doppler color flow imaging. J Clin Ultrasound 1987;15:591-597.

23. Merritt CRB. Real-time Doppler color-flow imaging: Other applications. In Bernstein EF ed. Recent advances in noninwasive diagnostic techniques in vascular disease. St Louis: The CV Mosby $\mathrm{Co}, 1990,42-56$.

24. Zierler RE. Color-flow Doppler imaging: Normal and abnormal carotid studies. In Bernstein EF ed. Recent adwances in noninvasive diagnostic techniques in vascular disease. St Louis: the CV Mosby Co, $1990 ; 37-41$.

25. Zierler RE. Duplex and color-flow imaging of the lower extremity arterial circulation. Seminars in Ultrasound, CT, and MRI 1990;1 1:168-179.

26. Kremkau FW. Principles of color flow imaging. The Journal of Vascular Technology $1991 ; 15 ; 104-111$. 


\title{
CHAPTER 3
}

\section{Development of ultrasound techniques for assessment of aortoiliac obstructive disease}

\author{
A.A.E.A. de Smet, F.L. Moll, P. J.E.H.M. Kitslaar
}

Vascular Surgery 1996;30:311-321 


\begin{abstract}
The development of ultrasound techniques for the assessment of aortoiliac obstructive disease is described. This period started in 1959 with the detection of bloodflow with an ultrasonic device. Continuous wave Doppler devices were designed, and the pulse waves of readily accessible vessels like the common femoral artery were examined. It was soon recognized that the functional status of the aortoiliac arteries could be assessed by the Doppler characteristics of the common femoral artery pulse wave. Qualitative and quantitative methods were used to analyze the femoral Doppler signal. The introduction of duplex scanning made it possible to evaluate the hemodynamics of aortoiliac arteries directly. At present, duplex scanning offers the best method of evaluating the aortoiliac arteries noninvasively.
\end{abstract}

\title{
Introduction
}

The choice of optimal therapy in patients with arterial insufficiency of the lower leg necessitates an accurate assessment of the contribution of the aortoiliac segment. A history of buttock or thigh claudication, dimunition of the femoral pulse, and the presence of a femoral bruit are indicators of aortoiliac obstructive disease (AIOD), but these signs and symptoms are not accurate enough for determining the relative importance of proximal and distal disease. ${ }^{1,2}$ Diagnostic tests like thigh pressure measurements and pulse volume recordings have been developed for noninvasive evaluation of AIOD. However, the difficulty to get consistently satisfactory tracings and the influence of obstructed femoropopliteal arteries on these measurements limit the value of these techniques. ${ }^{3}$ The discovery that an ultrasonic beam can investigate the behavior of bloodflow introduced a new noninvasive modality in the field of vascullar diagnostics. ${ }^{45}$

The earliest ultrasonic Doppler instruments were nondirectional continuous wave (CW) devices transmitting ultrasound with a frequency of about $5 \mathrm{MHz}$. By means of continuous wave transmission into the tissues, the instrument detects blood flow velocity by employing the Doppler effect. Backscattered ultrasound is processed and presented by the instrument as an audible signal, or the signal may be further processed for graphic recording by spectrum analysis techniques. It was quickly recognized that Doppler ultrasound could be valuable for the assessment of AIOD. It started with the indirect assessment of AIOD by the audible interpretation of the Doppler ultrasound of the common femoral pulse wave and evolved into direct assessment of AIOD by color-flow duplex scanning. The development of ultrasound techniques for the assessment of AIOD is reviewed in this article. 
Assessment of AIOD by analysis of Doppler characteristics of the common femoral puilse wave

Recording of Doppler velocity waveforms from the common femoral artery (CFA) offers a noninvasive means of identifying obstructive disease of the aortoiliac segment. The Doppler velocity tracings can be obtained by both $\mathrm{CW}$ and pulsed Doppler devices, although mostly a CW bidirectional probe with a transmitting frequency in a range from 5 to $10 \mathrm{MHz}$ is used. The width of the frequency spectrum obtained with a pulsed Doppler system is narrower than those of a CW Doppler system, because the pulsed Doppler system measures flow velocity in the midstream of a vessel, thereby rejecting signals from near the vessel walls. This difference in spectral width can be clearly heard; the sound from a pulsed Doppler system is a purer tone than that from a CW Doppler sytem. The diagnostic accuracy of the Doppler spectrum analysis in the detection of obstructive disease using either $C W$ or pulsed Doppler techniques is relatively simillar. Qualitative and quantitative methods are used for analyzing the Doppler audio and velocity signal and are discussed below. The sensitivity, specificity, and accuracy of these methods are summarized in Table I. 
Table 1. Sensilivity (sens). specificity (spec), and accuracy (acc) of several Doppler analysis methods of the common femoral artery pulse wave for detecting significant aortoiliac stenoses

Arreitography, intratarterial aorlofemoral, and femoral pressure measurements are used as gold stondards

\begin{tabular}{|c|c|c|c|c|c|c|}
\hline $\begin{array}{l}\text { Author, year and } \\
\text { reference }\end{array}$ & $\begin{array}{l}\text { Diagnostic method } \\
\text { (cutoff value) }\end{array}$ & SFA & $\begin{array}{l}\text { Gold standard with } \\
\text { cutoff value }\end{array}$ & Sens & Spec & Acc \\
\hline \multirow[t]{4}{*}{ Thiele, $1983^{15}$} & $P(4.0)$ & patent & AF $\triangle P 10$ (rest) & 94 & 82 & 86 \\
\hline & PI $(4: 0)$ & patent: & AF $\triangle \mathbb{P} 20$ (hyperemia) & 92 & 92 & 92 \\
\hline & $P \mid(4,0)$ & occluded & AF $\triangle P 10$ (rest) & 99 & 45 & 62 \\
\hline & PI $(4,0)$ & occluded & $\mathrm{AF} \triangle \mathrm{P} 20$ (hyperemia) & 92 & 51 & 69 \\
\hline \multirow[t]{2}{*}{ Johnston, $1983^{16}$} & $\operatorname{PI}(5,0)$ & patent & AF $\triangle \mathrm{P} 10$ (rest) & 96 & 99 & \\
\hline & $\operatorname{PI}(5.0)$ & occluded & AF $\triangle \mathrm{P} 10$ (rest) & 96 & 92 & \\
\hline Baker, $1984^{18}$ & PI (5.5) & & Arteriography $50 \%$ DR & 100 & 53 & 66 \\
\hline Campleell, $1984^{12}$ & $P \|(4.0)$ & & Arteriography $50 \%$ DR & 92 & 75 & \\
\hline Baird, $1980^{25}$ & $\operatorname{LT} \delta(0.60)$ & & Arteriography $50 \% \mathrm{DR}$ & 85 & 84 & \\
\hline Baker, $1984^{1 \mathrm{~s}}$ & $\operatorname{LT} 8(0.60)$ & & Arteriography $50 \% \mathrm{DR}$ & 100 & 93 & 95 \\
\hline Campleell, $1984^{12}$ & LT ô $(0.55)$ & & Arteriography $50 \% \mathrm{DR}$ & 86 & 69 & \\
\hline Burnham, $1992^{26}$ & rise time $(144 \mathrm{~ms})$ & & Arteriography $75 \%$ DR & 89 & 98 & 94 \\
\hline 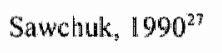 & MPFI $(0.50)$ & & FAP test & 87 & 100 & 90 \\
\hline \multirow[t]{2}{*}{ Harward, $1987^{28}$} & PFSA $(2000-2100 \mathrm{~Hz})$ & patent & Arteriography $50 \%$ DR & 93 & 93 & 93 \\
\hline & PFSA $(2000-2100 \mathrm{~Hz})$ & occluded & Arteriography $50 \% \mathrm{DR}$ & 93 & 88 & 91 \\
\hline van Asten, $1991^{25}$ & selected parameters & & FAP test & 74 & 91 & 84 \\
\hline
\end{tabular}

Abbreviations: $\mathrm{SFA}=$ superficial femoral artery, $\mathrm{AF} \triangle \mathrm{P} 10=$ aortofemoral pressure gradient of $10 \mathrm{mmHg}, \mathrm{AF}$ $\Delta \mathbb{P} 20=$ atortofemotal pressure gradient of $20 \mathrm{mmHg}$, FAP test $=$ intraarterial common femoral artery pressures, $D R=$ diameter reduction.

\section{Qualitative Doppler analysis of the common femoral pulse wave}

Audible Interpretation. The ear serves as the simplest and most readily available means of interpreting the audio output of the Doppler instrument. The spectral characteristics of the Doppler sound of the common femoral pulse wave vary depending on the patency of the aortoiliac segment. A clear multiphasic signal with a high systolic frequency corresponds to a normal flow in the aortoiliac segment. High-frequency components of the pulse wave are filtered out by an aortoiliac stenosis or high-resistance collateral channels leaving a lowpitched, monophasic Doppler signal at the femoral artery. The Doppler signal at or 
immediately distal to a stenosis sounds high-pitched, noisy, and monophasic. These characteristics reflect the increased velocity of flow within the narowed lumen and the development of disturbed or turbulent flow patterns in the jet of blood emerging from the stenosis. ${ }^{6}$ In Doppler recordings from the CFA it implies a stenosis of this artery. The different sound qualities can be recognized by exercise; for maximal accuracy a considerable experience is needed. ${ }^{7}$

Waveform Interpretation. Another approach is the visual interpretation of the analog velocity waveform or sonogram of the common femoral artery (Figure 1). A simple inspection of the spectral envelope has a considerable diagnostic value. The normal Doppler spectral envelope of the common femoral artery, corresponding to the maximum velocity waveform, is triphasic. The velocity increases rapidly in early systole, reaches a peak, and then drops almost as equally as rapidly, reversing in early diastole. In late diastole, the velocity tracing again becomes positive before returning to the zero-flow baseline. The reverse flow in diastole results from a negative pressure gradient that develops during early diastole. The absence of the reverse flow component is the first deviation from normal. More severe proximal lesions, obstructing the blood flow, prolong the upslope of the forward flow velocity component and diminish the amplitude of the systolic peak. The contour of the common femoral waveform can also be affected by distal arterial disease, especially resulting in the absence of reverse flow in patients with isolated superficial femoral artery acclusions. ${ }^{8}$ Some authors have reported high accuracy using the visual interpretation of the CFA Doppler waveform, ${ }^{9,10}$ but generally the specificity of this simple technique is regarded as too low. To obtain a more accurate and objective interpretation, various methods have been proposed for qualifying the Doppler flow signal.

A

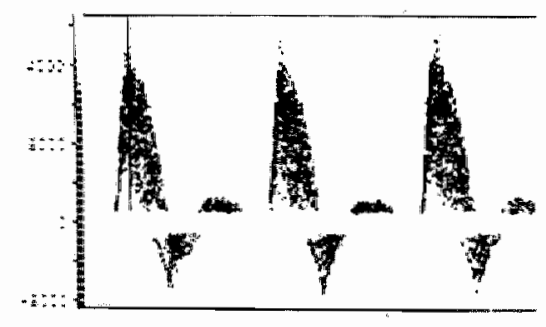

B

c

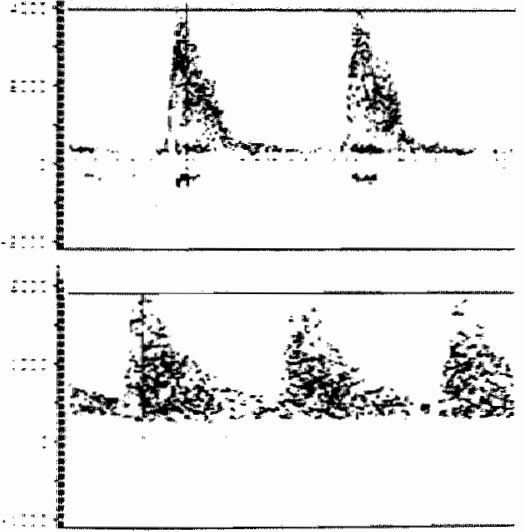

Figure 1. Sonograms of common femoral pulse wowes. (A) Normal triphasic signal, (B) absence of the reverse flow in the presence of a maderately severe aortoiltac stenosis, (C) abnormal signal with prolongation of the upslope of the forward flow velocity component and dimunition of the amplitudo in the presence of very severe aortoiliac abstructive disease. 
The uncertainty about the angle of the Doppler ultrasonic beam in relation to the stream direction of red blood cells limited quantitative velocity evaluation. In an effort to circumvent this difficulty, Gosling et al. "introduced the pulsatilty index, which does not require the knowledge of this angle. Since then, a large number of similar evaluation methods have been developed.

The Pulsatility Index. The pulsatility index (PI) was the first objective method of velocity waveform analysis. "The pulsatility index is defined as the peak to peak height of the Doppler wave divided by its mean value over the cardiac cycle. The mean values of the PI from the common femoral artery of healthy persons range from 7.1 to 11.8 . With advancing aortoiliac stenosis, the femoral PI decreases and drops to 3 and even to 2 in very severe stenosis. ${ }^{12,13}$ Several authors have shown that the femoral PI is also reduced by advanced disease of the superficial femoral artery, ${ }^{14,15}$ resulting in a low specificity of the femoral PI in assessing hemodynamically significant aortoilliac stenosis. Johnston et al. ${ }^{16,17}$ achieved a high accuracy with this technique, but the results reported by other investigators have been less promising. ${ }^{6,12,15,18}$ In general, a normal PI ( $>4.0$ ) probably rules out significant aortoiliac stenosis and an abnormal index must be interpreted with caution, especially in the presence of superficial femoral artery obstructive disease. ${ }^{15}$

The LaPlace Transform Analysis. The problems encountered with the PI led to a more complex method of waveform analysis. Skidmore et al. ${ }^{19 \cdot 21}$ developed the LaPlace transform method of characterizing velocity waveforms. This method describes the waveform with a third-order mathematical equation. A computer is required to perform a curve-fitting analysis of the Doppler waveform and yields the three parameters of the equation, $\omega_{0}, \gamma$, and $\delta$, that relate to arterial wall stifness, peripheral impedance, and proximal stenosis, respectively. The damping factor $\delta$ of the LaPlace transform (LT) analysis of the CFA Doppler signal is affected by a stenosis of the aortoiliac segment. The LaPlace $\delta$ increases from $\prec 0.40$ for nonstenotic aortoiliac segments to above 0.60 for $\succeq 50 \%$ aortoiliac segments. ${ }^{18}$ Some reports from the institute of Skidmore have concluded that the LaPlace $\delta$ is a more sensitive technique than the PI in the detection of iliac stenosis. ${ }^{12,18}$ These and other studies of the method have yielded sensitivity between 84 and $100 \%$ and specificity between 84 and $98 \% .22$.

The Principal Component Analysis. Another mathematical technique requiring the use of a computer is the principal component analysis (PCA). It is essentially a form of pattern recognition. The CFA waveform can be described by principal components, of which the first two convey the majority of the information. In the study reported by Macpherson and $\mathrm{al}^{22}{ }^{22}$ the PCA was more accurate than either the PI or the LaPlace $\delta$. Only limited work has been done with the PCA.

The Systolic Rise Time. The systolic rise time, also called upslope time or acceleration time, is the time interval between the onset of the systolic upslope and the maximum velocity. Kitslaar showed that the diagnostic value of the systolic rise time of the CFA Doppler signal 
was superior to the $\mathrm{PI}_{3}^{0,25}$ but he also concluded that the diagnostic value of Doppler waveform analysis of the CFA for aortoiliac stenosis is equivalent to normal physical examination. A rise time of $100 \mathrm{~ms}$ or more represented an $80 \%$ probability of a pathologic femoral artery pressure measurement. Burnham showed that a rise time of $144 \mathrm{~ms}$ or greater is associated with iliac stenosis ( $\succeq 75 \%$ diameter reduction) or occlusion. ${ }^{26}$ A prolonged rise time is specific for iliac disease and not influenced by superficial femoral artery obstruction.

\section{Analysis of the relation between an aortic Doppler signal and a femoral artery Doppler signal}

The Transit Time. The transit time is the time taken for the pressure or velocity pulse wave to travel from the heart to the CFA. Using this method, Ward et al. ${ }^{14}$ were unable to show any difference between normal subjects and patients with an iliac stenosis either less than or greater than $75 \%$. Only complete iliac oclusion was associated with a significant increase of the transit time. Others have made similar observations. ${ }^{6}$

The Mean Power Frequency Index. In this technique the relation between the aortic Doppler frequency spectrum and the femoral artery Doppler frequency spectrum is quantified by a transfer function. Downstream from an iliac stenosis, the frequency spectrum shifts to lower frequencies. The mathematical relationship between an aortic Doppler signal and femoral artery Doppler signal is different when a stenosis is present between the arterial segments. Using this technique, Sawchuk et al. ${ }^{27}$ could differentiate patients with normal arteries from those with subcritical or critical stenosis with an accuracy similar to intraarterial pressure measurements (accuracy of $92-100 \%$, depending of the degree of stenosis). Other studies of this technique have not been published since.

\section{Doppler analysis of the common femoral artery during reactive hyperemia}

Further efforts to increase the diagnostic value of Doppler analysis were made by the induction of lower limb hyperemic reactions. Quantitative Doppler spectrum analysis of blood flow velocities may become more accurate when measurements are done at rest and during reactive hyperemia.

Reactive Hyperemia Recovery Time. In this test the velocity in the CFA is recorded before and during reactive hyperemia. On cuff release a hyperemic response occurs indicated by an increase in peak femoral velocity followed by a recovery phase. The half-recovery time $\left(T_{y_{2}}\right)$ is defined as the time taken for the velocity to decrease from the peak velocity to a value midway the peak and the rest velocity. The mean $T_{1 / 2}$ value increases with increasing severity of arteriographic disease. Ward et al. ${ }^{14}$ showed that the $T_{1 / 4}$ values of the iliac stenoses differed significantly from those of the normal group.

Power Frequency Spectrum Analysis. Harward et al..$^{28}$ combined power frequency 
spectrum analysis (PFSA) with postocclusive reactive hyperemia to improwe the identification of significant proximal disease. In contrast to the usual spectrum analysis, where the spectral composition is analyzed as a function of time, in PSFA the power (or amplitude) of the recorded signal is plotted as a function of frequency. The frequency bandwidth at $50 \%$ of the maximal amplitude $\left(\mathbb{f}_{50 \%}\right)$ provided the highest diagnostic information. The $\mathrm{f}_{5 \mathrm{~s} \%}$ is essentially a measure of the extent of proximally generated turbulence. Harward et al. demonstrated a $\mathrm{f}_{90 \%}$ value of 2000 to $2100 \mathrm{~Hz}$ during reactive hyperemia as the best cutoff point to differentiate between a $\prec 50 \%$ and $\succeq 50 \%$ aortoiliac lesion (sensitivity $93 \%$, specificity $90 \%$, accuracy 92\%). No other reports of this technique have been published.

Combination of Doppler Spectrum Analysis Parameters. In a study of van Asten et al. $^{29}$ it was shown that a combination of parameters of the CFA Doppler spectrum at rest and during reactive hyperemia was able to assess the functional status of the aortoiliac segment (sensitivity $74 \%$, specificity $91 \%$, accuracy $84 \%$ ). The parameters that were the most discriminative for separation between the presence or absence of hemodynamically significant AIOD (the acceleration time and the slope of the acceleration phase at rest and during reactive hyperemia, and the resistance index during reactive hyperemia) were hardly affected by the status of the superficial femoral artery. ${ }^{30}$ This can be explained by the fact that these parameters are especially sensitive to the proximal impedance in the arterial system and less to the distal impedance governed by the status of the superficial femoral artery.

\section{Assessment of aortoiliac occlusive disease by duplex scanning}

The quantitative Doppler methods of the CFA provide information about the functional status of the entire aortoiliac segment, but they do not establish the sites of hemodynamically significant lesions. Also the quantitative assessment of moderate degrees of stenosis is not reliable with this indirect technique. ${ }^{31}$ Duplex scanning overcomes these problems by visualizing the aortoiliac arteries and assessing the blood flow characteristics through the region of disease.

The conventional duplex scanner is an ultrasound system which combines real time $B$ (B $=$ Brightness) imaging with single-gate pulsed Doppler ultrasound. It allows the visualization of a blood vessel in the longitudinal section and the positioning of the Doppler sample volume under visual control. Velocity information is obtained by placing the Doppler sample in the center stream of the artery at an angle of 60 degrees between the Doppler beam and the blood vessel axis. A stenosis is identified by the sampled velocity information; ie, the reduction of cross-sectional area at the site of a stenosis causes an increase in velocity.

Jager et al ${ }^{32}$ were the first to show that duplex scanning is an accurate method of evaluating aortoiliac segments. They described criteria based on characteristics of the Doppler flow patterns through the region of the stenosis (Figure 2). The most important parameter is the increase of peak systolic velocity (PSV) at the stenosis in respect to the prestenotic 
velocity. $A \succeq 50 \%$ stenosis is indicated by a $100 \%$ increase of the PSV.

Many authors have applied the classification eriteria described by Jager et al. ${ }^{32}, 3$ ? although in recent reports a $150 \%$ increase of the PSV or a PSV ratio of 2.5 (stenotic PSV divided by the nonstenotic PSV) are advocated to distinguish between greater than or less than $50 \%$ stenoses. ${ }^{38-44}$ The PSV ratio is also the most important parameter to grade aortoiliac arteries in $<20 \%, 20$ to $49 \%, 50$ to $74 \%$, and 75 to $99 \%$ stenoses, but additional parameters such as the absolute PSV value, the end diastolic velocity, and the presence or absence of reverse flow and spectral broadening in the Doppler spectrum are helpful in the gradation. ${ }^{45}$ The results in the publications concerning aortoiliac duplex scanning are summarized in Table III..$^{3244}$

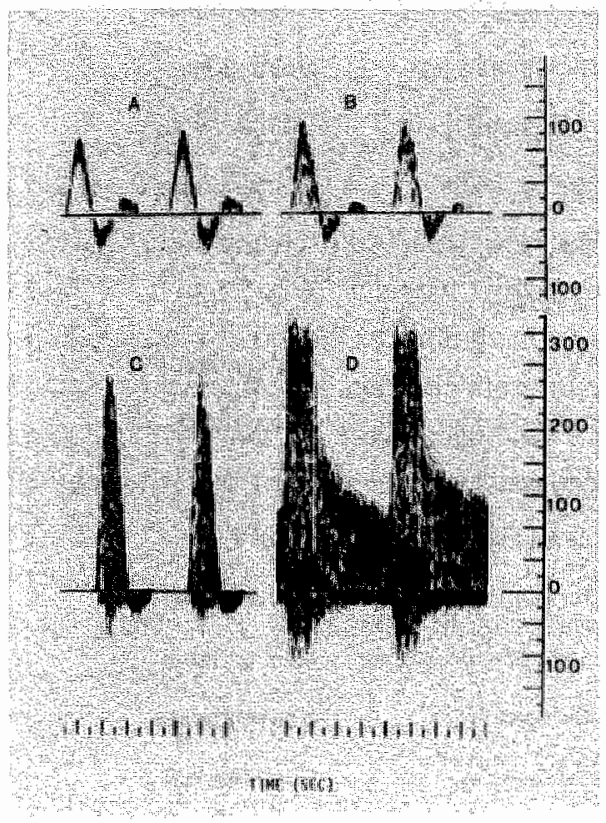

Figure 2. Spectral and velocity changes for different degrees of stenosis. (A) normal, (B) $1-19 \%$ diameter reduction, (C) $20-49 \%$ stenosis and (D) $50-99 \%$ diameter reduction. From Jager et al. ${ }^{32}$
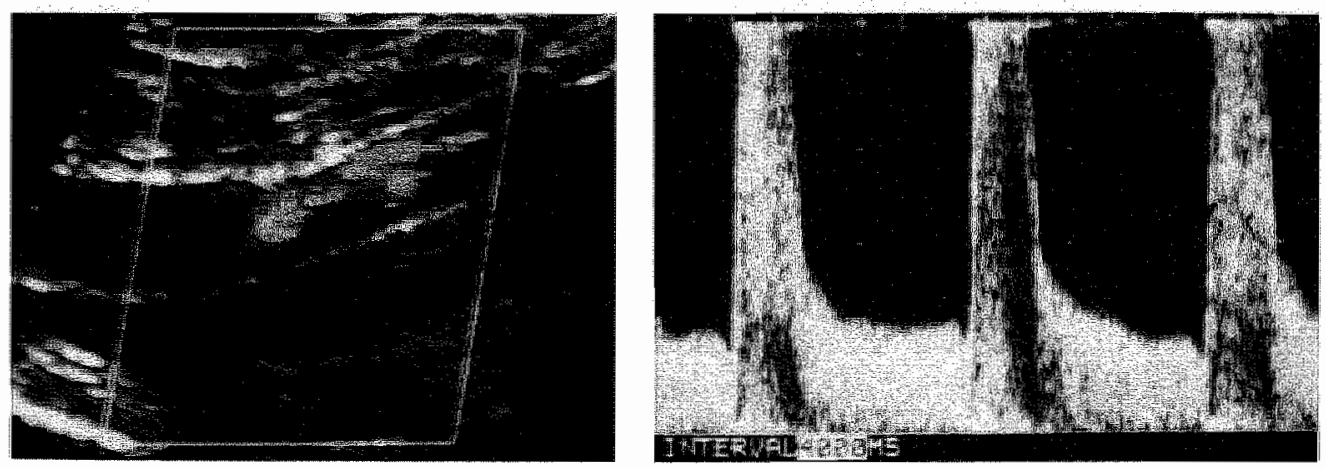

Figure 3. Color flow image of an iliac stenosis and the single-gate pulsed Doppler analysis of the bloodstream at the stenosis. 
Table II Senwitivily (sens), specifichy (spec), or koppa valtus ( $k$ ) of duplex scanning for detecting $\geq$ $50 \%$ diameter reducing aortollicic stenoses or hemodynamically significant aortolliac stenoses as assiessed by intraarterial arortoiliac or common femoral pressure measurements

The criterion is the percent increase in PSW or the PSV ratio (stentic PSV divided by the nonstenotic PSW

\begin{tabular}{|c|c|c|c|c|c|c|}
\hline $\begin{array}{l}\text { Author, year and } \\
\text { reference }\end{array}$ & Criterion & Sens & Spec & к & Gold standard & Duplex scarning \\
\hline Jager, $1984^{3.8}$ & 100 & 81 & 100 & & Arteriography & Conventional \\
\hline Koluler, $1987^{31}$ & 100 & 89 & 90 & & Arteriography & Conventional \\
\hline Langsfeld, $1988^{34}$ & 100 & 82 & 93 & & Arteriography & Conventional \\
\hline Moneta, $1992^{15}$ & 100 & 89 & 99 & & Arteriography & Color-flow \\
\hline Moneta, $1992^{36}$ & 100 & 88 & 97 & & Arteriography & Color-flow \\
\hline Rosfors, $1993^{37}$ & 100 & & & 0.78 & Arteriography & Conventional, color-flow \\
\hline Legenate, $1989^{38}$ & $\mathbb{1 5 0}$ & 92 & 98 & & Arteriography & Conventional \\
\hline Legemate, $1989^{38}$ & 150 & 73 & 97 & & ia aortoiliac pressures & Conventional \\
\hline de Smet, $1990^{39}$ & 150 & 69 & 94 & & FAP test & Conventional \\
\hline Wittens, $1990^{40}$ & 150 & 95 & 99 & & Arteriography & Color-flow \\
\hline Currie, $1995^{44}$ & 150 & 91 & 93 & & Arteriography & Color-flow \\
\hline Currie, $1995^{\text {th }}$ & 150 & 88 & 97 & & ia aortoiliac pressures & Color-flow \\
\hline Legemate, $1991^{41}$ & 2.5 & 89 & 92 & 0.81 & Arteriography & Conventional \\
\hline Legemate, $1991^{41}$ & 2.5 & 75 & 89 & 0.63 & ia aortoiliac pressures & Conventional \\
\hline Ranke, $1992^{\text {d2 }}$ & 2.4 & 87 & 94 & & Arteriography & Conventional \\
\hline dé smet, $1994^{4 t}$ & 2.5 & & & 0.82 & Arteriography & Conventional \\
\hline de Smet, $1994^{43}$ & 2.5 & & & 0.52 & FAP test & Conventional \\
\hline
\end{tabular}

Abbreviations: la en intraarterial; FAP test: intraarterial conmon femoral artery pressure measurements.

Color-flow imaging provides another way to display the Doppler information. It presents blood flow information in real time in conjunction with gray-scale anatomic imaging and is an addition to conventional duplex scanning. Color-flow aids in rapid localization and identification of arteries and detection of flow disturbances caused by arterial disease. For instance, occlusions with collateral flow are much easier to identify. Color Doppler characteristics of normal and stenotic aortoiliac arteries have been determined. A good correlation exists between the spectral waveform finding of reverse flow and the presence of triphasic flow as seen with color Doppler. ${ }^{46}$ Schroedter et al ${ }^{47}$ have shown that $60 \%$ aortoiliac stenoses are detected by color Doppler patterns with a sensitivity of $88 \%$ and a specificity of 
$96 \%$. Nevertheless, it is our opinion that color-flow imaging does not supplant the need for Doppler spectral analysis. After visual evaluation of the color flow image, the system has to be swithed back to single-gate Doppler mode for spectral analysis (Figure 3). Duplex scanning is the most accurate noninvasive technique for evaluating the aortolliac arteries. Because of bowel gas and obesity, the deeply located and often tortuous iliac arteries may be difficult to examine optimally with duplex scanning. A few investigators have been disappointed at the failure to visualize the iliac arteries optimally, ${ }^{48,49}$ but the majority have realized that a complete aortoiliac examination is possible in more than $95 \%$ of patients. ${ }^{35,37,39,44}$

\section{Conclusions}

Qualitative Doppler waveform analysis has been shown to be inaccurate in detecting aortoiliac stenosis. This can be detected more easily by simple clinical examination. Quantitative analysis of the femoral waveforms is more objective, and some institutions have achieved an acceptable accuracy with various methods of quantitative Doppler analysis. The combination of Doppler recordings at rest and during reactive hyperemia seems to increase the accuracy. However, none of these methods have gained widespread clinical acceptance. Zierler and Sumner have postulated, that many Doppler waveform analysis methods, despite the aura of accuracy that numbers convey, are little better than simple pattern recognition and perhaps not as good..$^{50}$ Duplex scanning is the only ultrasonic method that can accurately examine the area of stenosis directly, and its diagnostic value is comparable to that of arteriography. At present, it is the best method for evaluating the aortoiliac segment noninvasively. 


\section{References}

1. Myers KA, Scott DF, Devine TJ, et al. Palpation of the femoral and popliteal pulses: a study of the accuracy as assessed by agreement between multiple observers. Eur J Vasc Surg 1987;1:245249.

2. Johnston $\mathrm{KW}$, Demorais $\mathrm{D}$, Colapinto RF. Difficulty in assessing the severity of aorto-lilac disease by clinical and arteriographic methods. Angiology 1981,31;609-614.

3. Baker JD. Hemodynamic assessment of aortoiliac segment. Surgical Clinics of North America $1990 ; 70: 31-40$.

4. Satomura S. Study of the flow patterns in peripheral arteries by ultrasonics. J Acoust Soc Jpn $1959 ; 15: 151-158$.

5. Franklin DL, Schegel W, Rushmer RF. Blood flow measured by Doppler frequency shift of backscattered ultrasound. Science 1961;93;:564-565.

6. Kitslaar PJEHM. Doppler ultrasound tests in the diagnosis of chronic aortoiliac obstruction. Thesis. Maastricht 1982.

7. Sumner DS. Noninvasive assessment of peripheral arterial occlusive disease. In Rutherford RB ed. Vascular Surgery. Philadelphia: Saunders, 1989;61-111.

8. Nicolaides AN, Gordon-Smith IC, Dayandas I, Eastcott HHG. The value of Doppler blood velocity tracings in the detection of aortoiliac disease in patients with intermittent claudication. Surg 1976;80:774-778.

9. Persson AV, Gibbons G, Griffey S. Noninwasive evaluation of the aorto-iliac segment. $J$ Cardiovase Surg 1981;22;539-542.

10. Walton L, Martin TRP, Collins M. Prospective assessment of the aorto-iliac segment by visual interpretation of frequency analysed Doppler waveforms: A comparison with arteriography. Ultrasound Med Biol 1984;10;27-32.

11. Gosling RG, Dunbar G, King DH, Newman DL, Side CD, Woodcock JP, Fitzgerald DE, Keates JS, MacMillan D. The quantative analysis of peripheral arterial disease by a nonintrusive ultrasonic technique. Angiology 1971;22:52-55.

12. Campbell WB, Cole SEA, Skidmore $R$, Baird RN. The clinician and the vascular laboratory in the diagnosis of aortoiliac stenosis. Br J Surg 1984;71:302-306.

13. Demorais $\mathrm{D}$, Johnston $\mathrm{KW}$. Assessment of aorto-iliac disease by non-invasive quantitative Doppler waveform analysis. Br J Surg 1981;68:789-792.

14. Ward SA, Martin AS. Some aspects of ultrasound in the diagnosis and assessment of aortoiliac disease. Am J Surg 1980;140:260-265.

15. Thiele BL, Bandyk DF, Zierler RE, Strandness DE Jr. A systematic approach to the assessment of aortoiliac disease. Arch Surg 1983;118:477-481.

16. Johnston $\mathrm{KW}$, Kassam M, Cobbold. Relationship between Doppler pulsatility index and direct femoral pressure measurements in the diagnosis of aortoiliac occlusive disease. Ultrasound Med Biol 1983;9:271-281.

17. Johnston KW, Kassam M, Koers J, Cobbold RSC, Machattic D. Comparative study of four methods for quantifying Doppler ultrasound waveforms from the femoral artery. Ultrasound Med Biol 1984:10:1-12.

18. Baker JD, Machleder HI, Skidmore R. Analysis of femoral artery Doppler signals by laplace transform damping method. J Vasc Surg 1984;1:520-524.

19. Skidmore R, Woodcock JP. Physiological interpretation of Doppler-shift waveforms: I. 
Theoritical considerations. Ultrasound Med Biol 1980;6:7-10.

20. Skidmore $\mathrm{R}$, Woodcock JP: Physiological interpretation of Doppler-shift waveforms: II. Validation of the Laplace transform method for the characterisation of the common femoral blood velocity/time waveform. Ultrasound Med Biol 1980;6:219-225.

21. Skidmore R, WoodcockJP. Physiological interpretation of Doppler-shift waveforms: MI. Clinical results. Ultrasound Med Biol 1980;6:227-231.

22. Macpherson DS, Evans DH, Bell PRF. Common femoral artery Doppler waveforms: A comparison of three methods of objective analysis with direct pressure measurements. Br J Surg $1984 ; 71: 46-49$

23. Baird RN, Bird Dr, Clifford PC, Lusby RJ, Skidmore $\mathbb{R}$, Woodcock JP. Upstrean stenosis. Its diagnosis by Doppler signals from the femoral artery. Arch Surg 1980;115:1316-1322.

24. Baker JD, Skidmore R, Cole SE. LaPlace transform analysis of femoral artery Doppler signals: the state of the art. Ultrasound Med Biol 1989;15:13-20.

25. Kitslaar PJEHM, Jörning PJG, Köhlen JPFM. Assessment of aortoiliac stenosis by femoral artery pressure measurement and Doppler waveform analysis. Eur J Vasc Surg 1988;2:35-40.

26. Burnham SJ, Jaques $P$, Burnham CB. Noninvasive detection of aliac artery stenosis in the presence of superficial femoral artery obstruction. J Vasc Surg 1992;16:445-452.

27. Sawchuk AP, Flanigan DP, Tober JC, Eton D, Schwarcz TH, Eldrup-Jorgensen J, Meyer JP, Durham JR, Schuler JJ. A rapid, accurate, noninvasive technique for diagnosing critical and subcritical stenoses in aortoiliac arteries. J Vase Surg 1990;12:158-167.

28. Harward TR, Bernstein EF, Fronek A. The value of power frequency spectrum analyis in the identification of aortoiliac artery disease. J Vasc Surg 1987;5:803-813.

29. van Asten WNJC, Beijneveld WJ, Pieters BR, van Lier HJJ, Wijn PFF, Skotnicki SH. Assessment of aortoiliac obstuctive disease by Doppler spectrum analysis of blood flow velocities in the common femoral artery at rest and during reactive hyperemia. Surgery 1991;109:633-639.

30. van Asten WNJC, Beijneveld WJ, van Lier HJJ, Wijn PFF, Skotnicki SH. Effect of distal occlusions on the assessment of aorto-iliac pathology by analysis of Doppler spectra. Ultrasound in Med Biol 1991;17:849-855.

31. Evans DH, Macpherson DS, Asher MJ, Bentley, Beel PRF. Changes in Doppler ultrasound sonagrams at varying distances from stenoses. Cardiovaseular Res 1982;16:631 -636.

32. Jager KA, Phillips DJ, Martin RL, Hanson C, Roederer GO, Langlois YE, Ricketts HJ, Strandness Ir DE. Noninvasiwe mapping of lower limb arterial lesilons. Ultrasound Med Biol $1985 ; 1: 1: 515-521$.

33. Kohler TR, Nance DR, Cramer MM, Vandenbrughe N, Strandness Jr DE. Duplex scanning for diagnosis of aortoiliac and femoropopliteal disease: a prospective study. Circulation 1987;76:1074-1080.

34. Langsfeld M, Nepute J, Hershey FB, Thorpe L, Auer AI, Binnington HB, Hurley JJ, Peterson GJ, Schwartz R, Woods JJ. The use of deep duplex scanning to predict hemodynamically significant aortoilliac stenoses. J Vasc Surg 1988;7:395-399.

35. Moneta GL, Yeager RA, Antonovic R et al. Accuracy of lower extremity arterial duplex mapping. J Vasc Surg 1992;15:275-284.

36. Moneta GL, Yeager RA, Lee RW et al. Noninvasive localization of arterial occlusive disease: A comparison of segmental Doppler pressures and arterial duplex mapping. $J$ Vasc Surg 1993;17:578-582.

37. Rosfors S, Eriksson M, Höglund N, Johansson G. Duplex ultrasound in patients with suspected 
aorto-lliac ocellusive disease. Eur J Vasc Surg 1993;7:513-517.

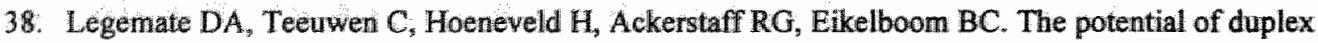
scaning to replace aorto-iliac and femoro-popliteal angiography. Eur $J$ Vasc Surg 1989;3:49-54

39. de Smet AAEA, Kitslaar PJEHM. A duplex criterion for aorto-iliac stenosis. Eur J Vase Surg $1990 ; 4: 275-278$.

40. Wittens $\mathrm{CH}$, van Houtte $\mathrm{HJ}$, Bollen $\mathrm{EC}, \mathrm{Mol} \mathrm{N}$. The imaging quality of angiodynography in the ilo-femoral tract. Eur J Vasc Surg 1990;4:611-615.

41. Legemate DA, Teeuwen C, Hoeneveld H, Eikelboom BC. Value of duplex scanning compared with angiography and pressure measurement in the assessment of aortoiliac arterial lesions. $\mathrm{Br} \mathrm{J}$ Surg 1991;78:1003-1008.

42. Ranke C, Creutzig A, Alexander K. Duplex scanning of the peripheral arteries: correlation of the peak systolic velocity ratio with angiographic diameter reduction. Ultrasound Med Biol $1992 ; 18: 433-440$.

43. de Smet AAEA, Visser K, Kitslaar PJEHM. Duplex scanning for grading aortoiliac obstructive disease and guiding treatment. Eur J Vase Surg 1994.

44. Currie IC, Jones AJ, Wakeley CJ, et al. Non-invasive aortoiliac assessment. Eur J Vasc Endovasc Surg 1995;9:24-28.

45. de Smet AAEA, Ermers E, Kitsllaar PJEHM. Velocity characteristics of aortoiliac stenoses. J Vasc Surg 1996;23:628-636.

46. Hatsukami TS, Primozich J, Zierler RE, Strandness Jr DE. Color Doppler characteristics in nomal lower extremity arteries. Ultrasound Med Biol 1992;18: 167-171.

47. Schroedter WB, Tita $D_{3}$ Holec SW. Evaluation of the aorto-iliac segment by color flow Doppler. J Vasc Tech 1994; $18: 115 \cdots 120$.

48. Mulligan SA, Matsuda $T$, Lanzer $P$, et al. Peripheral arterial occlusive disease: prospective comparison of MR angiography and color Duplex US with conventional angiography. Radiology 1991;178:695-700.

49. Cossman DV, Ellison JE, Wagner WH, et al. Comparison of contrast arteriography to arterial mapping with color-flow duplex imaging in the lower extremities. J Vasc Surg 1989;10:522-529.

50. Zierler RE, Sumner DS. Physiologic assessment of peripheral arterial occlusive disease.. In Rutherford RB ed. Vaseular Surgery. Philadelphia: Saunders, 1995, 65-117. 
CHAPTER 4

A duplex criterion for aortoiliac stenosis

A.A.E.A. de Smet and P.J.E.H.M. Kitslaar

Eur J Vasc Surg 1990;4:275-278 


\begin{abstract}
Duplex scanning is a new noninvasive test, which enables direct evaluation of aortoiliac stenoses. The usual duplex criterion for an arterial stenosis is local increase in peak systolic velocity. For hemodynamically significant aortoiliac stenoses a threshold value for this increase has not yet been established. In order to define a duplex criterion for significant aortoiliac stenoses, we prospectively investigated 97 aortoiliac segments of 49 patients suspected of obstructive aortoiliac disease. The whole segment was scanned to locate areas with high peak systolic velocities which were then compared to the velocities recorded immediately up and downstream. The value of the highest proportional velocity change was used as the criterion for duplex classification of the segment. Duplex results were compared to the outcome of invasive femoral artery pressure measurements combined with reactive hyperemia (FAP test). For a range of threshold values of the duplex criterion the specificity and sensitivity was calculated using the FAP test as the gold standard (R.O.C. analysis). The combination of the highest sensitivity and specificity were obtained in the range of $100-200 \%$ change in peak systolic velocity as duplex criterion for significant aortoiliac stenosis. The highest accuracy (88\%) was obtained at a $200 \%$ change in the peak systolic velocity.
\end{abstract}

\title{
Introduction
}

In patients with ischemic vascular disease, aortoiliac stenoses may be present. The decision regarding the appropriate treatment of an aortoiliac stenosis depends on the hemodynamic importance of that stenosis. An acceptable method of assessing the hemodynamic significance of obstructive aortoiliac disease is invasive common femoral artery pressure measurements using reactive hyperemia (FAP test). ${ }^{1,2}$ The FAP test is an indirect method of determining the severity of upstream stenoses. Duplex scanning is a new noninvasive test, which enables direct evaluation of arterial lesions. It appears to be also applicable in the aortoiliac segment. The most important duplex criterion for a hemodynamically significant arterial stenosis is a local increase in systolic velocity. ${ }^{3.5}$ but few authors have set criteria for aortoiliac duplex scanning, ${ }^{5,6}$ and arteriography is used as the gold standard in most studies. However, it is a well accepted fact that arteriography is insufficient to evaluate the hemodynamic significance of aortoiliac stensoses. ${ }^{7}$ In order to obtain duplex criteria based on hemodynamic parameters, we compared aortoiliac duplex data with the FAP test results.

\section{Patients and methods}

A total of 49 patients suspected of obstructive aortoiliac disease on clinical grounds, were prospectively studied. Except for one patient with an amputated leg, all patients 
underwent bilateral FAP testing and aortoiliac duplex scanning.

After needle puncture of the common femoral artery with a 19 gauge needle connected to a pressure transducer, blood pressures were registered at rest and during reactive liyperemia. Reactive hyperemia was induced by the intraarterial injection of $50 \mathrm{mg}$ papaverine hydrochloride. Simultanously, brachial artery blood pressures were measured noninvasively at 1 min intervals with an automatic plethysmographic blood pressure device (Dinamap). Femorobrachial systolic pressure indices were calculated at rest and at the maximum pressure drop after papaverine injection. The criterion for hemodynamically important aortoiliac stenosis was a femorobrachial index at rest below $80 \%$ or a more than $15 \%$ difference between the index at rest and the lowest index during reactive hyperemia.

All duplex examinations were performed with an ATL Ultramark IV duplex scanner (Advanced Technology Laboratories, Seattle, USA). A 3-MHz single-frequency sector transducer and a multifrequency sector transducer (with 5-, 7.5-, and 10-MHz settings) were used to generate a B-mode image of the vessels and the pulsed Doppler signals. The signals were recorded at a Doppler angle of 60 degrees with a sample volume of $1.5 \mathrm{~mm}^{3}$ placed in the center stream of the vessel. Patients were investigated after fasting for 12 hours to avoid disturbance by intestinal gases.

The whole length of the infrarenal aorta, common iliac, external iliac and common femoral arteries were scanned to locate areas with high peak systolic velocities. These peak systolic velocities were compared to the velocities immediately up and downstream. Velocity increase at vessel branching points, e.g. the aortic and iliac bifurcations, was considered physiologic. Thus, if an increased velocity existed at the origin of a branching vessel, it was only compared to the velocity immediately downstream. The value of the highest proportional increase or decrease of velocity, expressed as a percentage, was used as the criterion for duplex classification of the entire aortoiliac segment. If no flow was detected in an artery, the artery was diagnosed as occluded.

The results of duplex examination are presented as the mean \pm standard deviation (SD). In order to determine the optimum threshold value of the local velocity change for the detection of hemodynamically significant aortoiliac stenoses, the sensitivity and specificity were calculated for a range of threshold values (R.O.C. analysis). ${ }^{8}$ 
Table 1. Peak systolic velocities ( $\mathrm{cm} / \mathrm{s}$ ) in wormal and stenotic arterial segments (mean $\pm S D$ ). For the abnomal FAP tests only the peak systolic velocities at the maximum stenosis are presented Between brackets the number of analyzed arteries.

\begin{tabular}{lcc}
\hline Artery & Normal FAP & Abnormal FAP \\
\hline Infrarenal aorta & $73 \pm 29(38)$ & $275(1)$ \\
Common iliac artery & $108 \pm 61(62)$ & $288 \pm 111(14)$ \\
External iliac artery & $129 \pm 45(61)$ & $338 \pm 119(10)$ \\
Common femoral artery & $88 \pm 33(61)$ & $300(1)$ \\
\hline
\end{tabular}

\section{Results}

Of the 97 aortoiliac segments, seven had to be excluded from data analysis for various reasons. Two iliac segments were occluded, which was easily discovered by duplex examination but precluded any velocity determination; two iliac segments could not be investigated completely by duplex scanning; two FAP tests failed and an aortic stenosis in one patient precluded analysis of one side for statistical reasons. In 26 of the remaining 90 aortoilliac segments, the FAP test indicated a hemodynamically significant aortoiliac stenosis. Duplex examination revealed an abdominal aortic aneurysm not previously suspected in four patients.

The maximum peak systolic velocities in the infrarenal aorta, common iliac, external iliac, and common femoral artery of hemodynamically normal aortoiliac segments are shown in Table I. In aortoiliac segments with an abnormal FAP test the velocities at the stenoses are presented. Velocity data from aneurysmal vessels are excluded from the table.

In Figure 1, the percentage of the highest proportional velocity increase or decrease for normal and abnomal FAP tests are shown. In segments with an abnormal FAP test, the percentage of maximum velocity increase or decrease at the stenosis is $303 \pm 250 \%$ and $294 \pm$ $203 \%$, respectively. Whether the maximum peak systolic velocity at the stenosis is compared with either the prestenotic or poststenotic velocity makes no significant difference. The combinations of highest sensitivity and specificity are obtained in the range of $100-200 \%$ change in peak systolic velocity as duplex criterion for significant aortoiliac stenosis. The highest accuracy $(88 \%)$ is obtained at a $200 \%$ increase of peak systollic welocity (Figure 2 ). 


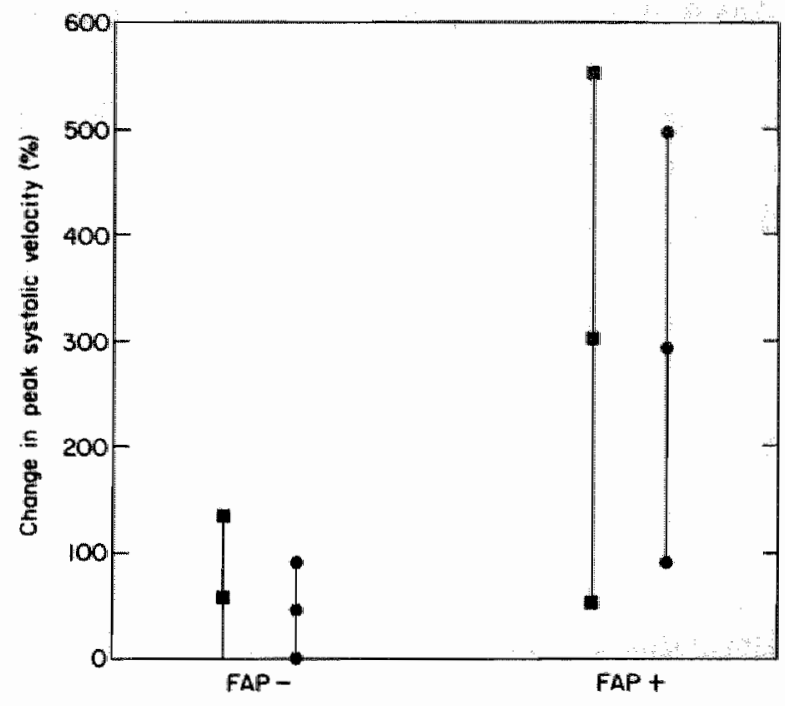

Figure 1. The maximum percentage increase (squares) or decrease (circles) of peak systolic velocity in nomal and abnormal aortoiliac segements, according to the FAP iest (mean \pm SD).

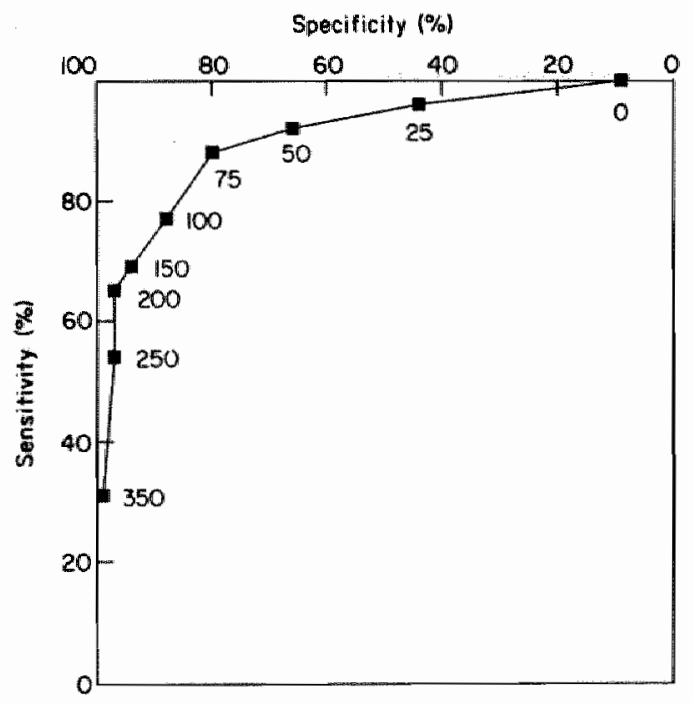

Figure 2. The R.O.C. curve for a range of threshold values of maximum peak systolic velocity changes $(0-350 \%)$ to differentiate between aortoiliac segments with or without hemodynamically significant stenosis, using the FAP test as the gold standard. 


\section{Discussion}

Until recently, evaluation of the entire aortoiliac segment by duplex scanning appeared impossible. ${ }^{9}$ With the introduction of better equipment, especially probes capable of deep duplex scanning, the iliac vessels have become accessible to this technique. Deep duplex scanning is still technically demanding, but the examinations are performed reliably in almost all patients after a training period of 3 months. Only in very obese patients may complete iliac duplex scanning be impossible. In this study only two of the 97 segments could not be investigated satisfactorily.

Jager et al. ${ }^{5}$ were the first to describe criteria by which peripheral arterial stenoses could be diagnosed. According to these authors, a stenosis with a diameter reduction of $50-99 \%$ was characterized by a more than $100 \%$ increase in peak systolic velocity at the stenosis, when compared to the velocity in the proximal segment. Secondly, a monophasic waveform with extensive spectral broadening and an abnormal distal waveform had to be present. Using these criteria their duplex results correlated very well with the arteriographic findings, especially for the aortoiliac segment. Others have used the same criteria with similar results. ${ }^{10,11}$ Better results were obtained by Legemate et al, who used a $150 \%$ increase of the peak systolic velocity as the most important parameter in predicting hemodynamically significant aortoiliac lesions (Table $\mathrm{I}$ ). ${ }^{6}$

Table II. Sensitivity, specificity, and accuracy of duplex scanning in defecting hemodynamically significant aortoiliac stenoses in various studies. For each study the percent increase of peak systolic velocity used as main criterion of hemodynamically significant stenosis and the gold standard are mentioned.

\begin{tabular}{lcccccl}
\hline Study & N & Sensitiwity & Specificity & Accuracy & Criterion & Gold standard \\
\hline Jager & 54 & 81 & 100 & & 100 & Arteriography \\
Kohler $^{31}$ & 55 & 89 & 90 & & 100 & Arteriography \\
Langsfeld $^{10}$ & 46 & 82 & 93 & & 100 & Arteriography \\
Legemate $^{6}$ & 80 & 92 & 98 & 97 & 150 & Arteriography \\
Legemate $^{6}$ & 77 & 73 & 97 & & 150 & ia aortoiliac pressures \\
Our study & 90 & 77 & 88 & 84 & 100 & ia femoral pressures \\
& 90 & 69 & 94 & 87 & 150 & ia femoral pressures \\
& 90 & 65 & 97 & 88 & 200 & ia femoral pressures \\
\hline
\end{tabular}

Duplex scanning is the only noninvasive test that directly visualizes a stenosis and evaluates its functional status. We used the change in peak systolic velocity as the only 
parameter to detect hemodynamically significant aortolliac stenoses and compared it to the outcome of an indirect hemodynamic test. Our results are comparable to those of other authors (Table I). Inclusion of the occluded iliac segments in the analysis, as other authors did, would have improved the sensitivity of our duplex examination. A further improvement might be possible by the use of additional duplex parameters like spectral broadening at the stenosis, poststenotic turbulence and forward diastolic flow at the stenosis $5.6,6012$

Our study showed that it made no difference in the overall results, whether the velocity at the stenosis was compared with either the prestenotic or poststenotic velocity. However, turbulence effects immediately downstream sometimes made it difficult to measure the exact poststenotic peak systolic velocity. Therefore, comparison of the peak systolic velocity at the stenosis proximally is preferable, unless the stenosis is sited at the origin of a branching vessel.

Depending on the purpose of the duplex examination, the optimum cut off value for aortoiliac stenosis can be selected between a 100 and $200 \%$ increase in peak systolic velocity at the stenosis. If a high specificity is required, as is the case when selecting patients for an operative procedure, the threshold is probably best set at a $200 \%$ velocity increase. If a high sensitivity is desired, as for instance in the selection of patients who can be spared elaborate aortoiliac analyses, a cutoff value of $100 \%$ velocity increase is better (Figure 2). Further studies are needed to assess to which extent additional duplex criteria can improve the results of aortoiliac duplex scanning. Clinical validation studies should place aortoiliac duplex scanning in the right perspective. 


\section{References}

1. Kitslaar PEJHM, Joming PIO, Kohlen JPFM. Assessment of aontoiliac stenosis by femoral artery pressure measurement and Doppler wave form analysis. Eur J Vase Surg 1988;2:35-40.

2. Baker AR, Macpherson DS, Evans DH, and Bell PRF. Pressure studies in arterial surgery. Eur J Vase Surg 1987,1273-283.

3. Blackshear WM, Phillips DJ, Chikos PM, et al. Carotid artery velocity patterns in normal and stenotic vessells. Stroke $1980 ; 11: 67-71$.

4. Knox RA, Breslau PJ, and Strandness DE. A simple parameter for accurate detection of severe carotid disease. Br J Surg 1982;69:230-233.

5. Jager KA, Phillips DJ, Martin RL, et al. Noninvasive mapping of lower limb arterial lesions. Ultrasound Med Biol 1985,11;515-521.

6. Legemate DA, Teeuwen $\mathrm{C}$, Hoeneveld $\mathrm{H}_{7}$ Ackerstaff $\mathrm{RGA}$, and Eikelboom $\mathrm{BC}$. The potential of duplex scanning to replace aorto-illiac and femoropopliteal angiography. Eur $\mathrm{J}$ Vasc Surg 1989;3:49-54.

7. Udoff EJ, Barth $\mathrm{KH}$, Harrington DP, Kaufman $\mathrm{SL}_{\text {, }}$ and White RI. Hemodynamic significance of illiac artery stenosis: Pressure measurements during angiography. Radiology 1979;132:289-293.

8. Sacket $\mathbb{D L}$. The interpretation of diagnostic data. In Sacket DL, Haynes RB, Tugwell $P$ eds. Clinical Epidemiology. Boston: Little, Brown and Company, 1985;59-138.

9. Grant EG. Duplex sonography in peripheral arteries. In Grant EG, White EM eds. Duplex Sonography. New York: Springer-Verlag, 1988;211-237.

10. Langsfeld $M$, Nepute J, Hershey FB, et al. The use of deep duplex scanning to predict hemodynamically significant aortoiliac stenoses. J Vasc Surg 1988;7:395-399.

11. Kohler TR, Nance DR, Cramer MM, Vandenburghe N, and Strandness DE. Duplex scanning of aortoiliac and femoropopliteal disease: a prospective study. Circ 1987:1074-1080.

12. Nicholls SC, Kohler TR, Martin RL, et al. Diastolic flow as a predictor of arterial stenosis. J Vasc Surg 1986;3:498-501. 
CHAPTER 5

Duplex velocity characteristics of aortoiliac stenoses

A.A.E.A. de Smet, E.J.M. Ermers, P.J.E.H.M. Kitslaar

J Vasc Surg 1996;23:628-636 


\section{Abstract}

Purpose: It is now possible to grade aortoiliac stenoses in broad categories based on peak systolic velocity (PSV) changes. The goal of this study was to see whether additional simple Doppler parameters would improve the grading of aortoiliac obstructive disease.

Methods: Duplex parameters were compared in 112 aortoiliac segments with four categories of arteriographic diameter reduction and four categories of common femoral artery pressure measurements. These parameters were PSV, PSV ratio, PSV difference, end diastolic velocity (EDV), the presence or absence of reverse flow, and the presence or absence of spectral broadening.

Results: The discriminative value of the PSV ratio was better than that of either the absolute PSV value or the PSV difference. A PSV ratio $<1.5$ combined with reverse flow and a clear systolic window in the Doppler spectrum predicted a diameter reduction $<20 \%$ (sensitivity, 100\%, specificity, 58\%; positive predictive value [PPV], 89\%; negative predictive value [NPV], 100\%; accuracy, 90\%). For the detection of $\succ 50 \%$ aortoiliac stenoses, a PSV ratio $\succeq 2.8$ provided $86 \%$ sensitivity and $84 \%$ specificity (PPV, $84 \%$; NPV, $85 \%$; accuracy, $85 \%$ ). An absolute PSV value of $200 \mathrm{~cm} / \mathrm{sec}$ has a high sensitivity (95\%), but a low specificity (55\%) in identifying a $\geq 50 \%$ stenoses (PPV, 68\%;NPV, 91\%; accuracy, $75 \%$. An EDV $>0 \mathrm{~cm} / \mathrm{sec}$ at the stenosis indicates a femorobrachial pressure index $<0.90$ with a $51 \%$ sensitivity and $89 \%$ specificity. An EDV $\varepsilon 40 \mathrm{~cm} / \mathrm{sec}$ indicates a femorobrachial index $<0.80$ with $50 \%$ sensitivity and $89 \%$ specificity, and indicates $\geq 75 \%$ arteriographic stenoses with 70\% sensitivity and $90 \%$ specificity (PPV, 64\%; NPV, 92\%; accuracy, 86\%). A stenosis $\succeq 75 \%$ was also identified by a PSV ratio of 5.0 with $65 \%$ sensitivity and $91 \%$ specificity (PPV, 65\%; NPV, 91\%; accuracy, 86\%).

Conclusions: The PSV ratio is the most important parameter to grade aortoiliac arteries into $<20 \%, 20 \%$ to $49 \%, 50 \%$ to $74 \%$, and $75 \%$ to $99 \%$ categories, but additional parameters such as absolute PSV value, EDV, and the presence or absence of reverse flow and spectral broadening in the Doppler spectrum are helpful in gradation.

\section{Introduction}

It is currently possible to grade aortoiliac stenoses in broad categories based on peak systolic velocity (PSV) changes.' Most published criteria allow a distinction between stenoses with $<50 \%$ diameter reduction and stenoses with $>50 \%$ diameter reduction, but distinguishing Doppler velocity patterns for further-differentiated degrees of aortoiliac stenoses is still difficult. It has been claimed that aortoiliac duplex scanning might substitute arteriography in planning conservative or invasive therapy. ${ }^{2}$ This substitution should be recommended onlly when the aortoiliac arteries can be visualized allong their whole course and the arterial stenoses can be classified more precisely than simply as $<50 \%$ or $\succ 50 \%$ stenoses. The addition of other velocity parameters to the PSV is possibly required to 
categorize the aortoiliac occlusive disease more accurately.

The value of the various Doppler velocity parameters for the diagnosis of aortoilua stenosis is still unsufficiently clarified. We assessed the additional value of simple velocity parameters for improved noninvasive grading of aortoiliac stenoses. For this purpose, 112 aortoiliac segments with minimal to severe arterial stenosis that were identified by arteriography and femoral artery pressure (FAP) measurements also were evaluated by duplex scanning.

\section{Patients and methods}

Duplex examinations and FAP studies were performed in patients who had symptoms of peripheral arterial occlusive disease and who were scheduled to undergo intraarterial arteriography to evaluate the need for interventional vascular therapy. These examinations were performed as part of the routine clinical practice to determine whether interventional aortoiliac therapy was indicated. Only patients who underwent arteriography within 3 months of their duplex examination and FAP measurements were included in the study. Aortoiliac segments that had more than one arteriographic stenosis with $>50 \%$ diameter reduction $(\mathrm{n}=$ 2) or that had an occlusion were excluded from analysis. Multiple $>50 \%$ stenoses in an aortoiliac segment can obscure the relationship between FAP measurements and duplex velocity characteristics. ${ }^{3}$ No Doppler recordings are present in occluded segments. One hunderd twelve aortoiliac segments were available for analysis.

Duplex scanning. All duplex examinations were performed with an ATL. Ultramark IV duplex scanner (Advanced Technology Laboratories; Seattle, USA) using a 3-MHz singlefrequency sector transducer and a multifrequency sector transducer (with 5-, 7.5-, and 10$\mathrm{MHz}$ settings) to generate a B-mode image of the vessels and the pulsed Doppler signals. The Doppler signals were analyzed under an Doppler angle that was set as near as possible to 60 degrees with a sample volume of $1.5 \mathrm{~mm}^{3}$ placed in the center stream of the vessel. Larger sample volumes occasionally were required for deeply located iliac arteries. Patients were examined after fasting for 12 hours to avoid disturbance by intestinal gases. For any area in which stenosis was suspected, Doppler spectra were recorded proximal to, at, and just distal. to the stenosis. A stenosis was considered to be present if a local change in velocity was observed along the aortoiliac segment. The Doppler signal parameters recorded were the PSV (in $\mathrm{cm} / \mathrm{sec}$ ), the end diastolic velocity (EDV; in $\mathrm{cm} / \mathrm{sec}$ ), the PSV ratio (stenotic PSV divided by prestenotic or poststenotic PSV), the PSV difference (difference between stenotic PSV and nonstenotic PSV), the presence or absence of spectral broadening of the Doppler signal at the stenosis, and the presence or absence of reverse flow of the Doppler signal at the stenosis. Spectral broadening was determined by visual interpretation of the Doppler velocity spectrum.

FAPs. Intraarterial FAPs were registered after a puncture of the common femoral artery with a 19-gauge needle connected to a pressure transducer. FAPs were measured at rest and 
during reactiwe hyperemia, which was induced by the intraarterial injection of $50 \mathrm{mg}$ papaverine: Simultaneously, brachial artery blood pressures were measured noninvasively at 1-minute intervals with an automatic pllethysmographic blood pressure device (Dinamap, wital signs monitor, Critikon Inc.; Tampa, Florida, USA). Femorobrachial systolic pressure indices (FBI; the systollic FAP divided by the systolic brachial artery pressure) were determined at rest and at the minimum pressure after papawerine injection. An FBI $\succ 0.90$ at rest is considered nomal, and results of the papaverine test are considered normal if the FBI reduction is $\leq 0.15$ during wasodilation. By using the FBIs at rest and during hyperaemia, the FAP test results can be categorized as follows: category 1, FBI $<0.90$ and normal papaverine test results; category $2, \mathrm{FBI} \succeq 0.90$ and abnormal papaverine test results; category $3, \mathrm{FBI} \prec$ $0.90 ;$ and category $4, \mathrm{FBI}<0.804^{4,5}$

Arteriography. Arteriography was performed routinely by transfemoral catheterization and occasionally by translumbar needle puncture. Anteroposterior views of the aortoiliac vessels were taken; multiple views were obtained in cases in which a significant lesion was suspected by the radiologist. Arterial diameter measurements were made with a caliper within the stenosis and in an unaffected artery site. The aortoiliac arteries were then graded into four categories of diameter reduction: $0 \%$ to $19 \%, 20 \%$ to $49 \%, 50 \%$ to $74 \%$, and $75 \%$ to $99 \%$.

Data analysis. The site of the aortoiliac segment with the highest PSV recorded by duplex scanning was compared with the arteriographic diameter reduction at that site and with the FAP test result. The results are presented in boxplots, representing the median (horizontal line inside the box) and the 25 th and 75 th percentile (lower and upper boundary of the box). Cases with values that are more than 3 box-lengths from the upper or lower edge of the box were considered extreme values and are designated with an asterisk. Cases with values that are between 1.5 and 3 box-lengths from the upper or lower edge of the box were considered outliers and designated with a circle. The largest and smallest observed values that were not considered outliers are also shown. Lines are drawn from the ends of the box connecting to these values. Differences between categorical data were evaluated by the MannWhitney $U$ test. Differences were considered significant if $p \prec 0.05$.

Cutoff values of the studied parameters for classifying the degree of aortoiliac stenosis were callculated with the receiver operating characteristic (ROC) method; the values presented include sensitivity, specificity, positive predictive value (PPV), negative predictive value (NPV), and accuracy. Kappa statistics were used to determine agreement between diagnostic tests. 


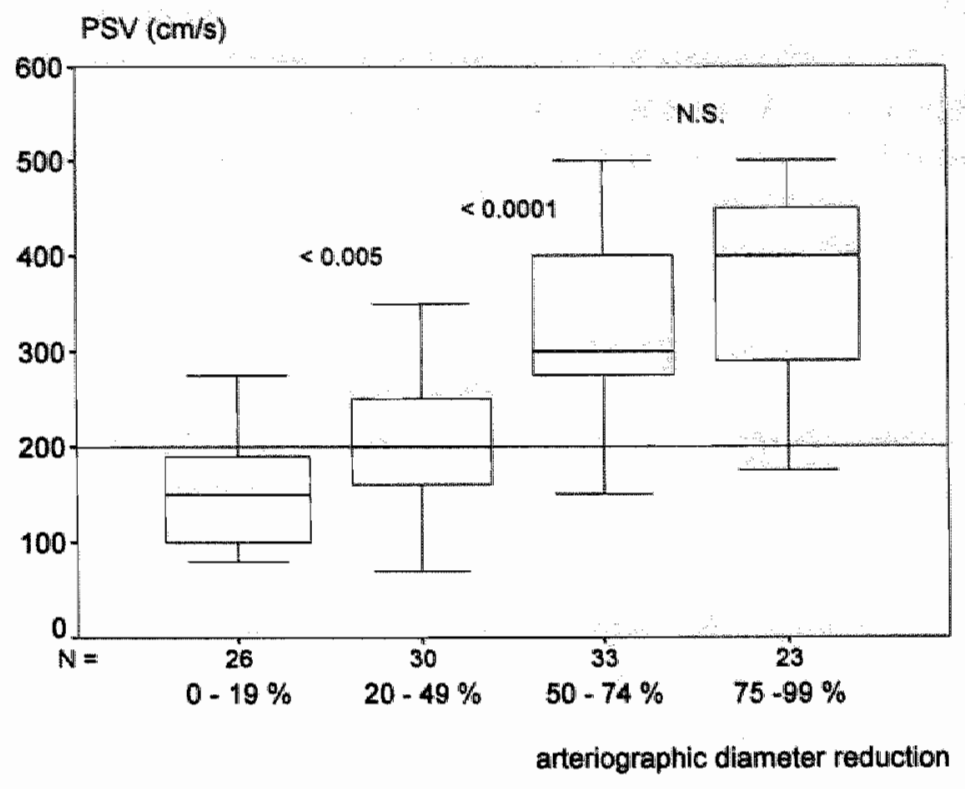

Figure 1. Boxplot of PSV by category of arteriographic diameter reduction. Horizontal line where $P S V=200 \mathrm{~cm} / \mathrm{sec}$ shows that PSV values $<200 \mathrm{~cm} / \mathrm{sec}$ coincide with a $<50 \%$ stenosis.

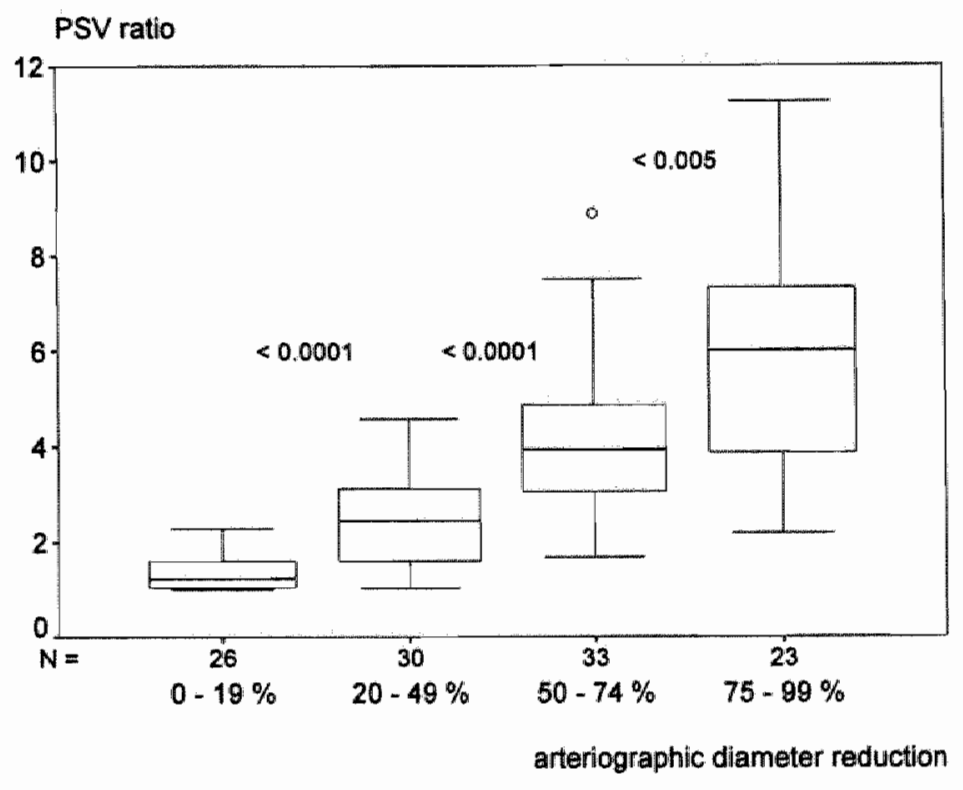

Figure 2. Boxplot of PSV ratio by categary of arteriographic diameter reduction. 


\section{Results}

Distribution of arteriographic diameter reduction. Twenty-six of the 112 aortolliac segments had diameter reduction $420 \%, 30$ segments had diameter reduction between $20 \%$ and 49\%, 33 segments had diameter reduction between $50 \%$ and $74 \%$, and 23 segments had diameter reduction between $75 \%$ and $99 \%$.

PSV. The PSV values for various degrees of aortoiliac occlusive disease according to arteriography are presented in Figure 1. The median PSV gradually rises from $150 \mathrm{~cm} / \mathrm{sec}$ for minimal disease to $400 \mathrm{~cm} / \mathrm{sec}$ for severely stenosed arteries. An aortoiliac stenosis $\succeq 50 \%$ is very unlikely with a PSV lower than $200 \mathrm{~cm} / \mathrm{sec}$. A PSV of $200 \mathrm{~cm} / \mathrm{sec}$ as a cutoff value identifies $\geq 50 \%$ stenosis $95 \%$ sensitivity, $55 \%$ specificity, $75 \%$ accuracy, a PPV of $68 \%$, and an NPV of $91 \%$

PSV ratio. The values of the PSV ratio also increase gradually with the severity of aortoiliac occlusive disease (Figure 2). The PSV ratios are significantly different between all arteriographic categories. Unlike the absolute PSV value, the PSV ratio significantly differentiates $(p<0.005$ ) between $50 \%$ to $74 \%$ and $75 \%$ to $99 \%$ lesions. The PSV ratio does not increase significantly among all FAP categories; the only significant increase ( $p<$ 0.0005 ) was in the PSV ratio from lesions with an FBI $<0.90$ (median PSV ratio 2.5 ) to lesions with an $\mathrm{FBI}<0.80$ (median PSV ratio 4.2 ). ROC analysis showed that a PSV ratio $z$ 2.8 is the optimum for predicting stenoses with $\succeq 50 \%$ diameter reduction (Figure 3 ). Table I lists the diagnostic value of several PSV ratios as cutoff values in the assessment of the degree of aortoiliac stenosis as defined with arteriography or with an FAP test. A PSV ratio of 1.5 differentiates $<20 \%$ from $\succeq 20 \%$ arteriographic lesions with $95 \%$ sensitivity and $73 \%$ specificity; a PSV ratio of 5.0 identifies $\succeq 75 \%$ stenoses with $65 \%$ sensitivity and $91 \%$ specificity.

PSV difference. The trends in the data of the PSV difference are very similar to those of the absolute PSV values. Like the absolute PSV, the PSV difference discriminates less effectively between the $50 \%$ to $74 \%$ and $75 \%$ to $99 \%$ lesion then does the PSV ratio.

EDV. The median EDV increases significantly $(p<0.0005)$ from $0 \mathrm{~cm} / \mathrm{sec}$ for $20 \%$ to $49 \%$ stenoses to $5 \mathrm{~cm} / \mathrm{sec}$ for $50 \%$ to $74 \%$ stenoses, and increases further $(p<0.0005)$ to 50 $\mathrm{cm} / \mathrm{sec}$ for $75 \%$ to $99 \%$ stenoses (Figure 4$)$. The EDV increases significantly $(p<0.005)$ from lesions with an FBI $\prec 0.90$ to lesions with an FBI $\prec 0.80$ (Figure 5 ). An EDV $>0 \mathrm{~cm} / \mathrm{sec}$ indicates an $\mathrm{FBI}<0.90$ with $51 \%$ sensitivity and $89 \%$ specificity, and it detects $\measuredangle 50 \%$ stenoses with $67 \%$ sensitivity and $93 \%$ specificity. ROC analysis showed that an EDV of 40 $\mathrm{cm} / \mathrm{sec}$ is $70 \%$ sensitive and $90 \%$ specific for differentiating $<75 \%$ from $\geq 75 \%$ stenoses (Figure 6). Table II lists the diagnostic value of several EDV values as cutoff points in the assessment of the degree of aortoiliac stenosis as defined by arteriography or by FAP test.

Reverse flow and spectral broadening. Aortoiliac segments with $<20 \%$ arteriographic stenoses $(\mathrm{n}=26$ ) showed reverse flow in all Doppler spectra and spectral broadening in $20 \%$ of the spectra. In $20 \%$ to $49 \%$ stenoses $(\mathrm{n}=30$ ) reverse flow was present in $57 \%$ and spectral broadening in $73 \%$ of the Doppler spectra. In $50 \%$ to $74 \%$ stenoses $(n=33)$ reverse flow 
occurred in $18 \%$ and spectral broadening in $91 \%$ of the spectra. In $75 \%$ to $99 \%$ stenoses $(n=23)$ reverse flow was absent and spectral broadening present in all spectra.

Combination of PSV ratio with reverse flow and spectral broadening. A Doppler spectrum analysis with a PSV ratio $\times 1.5$ together with reverse flow and absence of spectral broadening predicted $<20 \%$ stenoses in all cases (sensitivity, 100\%, specificity, $58 \%$; PPV, $89 \%$; NPV, $100 \%$; accuracy, $90 \%$ ).

Combination of PSV ratio with EDV. The optimum cutoff values of the PSV ratio and EDV values were used to grade the lesions into $0 \%$ to $20 \%, 20 \%$ to $49 \%, 50 \%$ to $74 \%$, and $75 \%$ to $99 \%$ diameter reductions. These duplex results were compared to the arteriographic results in a two-way contingency table (Table III). The agreement between the two techniques in distinguishing the four categories of aortoiliac stenosis was fair $(\kappa=0.52)$.

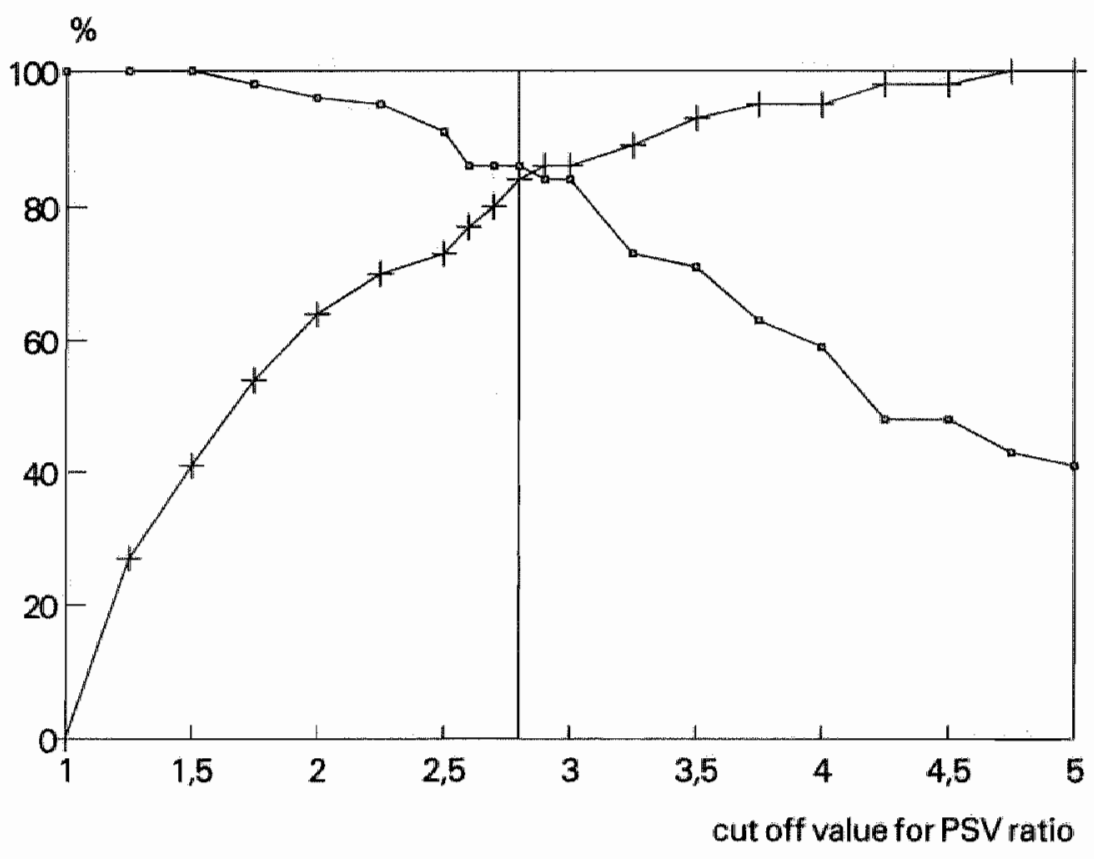

Figure 3. Graph of sensitivity and specificity of PSV ratio in identifying $250 \%$ arteriographic stenoses. Line where PSV ratio $=2.8$ shows optimal combination of sensitivity and specificity. sens, sensitivity; spec, specificity. 
Table I sensitwity, specificity, posiwive and negatiwe predictive walwes, and accuracy for several PSV ratios as cutoff points in assessment of degree of aortoiliac stenosis as defined by arteriography or by FAP test

\begin{tabular}{|c|c|c|c|c|c|c|}
\hline & PSV ratio & Sens $(\%)$ & $\operatorname{Spec}(\%)$ & PPV $(\%)$ & NPV $(\%)$ & Acc $(\%)$ \\
\hline Arteriography (\% stenosis) & & & & $\because$ & & \\
\hline \multirow[t]{3}{*}{220} & 21.3 & 97 & 54 & 87 & 82 & 87 \\
\hline & $\Leftrightarrow H .5$ & 95 & 73 & 92 & 83 & 90 \\
\hline & $z 1.7$ & 88 & 81 & 94 & 68 & 87 \\
\hline \multirow[t]{4}{*}{850} & $\geq 2.0$ & 96 & 64 & 73 & 95 & 80 \\
\hline & $\geq 2.5$ & 91 & 73 & 77 & 89 & 82 \\
\hline & $\succeq 2.8$ & 86 & 84 & 84 & 85 & 85 \\
\hline & $\varepsilon 3.0$ & 84 & 86 & 85 & 84 & 85 \\
\hline \multirow[t]{3}{*}{$\succ 75$} & $\succeq 4.5$ & 65 & 85 & 54 & 90 & 81 \\
\hline & $\geq 5.0$ & 65 & 91 & 65 & 91 & 86 \\
\hline & $\geq 5.5$ & 52 & 94 & 71 & 88 & 86 \\
\hline \multicolumn{7}{|l|}{ FAP test } \\
\hline \multirow[t]{3}{*}{ FBI $<0.90$} & $\geq 2.0$ & 78 & 58 & 78 & 58 & 71 \\
\hline & $\succ 2.5$ & 74 & 71 & 83 & 59 & 73 \\
\hline & $\geq 3.0$ & 66 & 84 & 89 & 56 & 72 \\
\hline \multirow[t]{5}{*}{$|F B|<0.80$} & $=3.0$ & 84 & 68 & 56 & 89 & 73 \\
\hline & 23.5 & 76 & 79 & 64 & 87 & 78 \\
\hline & $\succeq 4.0$ & 65 & 84 & 67 & 83 & 78 \\
\hline & 24.5 & 49 & 87 & 64 & 77 & 74 \\
\hline & $\geq 5.0$ & 46 & 92 & 74 & 78 & 77 \\
\hline
\end{tabular}




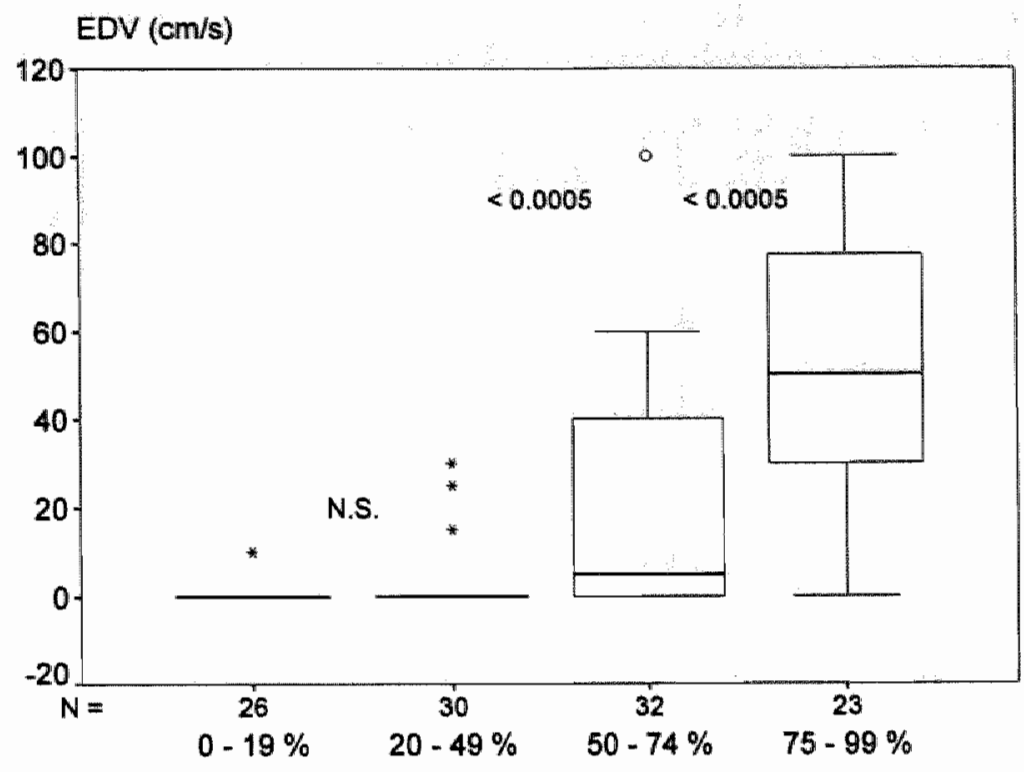

arteriographic diameter reduction

Figure 4. Boxplot of EDV by category of arteriographic diameter reduction.

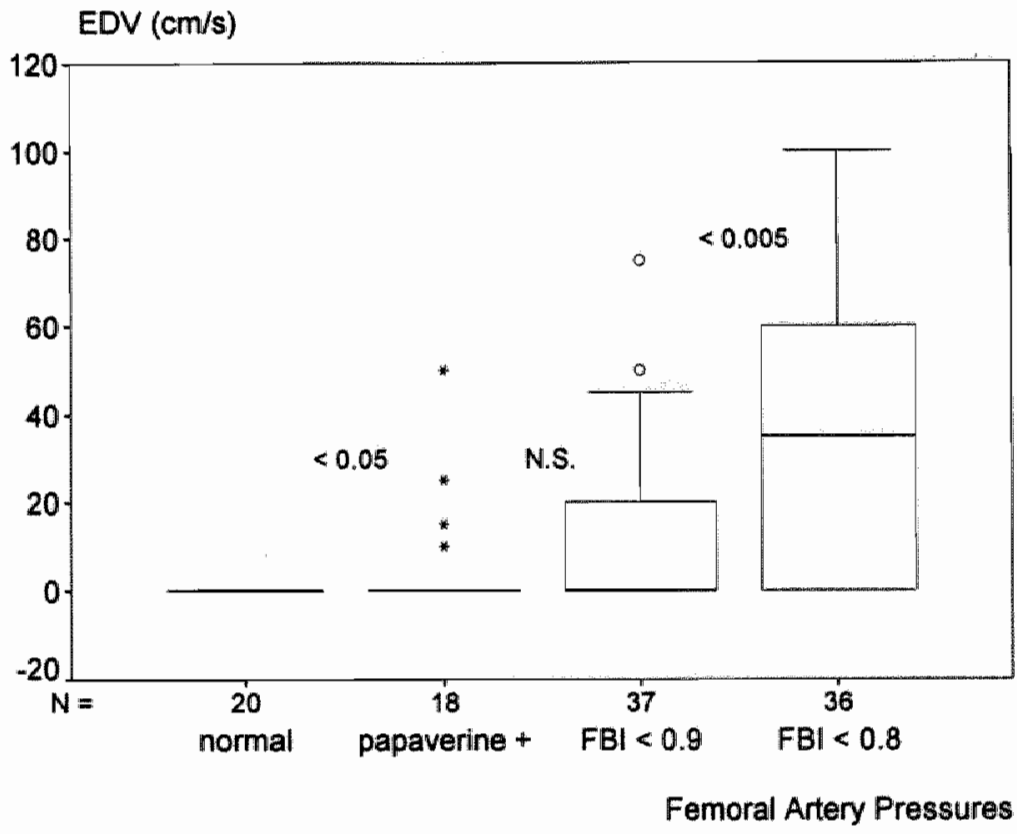

Figure 5. Boxplot of EDV by FAP test category. 


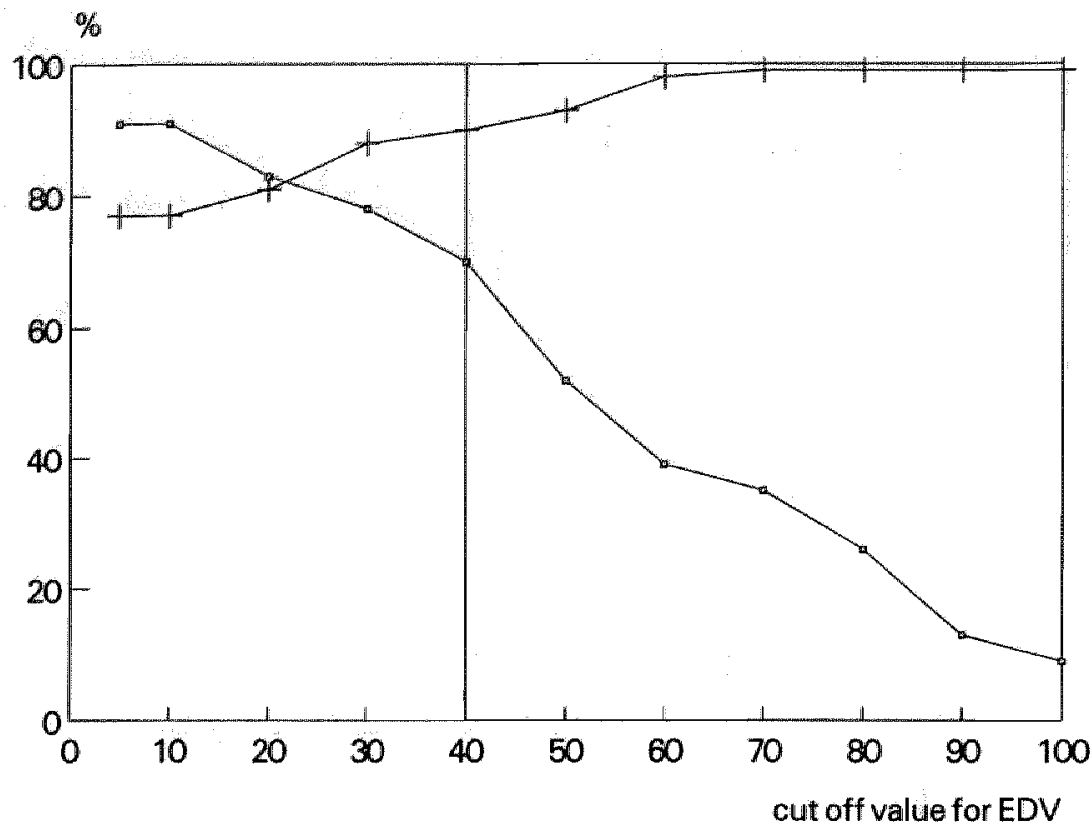

Figure 6. Graph of sensitivity and specificity of EDV in identifying $\longleftarrow 75 \%$ stenosis. Line where EDV $=$ $40 \mathrm{~cm} / \mathrm{sec}$ shows $70 \%$ sensitivity and $90 \%$ specificity. Above this line significant loss of sensitivity with little gain in specificity is seen. 
Table II. Sensitivity, specificity, positive and negative predictive walues, and accuracy for severat ED values as cutoff points

EDV $(\mathrm{cm} / \mathrm{sec}) \quad$ Sens $(\%) \quad$ Spec $(\%)$ PPV $(\%)$ NPV $(\%) \quad A c c(\%)$

\section{Arteriography (\% stenosis)}

\begin{tabular}{|c|c|c|c|c|c|}
\hline$\succeq 50$ & $>0$ & 67 & 93 & 90 & 74 \\
\hline & $\geq 10$ & 67 & 93 & 90 & 74 \\
\hline & 220 & 62 & 96 & 94 & 72 \\
\hline$\approx 75$ & $\succeq 40$ & 70 & 90 & 64 & 92 \\
\hline & 250 & 52 & 93 & 67 & 88 \\
\hline & $\simeq 60$ & 39 & 98 & 82 & 86 \\
\hline
\end{tabular}

FAP test

\begin{tabular}{ccccccc} 
FBI $<0.90$ & $>0$ & 51 & 89 & 90 & 49 & 60 \\
& $\succ 10$ & 51 & 89 & 90 & 49 & 60 \\
& $\succ 20$ & 47 & 95 & 94 & 48 & 63 \\
FBI $<0.80$ & $\succ 40$ & 50 & 91 & 72 & 79 & 77 \\
& $\geq 50$ & 39 & 95 & 78 & 76 & 77 \\
& $\geq 60$ & 28 & 99 & 91 & 74 & 76 \\
\hline
\end{tabular}

Table III. Two-way contingency table of duplex scannning based on PSV ratio and EDV by arteriography

\begin{tabular}{|c|c|c|c|c|c|}
\hline & \multicolumn{4}{|c|}{ Arteriography } & \multirow[b]{2}{*}{ n } \\
\hline & $0 \%$ to $20 \%$ & $20 \%$ to $49 \%$ & $50 \%$ to $74 \%$ & $75 \% 1099 \%$ & \\
\hline \multicolumn{6}{|l|}{ Duplex scarnning } \\
\hline PSV ratio $<1.5$ & 19 & 4 & & & 23 \\
\hline PSV ratio $\geq 1.5$ and $<2.8$ & 7 & 17 & 7 & 1 & 32 \\
\hline PSV ratio $z 2.8$ and $<5.0$ & & 9 & 23 & 9 & 41 \\
\hline PSV ratio $\approx 5.0$ and EDV $\sqsubset 40$ & & & 3 & 13 & 16 \\
\hline $\mathrm{n}$ & 26 & 30 & 33 & 23 & 112 \\
\hline
\end{tabular}




\section{Discussion}

Ultrasound Doppler techniques are ideally suited for quantification of lumen-reducing lesions, because they have been shown to be sensitive to diameter reductions of as little as $10 \%$ when used to evaluate areas of stenosis directly, whereas pressure and flow changes require reductions of about $50 \%$ for detection. ${ }^{6}$ The most frequently used Doppler parameters are the increase in PSV at the site of the stenosis and the ratio of the stenotic PSV to the nonstenotic PSV. In healthy people the PSV of the aorta and of the iliac arteries is $90 \pm 20$ $\mathrm{cm} / \mathrm{sec}$ (mean $\pm \mathrm{SD}$ ), and a gradual decrease in PSV is observed from the iliac to the popliteal arteries. In patients with symptoms of atherosclerotic disease but normal aortolliac segments, Sacks et al. ${ }^{8}$ found absolute PSV values of $76 \pm 17 \mathrm{~cm} / \mathrm{sec}$ for the aorta, $111 \pm 17 \mathrm{~cm} / \mathrm{sec}$ for the common iliac artery, and $112 \pm 49 \mathrm{~cm} / \mathrm{sec}$ for the external iliac artery. Similar data had been reported previously. ${ }^{910}$ In our study the median PSV value of minimally affected arteries ( $<20 \%$ diameter reduction) was $150 \mathrm{~cm} / \mathrm{sec}$.

Velocity recordings with an absolute PSV value $z 200 \mathrm{~cm} / \mathrm{sec}$ in the common illiac arteries have been reported as indicative of $\_50 \%$ stenoses. "Our study showed that a PSV $<$ $200 \mathrm{~cm} / \mathrm{sec}$ almost rules out an aortoulliac stenosis with a diameter reduction of $\geq 50 \%$, but also showed that a PSV $>200 \mathrm{~cm} / \mathrm{sec}$ must be interpreted cautiously.

Because of the intraindividual and interindividual variability of blood flow velocity in the peripheral arteries, it seems better to use the PSV ratio rather than the absolute value of the PSV to grade the stenoses. In a recent study the PSV difference was shown to be possibly another valuable criterion. ${ }^{3}$ The PSV difference is related not only to the change in crosssectional area, but also to the amount of flow. This relationship can be beneficial in detecting subcritical aortoiliac lesions, that is, lesions that are only hemodynamically significant if flow is also increased. Our study shows that under resting conditions the discriminative value of the PSV ratio is better than both the absolute PSV value and the PSV difference. The value of the PSV difference in detecting subcritical stenosis must be examined under conditions of increased flow. Jager et al.' applied a $>100 \%$ increase in PSV at the stenosis as a criterium to identify $\measuredangle 50 \%$ diameter reduction. Recent literature and our own results show that the best cutoff value for the PSV ratio in differentiating $<50 \%$ from $\succeq 50 \%$ lesions lies between 2.4 and 3.0., 92,13 The PSV ratio can also be used for a more differentiated grading of the aortoiliac lesions. We showed that a PSV ratio of 1.5 differentiates $<20 \%$ lesions from $\succeq 20 \%$ lesions with $95 \%$ sensitivity and $73 \%$ specificity, and that a PSV ratio of 5.0 identifies $\succeq 75 \%$ stenoses with $65 \%$ sensitivity and $91 \%$ specificity.

Other parameters, such as reverse flow and spectral broadening, appear to give additional information about the degree of obstructive disease. We showed that a clear Doppler spectrum with reverse flow in conjunction with a PSV ratio $\prec 1.5$ excludes an aortoiliac lesion of $>20 \%$ diameter reduction. If reverse flow is absent in the Doppler spectrum, it is likely that narrowing is present at or proximal to the recording site. Because reverse flow often reappears only a few diameters downstream from the stenosis, it is important to obtain velocity waveforms directly from the stenosis. ${ }^{13}$ Our study confirms the findings of Kohler et 
al. ${ }^{14}$ that although loss of reverse flow cannot be used to quantitate the degree of stenosis, it is an important indicator of hemodynamically important stenoses. Our study showed that reverse flow is always present in arteries that are only minimally affected and is always absent in $\geq 75 \%$ stenoses: The spectral broadening of a pulsed Doppler signal depends on the size and shape of the sample volume of the Doppler system and on the velocity distribution within this volume. ${ }^{15}$ Spectral broadening is absent in normal aortoiliac arteries. "We noted spectral broadening in $21 \%$ of the minimally affected arteries ( $<20 \%$ diameter reduction). We conclude that a significant stenosis at or just proximal to the recording site is very unlikely if reverse flow is present in conjunction with a clear systolic window.

The EDV is a parameter that may be helpful in the differentiation of hemodynamically significant aortoiliac occlusive disease. Altered peripheral vascular resistance distal to the stenosis affects the magnitude of the forward diastolic flow. Variation in outflow resistance, inflow velocities, and the presence of diffuse disease may therefore affect the diastolic velocity. Under resting conditions, the presence of a forward diastolic flow in a hemodynamically nonsignificant aortoiliac lesion is rarely seen. A correlation between the diastolic velocity and the arteriographic diameter reduction of aortoiliac and femoropopliteal stenoses was observed by Nicholls et al. ${ }^{16}$. Ranke et al. ${ }^{12}$ found that an EDV $>25 \mathrm{~cm} / \mathrm{sec}$ had $47 \%$ sensitivity and $89 \%$ specificity in diagnosing $>50 \%$ stenoses of iliac and femoral arteries. Legemate et al. ${ }^{13}$ showed that an absolute EDV of $\succeq 60 \mathrm{~cm} / \mathrm{sec}$ strongly indicates a stenosis of $\geq 75 \%$. Our study shows that an EDV $>0 \mathrm{~cm} / \mathrm{sec}$ at the stenosis indicates lesions of hemodynamic importance and that a EDV $\succeq 40 \mathrm{~cm} / \mathrm{sec}$ detects $\geq 75 \%$ lesions with $70 \%$ sensitivity and $90 \%$ specificity. It seems that the EDV is a valuable parameter in assessing the severity of aortoiliac stenoses. We showed that grading of the stenoses by duplex scanning on the basis of a combination of PSV ratios and EDV agreed fairly with the four categories of arteriographic diameter reduction (Table III).

\section{Conclusion}

The duplex classification of aortoiliac stenoses is validated in only a few clinical studies, which each used differing criteria. ${ }^{17-20}$ Percutaneous transluminal angioplasties have been scheduled on the basis of duplex scanning only. Only one publication mentions PSV ratios before angioplasty, which where above 4.0 for all aortoiliac stenoses selected for angioplasty. ${ }^{17}$ Consequently, the authors suggested that the criteria recommended by Jager might be too sensitive for use in selecting peripheral artery stenosis for invasive therapy. The value of duplex scanning in the planning of invasive therapy must be validated with more studies, and we suggest that the Doppler parameters of the lesions selected for invasive therapy by duplex scanning be reported precisely.

On the basis of our study and other recentlly published data, ${ }^{12,13}$ the following criteria for aortoiliac stenoses are proposed: a PSV ratio $<1.5$, reverse flow and a clear systolic window indicate $\prec 20 \%$ stenoses; a PSV $\prec 200 \mathrm{~cm} / \mathrm{sec}$ and/or a PSV ratio $\prec 2.5$ indicate $<50 \%$ 
stenoses; a PSW ratio $\geq 2.5$ indicates $\geq 50 \%$ stenoses; a PSV ratio $z 5.0$ and an EDV $>40$ $\mathrm{cm} / \mathrm{sec}$ indicate $275 \%$ stenoses; and an EDV $>0 \mathrm{~cm} / \mathrm{sec}$ indicates stenoses of hemodynamic importance.

Color-wlow imaging provides another method of displaying Doppler information but does not supplant the need for Doppler spectral analysis. The adwantage of color-flow imaging is that it facilitates the visualization of the aortoiliac arteries. After visual evaluation of the color-flow image, the systen must be switched back to the single-gate Doppler mode for spectral analysis. Currently, the aortoiliac stenosis can be quantified accurately by using the above-mentioned Doppler parameters; these parameters offer the best method of evaluating the hemodynamics at the stenosis. 


\section{References}

1. Jager KA, Phillips DJ, Martin RL, Hanson $C$, Roederer $\mathrm{GO}$, Langlois YE, Ricketts HJ, Strandness DE Jr. Noninvasive mapping of lower limb arterial lesions. Ultrasound Med Biol 1985;11:515-521.

2. Vashisht $\mathrm{R}$, Ellis MR, Skidmore $\mathrm{C}$, Blair SD, Greenhalgh RM, O'Malley MK. Colour-coded duplex ultrasonography in the selection of patients for endovascullar surgery. $\mathrm{Br}$ I Surg 1992;79:1030-1031.

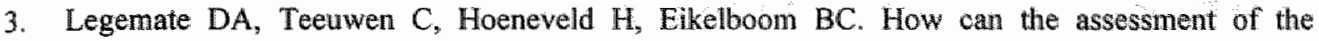
haemodynamie significance of arterial stenosis by duplex scanning be improved? A comparative study with intra-arterial pressure measurement.J Vasc Surg 1993;17:676-684.

4. Baker AR, Macpherson, Evans DH, Bell PRF. Pressure studies in arterial surgery. Eur J Vasc Surg 1987;1:273-283.

5. Flanigan DP, Ryan TJ, Williams LR, Schwartz JA, Gray B, Schuler JJ. Aortofemoral or femoropopliteal revascularization? A prospective evaluation of the papaverine test. J Vase Surg $1984 ; 1: 2 \llbracket 5-223$.

6. Rutherford RB, Jones Dn, Lowenstein D, Fleming P. The effects of change in lumen and flow on the arterial velocity waveform.J Surg Res 1982;32:10-20.

7. Hatsukami TS, Primozich J, Zierler RE, Strandness DE Jr. Color Doppler characteristics in normal lower extremity arteries. Ultrasound Med Biol 1992;18:167-171.

8. Sacks D, Robinson ML, Marinelli DL, Perlmutter GS. Peripheral arterial Dopples ultrasonography: Diagnostic criteria. J Ultrasound Med 1992;11:95-103.

9. de Smet AAEA, Kitslaar PJEHM. A duplex criterion for aorto-iliac stenosis. Eur J Vasc Surg 1990;4:275-278.

10. Langsfeld M, Nepute J, Hershey FB, Thorpe L, Auer AI, Binnington HB, Hurley JJ, Peterson GJ, Schwartz R, Woods JJ. The use of deep duplex scanning to predict hemodynamically significant aortoiliac stenoses. J Vasc Surg 1988;7:395-399.

11. Moneta GL, Yeager RA, Antonovic $\mathbb{R}$, Hall LD, Caster JD, Cummings CA, Porter JM. Accuracy of lower extremity arterial duplex mapping. J Vase Surg 1992;15:275-284.

12. Ranke $\mathrm{C}_{x}$ Creutzig $\mathrm{A}$, Alexander $\mathrm{K}$. Duplex scanning of the peripheral arteries: correlation of the peak velocity ratio with angiographic diameter reduction. Ultrasound Med Biol 1992;18:433-440.

13. Legemate DA, Teeuwen $C$, Hoeneveld H, Ackerstaff RGA, Eikelboom BC. Spectral analysis criteria in duplex scanning of aortoiliac and femoropopliteal arterial disease. Ultrasound Med Biol 1991;17:769-776.

14. Kohler TR, Nicholls SC, Zierler RE, Beach KW, Schubert PJ, Strandness DE Jr. Assessment of pressure gradient by Doppler ultrasound: Experimental and clinical observations. J Vasc Surg $1987 ; 6: 460-469$.

15. Hoeks AP, Hennerici Michael, Reneman RS. Spectral composition of Doppler signals. Ultrasound Med Biol 1991;17:751-760.

16. Nicholls SC, Kohler TR, Martin RL, Neff R, Phillips DJ, Strandness DE Jr. Diastolic flow as a predictor of arterial stenosis.J Vasc Surg 1986;3:498-501.

17. Sacks D, Robinson ML, Marinelli DL, Perlmutter GS. Evaluation of the peripheral arteries with duplex US after angioplasty. Radiology 1990;176:39-44.

18. Edwards JM, Coldwell DM, Goldman ML, Strandness Jr DE. The role of duplex scanning in the selection of patients for transluminal angioplasty. J Vasc Surg 1991;13:69-74. 
19. wan der Heijden FHWM, Legemate DA, van Leeuwen MS, Mali WPThM, Eikelboom. Value of duplex scamning in the selection of patients for percutaneous transluminal angioplasty. Eur J Vase Surg 1993:7:71-76.

20. de Smet AAEA, Visser $K$, Kitslaar PJEHM. Duplex scamning for grading aortolliac obstructive disease and guiding treatment. Eur J Vasc Surg 1994;8:711-715. 


\section{CHAPTER 6}

Duplex scanning for grading aortoiliac obstructive disease and guiding treatment

A.A.E.A. de Smet, K. Visser, P.J.E.H.M. Kitslaar

Eur J Vasc Surg 1994;8:711-715 


\begin{abstract}
Standard assessment of aortoiliac obstructive disease (AIOD) includes arteriography preferably supplemented with femoral artery pressure (FAP) measurements. This study investigated the value of duplex scanning in classifying AIOD and compared the outcome of duplex scanning with clinical decision making. One-hunderd-and-fifty-three aortoiliac segments of 87 patients were prospectively examined by duplex scanning, arteriography, and FAP nieasurements to establish the presence or absence of significant AIOD. The results of these tests were compared to each other and to the subsequent vascular interventions and their success rates. Excellent agreement $(\kappa=0.82)$ was found between duplex scanning and arteriography. The agreement between duplex scanning and FAP measurements was much lower $(\kappa=0.52)$. The correlation between the performed treatment and the assessment of AIOD by duplex scanning or arteriography was good, whereas the FAP results correlated only moderately with the performed treatment. Endovascular or operative treatment was actually performed in only $63 \%$ of the aortoiliac segments with an abnormal FAP test (success rate $80 \%$ ). Aortoiliac segments with significant AIOD according to arteriography or duplex scanning were treated invasively in $86 \%$ (success rate $81 \%$ ) and $82 \%$ (success rate $80 \%$ ), respectively. In conclusion, duplex scanning can replace arteriography as a screening tool for the identification of treatable aortoiliac lesions whereas the value of FAP measurements in the decision making process is limited.
\end{abstract}

\title{
Introduction
}

An accurate assessment of the anatomic and hemodynamic condition of the aortoiliac segment is a prerequisite for correctly treating patients with peripheral arterial disease. Standard assessment of aortoiliac obstructive disease (AIOD) includes arteriography prefierably supplemented with femoral artery pressure (FAP) measurements.' Until recently, arteriography was the only diagnostic test that could provide an accurate anatomic picture of the aortoiliac tree. The best evaluation of the hemodynamic impact of proximal disease is provided by intraarterial pressure measurements. The technique of pressure determination before and after vasodilatation with papaverine as described by Flanigan et al. ${ }^{2}$ is probably the most widely used approach. Noninvasive tests developed to assess the hemodynamic significance of AlOD have not gained widespread clinical acceptance. ${ }^{3.5}$ Duplex scanning permits study of the peripheral arterial system and recent studies have shown that duplex scanning of AIOD correlates well with the results of arteriography. ${ }^{6.9}$ Unlike arteriography, duplex scanning classifies the arteries by interpretation of physiologic information. Duplex scanning has only occasionally been applied in the selection of aortoiliac lesions suitable for invasive treatment ${ }^{10.11}$ and the value of aortoiliac duplex scanning in clinical practise needs further clarification.

The objectives of this study were to investigate the value of duplex scanning compared to 
arteriography and FAP measurements in classifying the severity of AIOD and to compare the outcome of duplex scanning with the results of treatment:

\section{Patients and methods}

One-hunderd-and-fifty-three aortoiliac segments of 87 patients who were possible candidates for vascular treatment were prospectively examined by duplex scaning, arteriography and intraarterial FAP measurements to establish the presence or absence of significant AIOD. Each test was used to classify the aortoiliac segments according to the criteria mentioned below, without knowledge of the other test results.

Seventy-two of the patients in this study underwent an aortoiliac and/or femorodistal endovascular or operative procedure as shown in Table I. In 44 patients an aortic or lliac percutaneous transluminal angioplasty (PTA) was performed, seven of whom underwent an aortofemoral operation within one year after the PTA. In 12 patients a primary aortofemoral operation was performed, four of which were combined with a femorodistal procedure. Femorodistal procedures were performed in another 16 patients. The decision to intervene on the aortoiliac segment was based upon the symptoms of the patient, ankle-brachial pressure indices determined at rest and after treadmill exercise, and the outcome of arteriography and FAP test. The duplex scanning result was not used in the decision making process.

Table I. Endovascular and operative procedures performed

\begin{tabular}{ll}
\hline Number of patients & Vascular procedure \\
\hline 4 & aortic PTA (1) \\
32 & unilateral iliac PTA (4) \\
7 & bilateral iliac PTA (2) \\
1 & iliac PTA and femorofemoral bypass \\
2 & aortofemoral bypass \\
6 & aortobifemoral bypass \\
4 & combined aortoiliac and femorodistal procedure \\
16 & femorodistal procedure \\
\hline
\end{tabular}

The number of patients who underwent an aortofemoral operation within I year after PTA are given in brackets. 
Duplex scanning. All duplex examinations were performed with an ATL Ultramark IV duplex scanner (Advanced Technology Laboratories, Seattle, USA) with the patient in the supine position. A 3-MHz single-frequency sector transducer and a multifrequency sector transducer (with 5-,7.5- and 10-MHz settings) were used to generate a B-mode image of the vessels and the pulsed Doppler signals. The signals were recorded at a Doppler angle of 60 degrees with a sample volume of $1.5 \mathrm{~mm}^{3}$ placed in the center stream of the vessel. Problems with bowel gas were minimized by fasting the patient. The infrarenal aorta, the common iliac, and external iliac arteries were scanned and hard copies of Doppler recordings were made of the proximal, middle and distal part of each artery. In any area suspicious of stenosis, hard copies of Doppler recordings were also made before, at, and just distal to the stenosis. The segments were classified into four categories according to the increase in peak systolic velocity (PSV) ratio (the stenotic PSV divided by the pre- or poststenotic PSV) and the magnitude of the enddiastolic velocity (EDV). ${ }^{12}$ In $0 \%$ to $49 \%$ stenoses the PSV ratio is less than $25,50 \%$ to $74 \%$ stenoses have a PSV ratio of 2.5 or more, $75 \%$ to $99 \%$ stenoses have an additional EDV of $40 \mathrm{~cm} / \mathrm{sec}$ or more, and in occluded segments there is no detectable flow. For the classification of the entire aortoiliac segment the highest category was used. A lesion of $z 50 \%$ diameter reduction was considered hemodynamically significant. ${ }^{12}$

Femoral Artery Pressure measurements. Intraarterial pressures were registered after needle puncture of the common femoral artery with a 19 gauge needle connected with a pressure transducer. Femoral blood pressures were measured at rest and during reactive hyperemia induced by the intraarterial injection of $50 \mathrm{mg}$ papaverine. Simultaneously, brachial artery blood pressures were measured noninvasively at 1 minute intervals with an automatic plethysmographic blood pressure device (Dinamap vital signs monitor, Critikon Inc;; Tampa, Florida, USA). Systolic femorobrachial pressure indices were calculated at rest and at the maximum pressure fall after papaverine injection.

A resting femorobrachial index $\prec 0.80$ was considered abnormal or $>0.15$ reduction of the index during vasodilatation by papaverine. ${ }^{1}$

Arteriography. All patients underwent intraarterial arteriography within 3 months of the other examinations. Arteriography was usually performed via the transfemoral approach. The infrarenal aorta, common iliac, and external iliac artery were arteriographically graded into four categories: $0 \%$ to $49 \%$ diameter reduction; $50 \%$ to $74 \%$ diameter reduction; $75 \%$ to $99 \%$ diameter reduction; and occlusion. For classification of the entire aortoiliac segment, the highest category was used. The criterion for significant AIOD was a $\succeq 50 \%$ diameter reduction on the arteriography.

The results of duplex scanning, FAP test and arteriography were compared to each other and the outcome of each of these examinations was correlated with the outcome of the vascular procedure performed. According to the standard suggested by Rutherford et al. ${ }^{13}$, a procedure was considered successful if the ankle-brachial pressure index improved by at least 0.10 and/or the clinical category based on noninvasive laboratory test criteria improved. Ankle-brachial pressure indices were measured before and 3 months after the intervention.

Data analysis. The results were tabulated and analysed by two-way contingency tables 
and kappa ( $\mathrm{k}$ ) statistics to determine the agreement between the diagnostic tests. ${ }^{14}$ The maximum $\mathrm{k}$ value, which would represent perfect agreement is $1 . \mathrm{A} \kappa$ value of 0 represents purely chance agreement. It is considered that a $\kappa$ value $>0.75$ represents excellent agreement, values between 0.4 and 0.75 represent fair to good agreement, and a value $<0.4$ represents poor agreement. The results of treatment were analysed by the $\chi^{2}$ test. $p<0.05$ was considered significant.

In patients with $a \geq 50 \%$ aortic lesion $(n=4)$ only the right side was included for data analysis, therefore 149 aortoilliac segments were available for analysis.

\section{Results}

Agreement between diagnostic tests. Excellent agreement $(\kappa=0.82)$ was found between duplex scanning and arteriography for differentation between $<50 \%$ and $\succeq 50 \%$ diameter reduction. The results of duplex scanning compared to arteriography in further differentiating aortoiliac lesions are shown in the two-way contingency table (Table II). The agreement between duplex scanning and arteriography in this more precise classification was also good $(\kappa=0.70)$. Duplex scanning erroneously diagnosed occlusion as high grade stenosis in three cases. This could be explained by misjudging collateral circulation for stenosis in two patients (Figure), and misinterpreting a high grade hypogastric artery stenosis in one patient. Two $75 \%$ to $99 \%$ arteriographic iliac stenoses were classified as insignificant lesions by duplex scanning. The first was graded as $<50 \%$ stenosis because of a PSV ratio just below 2.5 , and the second was not identified correctly despite the observed turbulent flow in the iliac artery. In this patient, atherosclerotic plaques probably prevented the ultrasound detection of the velocity increase at the site of the stenosis. Both last mentioned lesions received a PTA.

The agreement between FAP measurements on the one hand and duplex scanning ( $\kappa=$ $0.52)$ or arteriography $(\kappa=0.46)$ on the other hand was only fair. 
Table II Two-way conthgency table of duplex scanning versus arteriography in determining various degrees of AlOD, pepresented as \% diameter reduction

\begin{tabular}{lccccc}
\hline & \multicolumn{4}{c}{ Arteriography } & \\
\cline { 2 - 5 } & $0 \%$ to $49 \%$ & $50 \%$ to $74 \%$ & $75 \%$ to $99 \%$ & occlusion & n \\
\hline Duplex & 74 & 5 & 2 & & \\
$0 \%$ to $49 \%$ & 6 & 21 & 5 & 3 & 32 \\
$50 \%$ to $74 \%$ & 8 & 19 & 6 & 30 \\
$75 \%$ to $99 \%$ & & & & 6 & 6 \\
0cclusion & & 34 & 26 & 9 & 149 \\
\hline
\end{tabular}

$\kappa=0.70$

Correlation between vascular treatment and diagnostic tests. The correlations between the actual performance of aortoiliac endovascular or operative procedures and the three tests performed are presented in Table III. The correlation between the aortoiliac procedure and the presence of significant AIOD according to arteriography was good. Duplex scanning correlated well with aortoiliac treatment. Segments with significant AIOD according to arteriography or duplex scanning were treated by operative or endovascular intervention in $86 \%$ and $82 \%$, respectively. The correlation between the FAP results and the treatment performed was moderate. Operative or endovascular treatment was performed in only $63 \%$ of the aortoiliac segments with an abnormal FAP test. Aortoiliac segments with significant obstructive lesions according to arteriography or duplex scanning were treated significantly more often compared to segments with an abnormal FAP test ( $p<0.01, \chi^{2}$ analysis). The overall succes rate of the treated aortoiliac segments was $78 \% ; 12 \%$ improved minimally, $16 \%$ moderately, and $50 \%$ markedly. The higher success rate for the treatment of $\succeq 50 \%$ lesions according to the used tests compared to the treatment of $<50 \%$ lesions was not statistically significant.

The treatment of $<50 \%$ lesions on arteriography is explained by the fact that some patients with a significant lesion on one side and a minor obstructive lesion on the contralateral side were treated with bifurcated prostheses. The other treatments for $<50 \%$ lesions on arteriography were performed in claudicants and consisted of PTA in all cases. 
Table IIL. Correlation between the results of the diagnostic tests and the treatment of the aortoiliac segments

\begin{tabular}{lcccc}
\hline & & No Intervention & Intervention & Success Rate \\
\hline FAP test & - & 44 & 9 & $67 \%$ \\
\multirow{3}{*}{ Duplex scanning } & + & 36 & 60 & $80 \%$ \\
& - & 68 & 13 & $69 \%$ \\
Arteriography & + & 12 & 56 & $80 \%$ \\
& - & 70 & 10 & $60 \%$ \\
& + & 10 & 59 & $81 \%$ \\
\hline
\end{tabular}

The succes rate of intervention is tabulated in the last column.

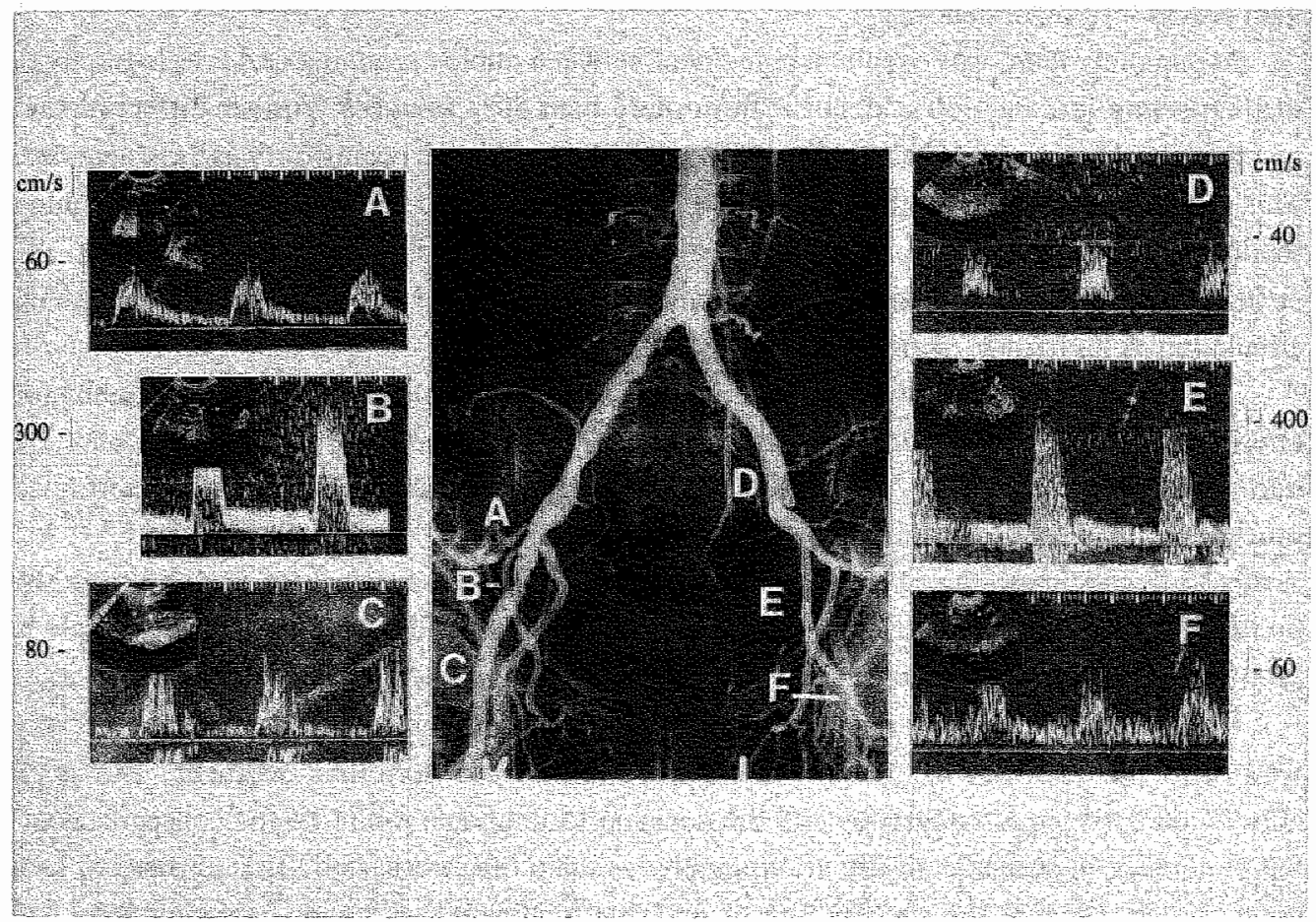

Figure. Arteriography and Doppler flow velocity spectra of an aorroillac tree with a short stenotic lesion in the right external iliac artery and an occluded left external iliac artery. The large collateral at the left side was misjudged by duplex scanning as a severe iliac stenosis. A: proximal of the stenosis; B: at the stenosis, PSV increased to $350 \mathrm{~cm} / \mathrm{sec}$ and EDV to $75 \mathrm{~cm} / \mathrm{sec}$; $C$ : distal to the stenosis; D: proximal of the occlusion; $E$ : at the collateral, and $F$. distal to the acclusion. 


\section{Discussion}

Arteriography is still considered indispensable for clinical decision making and the present value of aortoiliac duplex scamning in clinical practise is unclear. Until now, only few studies have concentrated on the application of duplex scanning prior to treatment of aortoiliac lestons. ${ }^{10,14}$ Most studies have compared duplex scanning with the results of arteriography and found a high correlation in identification of greater than $50 \%$ aortoiliac stenosis. ${ }^{6-9}$ Conventional duplex scanning identifies stenoses on velocity information alone, i.e. the reduction of cross-sectional area at the site of the stenosis causes a change in velocity. The criteria by which hemodynamically significant AlOD is diagnosed varies in literature. The criteria for discrimination of $<50 \%$ and $\succeq 50 \%$ stenoses published by Jager et al. ${ }^{6}$ have usually been applied (loss of reverse flow and a twofold increase of the stenotic PSV with respect to the prestenotic PSV). More recent literature indicates that a 2.5-fold increase of the PSV or a PSV ratio of 2.5 (intrastenotic PSV divided by proximal or distal PSV) may be more accurate. ${ }^{12,15-17}$ In this study we used a PSV ratio of 2.5 in distinguishing between greater than or less than $50 \%$ stenoses.

In our study there was excellent agreement between duplex scanning and arteriography in distinguishing less than $50 \%$ stenoses from more than $50 \%$ stenoses. Further differentiation of occlusive disease in $50 \%$ to $74 \%, 75 \%$ to $99 \%$ stenosis or occlusion was less accurate. This might be improved by the use of color-flow imaging, since color-flow duplex scanning facilitates the identification of the vessels and the visualization of the exact site of the stenosis. ${ }^{17-19}$ Better visualization can also overcome the problem of misinterpreting collateral circulation as high grade stenosis.

The moderate agreement of intraarterial pressure measurements with duplex scanning or arteriography has been observed previously and might be due to different flow condition during the papaverine test. ${ }^{12}$ The low number of endovascullar or operative aortoiliac procedures on limbs with an abnormal FAP test in this study indicates that the FAP test seems to overestimate the severity of disease. Our results and the lack of uniformity in the literature in defining the optimum cutoff pressure gradient illustrates that the FAP test is probably not the best test to select patients for an aortoiliac procedure., $12,12,20$

Unlike the FAP test, the outcome of arteriography or duplex scanning corresponded very well with the decision to perform an intervention of the aortoiliac segment. The good correlation between arteriography and the decision to intervene might be the consequence of the preference of surgeons to use arteriography as main diagnostic tool. This appears to be a good choice, because the success rate of invasive treatment was good if arteriography had graded the lesion as more than 50\% diameter reduction. This study shows that aortoiliac duplex scanning is comparable to arteriography as a basis for the selection of patients for treatment. The selection of patients based on duplex scanning makes arteriographic evaluation in a significant number of patients unnecessary. Patients with no significant aortoiliac lesion according to duplex scanning need no further evaluation and patients with a short lesion on duplex scanning can be selected for PTA without antecedent arteriography. 
In conclusion, duplex scanning can replace arteriography as a screening toof for the detection of treatable aortoiliac lesions whereas the value of FAP measurements in the decision making process is limited. 


\section{References}

1. Baker AR, Macpherson DS; Evans DH, Bell PRF. Pressure studies in arterial surgery. Eur J Vasc Surg 1987:1:273-283.

2. Flanigan DP, Ryan TJ, Williams $L$, Schwartz JA, Gray B, Schuler JJ. Aortofemoral or femoropopliteal revascularization? A prospective evaluation of the papaverine test. J Vase Surg $1984 ; 1: 215-223$.

3. Campbell WB, Cole SEA, Skidmore $\mathrm{R}$, Baird RN. The clinician and the vascular laboratory in the diagnosis of aortoiliac stenosis. Br J Surg 1984,71:302-306.

4. Baker JD, Machleder HI, Skidmore R. Analysis of femoral artery Doppler signals by Laplace transform damping method. J Vase Surg 1984;1520-524.

5. Kitslaar PJEHM, Jorning PJG, Kohlen JPFM. Assessment of aortoiliac stenosis by femoral artery pressure measurement and Doppler waveform analysis. Eur I Vase Surg 1988;2:35-40.

6. Jager KA, Phillips DJ, Martin RL, Hanson C, Roederer GO, Langois YE, Ricketts HJ, Strandness DE Jr. Noninvasive mapping of lower limb arterial lesions. Ultrasound Med Biol 1985;11: 515 521 .

7. Kohler TR, Nance DR, Cramer MM, Vandenburghe $\mathbb{N}$, Strandness DE Jr. Duplex scanning for diagnosis of aortoiliac and femoropopliteal disease: a prospective study. Circ 1987;5:1074-1080.

8. Legemate DA, Teeuwen $\mathrm{C}$, Hoeneveld $\mathrm{H}$, Ackerstaff RGA, Eikelboom BC. The potential of duplex scanning to replace aortoilliac and femoropopliteal angiography. Eur I Vasc Surg $1989 ; 3: 49-54$.

9. Rosfors $\mathrm{S}$, Eriksson M, Höglund N, Johansson G. Duplex ultrasound in patients with suspected aorto-iliac occlusive disease. Eur J Vasc Surg 1993;7:513-517.

10. Edwards JM, Coldwell DM, Goldman ML, Strandness Jr DE. The role of duplex scanning un the selection of patients for transluminal angioplasty. J Vase Surg 1991;13:69-74.

11. van der Heyden FHWM, Legemate DA, van Leenwen MS, Mali WPThM, Eikelboom BC. Value of duplex scanning in the selection of patients for percutaneous transluminal angioplasty. Eur $\mathbf{J}$ Vasc Surg 1993;7:71-76.

12. Legenate DA, Teeuwen $\mathrm{C}$, Hoeneveld $\mathrm{H}$, Eikelboom BC. Value of duplex scanning compared with angiograpliy and pressure measurement in the assessment of aortoiliac arterial lesions. $\mathrm{Br} J$ Surg 1991;78:1003-1008.

13. Rutherford RB, Flanigan DP, Gupta SK, Johnston KW, Karmody A, Whittemore AD, Baker JD, Enst CB. Suggested standards for reports dealing with lower extremity ischemia. J Vasc Surg $1986 ; 4: 80-94$.

14. Landis $J R$, Koch GG. The measurement of observer agreement for categorial data. Biometrics 1977;33:159-174.

15. Ranke C, Creutzig A, Alexandar K. Duplex scanning of the peripheral arteries: correlation of the peak velocity ratio with angiographic diamter reduction. Ultrasound Med Biol 1992;18:433-440.

16. de Smet AAEA, Kitslaar PJEHM. A duplex criterium for aorto-iliac stenosis. Eur J Vase Surg 1990;4:275-278.

17. Wittens CHA, van Houtte HJKP, Bollen ECM, Mol IMFA. The imaging quality of angiodynography in the ilio-femoral tract. Eur J Vasc Surg 1990;4:61 1-615.

18. Zierler RE. Duplex and color-flow imaging of the lower extremity arterial circulation. Seminars in Ultrasound,CT and MR 1990;11:168-179.

19. Merritt CRB. Doppler color flow imaging. J Clin Ultrasound 1987;15:591-597. 
20. Verhagen PF, van Vroonhoven ThJMV. Criteria for intra-arterial femoral artery pressure measurements combined with reactive thyperaemia to assess the aorto-iliac segment; a prospective study. Br J Surg 1984;71:706-708. 


\section{CHAPTER 7}

Is there still a place for common femoral Doppler sonography in the noninvasive evaluation of aortoiliac obstructive arterial disease?

A.A.E.A. de Smet, I. Zwiers, P.J.E.H.M. Kitslaar

Submitted 


\section{Abstract}

Duplex scanning is the most useful noninvasive technique for evaluation of aortoiliac obstructive arterial disease. The abundant requests for aortoiliac duplex scanning can be a burden for the vascular laboratory. The objective of this prospective study was to determine if the submission of patients to aortoiliac duplex scanning can be diminished by selecting the patients using common femoral Doppler sonography.

In 207 patients with peripheral arterial obstructive disease common femoral Doppler sonography and duplex scanning of the aortoiliac arteries at both sides were compared.

The sensitivity of common femoral sonography to detect a $\geq 50 \%$ aortoiliac stenosis was $78 \%$, the specificity for excluding a stenosis was $70 \%$. The negative predicitive value was $83 \%$, the positive predictive value $63 \%$, and the accuracy $73 \%$.

Common femoral Doppler sonography misses one out of five $\geq 50 \%$ aortoiliac stenoses. This is undesirable and we conclude therefore that femoral Doppler sonography is not longer suitable for the noninvasive evaluation of the aortoiliac arteries and that aortoiliac duplex scanning is preferred.

\section{Introduction}

Since its appearance on the scene of vascular diagnostics, the use of duplex scanning has increased continuously. Nowadays, it is mainly applied for evaluation of extracranial cerebral circulation, aortoiliac and femorodistal obstructive disease, peripheral bypass graft surveillance and venous disorders. The abundant requests for duplex scanning can be a burden for the vascular laboratory. The risk of abusing duplex scanning for all kinds of vascular disorders is real. Duplex scanning is the most accurate noninvasive technique to evaluate the aortoiliac arteries, ${ }_{*}{ }^{1.3}$ but a complete investigation of the aortoiliac arteries can be time consuming. This is due to the deep and often tortuous course of the iliac vessels through the pelvis and the presence of overlying bowel gas. Duplex investigation is even more demanding in obese patients. Because of this, other more simple noninvasive methods are employed to assess the functional status of the aortoiliac segments. Physical examination alone is not sufficient to evaluate the haemodynamic significance of aortoiliac obstructive disease. The continuous wave Doppler sonography of the common femoral artery is a commonly used method to evaluate the status of the aortoiliac segment. It has been shown that femoral Doppler sonography, if normal, reliably confirms the absence of aortoiliac obstructive disease, but is unteliable if abnormal. ${ }^{5}$ If this is true, one could limit duplex examination to the patients with an abnormal femoral Doppler sonography. Duplex scanning can than be done to verify the result of the femoral sonography, and to localize and quantify aortoiliac lesions. This can diminish significantly the number of aortoiliac segments to be evaluated by duplex scanning. The objective of this study was to investigate if duplex examination can be reserved for patients with an abnormal femoral Doppler sonography. 


\section{Patients and methods}

A prospective study was performed of 207 patients with signs and symptoms of peripheral arterial obstructive disease. All patients underwent continuous wave Doppler examination of the common femoral artery and duplex scanning of the aortoiliac arteries at both sides. Also Doppler waveforms were obtained from the popliteal and ankle arteries.

Doppler spectral analysis: The examination was done with a $8 \mathrm{MHz}$ continuous wave Doppler device (Vasculab bi-directional Doppler model D10, Medasonics; Mountain View, California, USA) connected to a audiofrequency spectrum analyser (Vasculab spectrum analyzer model SP25A, Medasonics; Mountain View, California, USA). The Doppler sonography of the common femoral artery was classified into 5 categories (Figure 1): $\mathrm{A}$, the normal Doppler sonography is triphasic. $B$, the first deviation from normal is turbulence during the late systolic phase (high frequency) and damping of the reverse flow component. $C$, with increasing stenosis the reverse flow component disappears. $E$ and $D$, as the stenosis becomes more severe, progressing to total occlusion, the flow velocity waveform becomes progressively damped. ${ }^{6}$ The criterium for significant aortoiliac obstructive disease was set at the disappearance of the reverse flow component. ${ }^{\text {? }}$

The patency of the superficial femoral artery was assessed by comparing the Doppler waveforms obtained from the common femoral and popliteal arteries. If the Doppler sonography of the popliteal artery differed 2 categories or more from the sonography of the common femoral artery, the superficial femoral artery was considered occluded.

Duplex scanning of the aortoiliac arteries: All duplex examinations were done with an ATL Ultramark IV duplex scanner (Advanced Technology Laboratories, Seattle, U.S.A.) with the patient in the supine position. A $3-\mathrm{MHz}$ single frequency sector transducer and a multifrequency sector transducer (with $5-, 7.5-$ and $10-\mathrm{MHz}$ settings) were used to generate a B-mode image of the vessels and the pulsed Doppler signals. Significant stenoses were diagnosed when there was a rise of $150 \%$ in the peak systolic velocity in the jet compared to adjacent velocities (Figure 2).

The diagnostic values of common femoral Doppler sonography were analyzed using aortoiliac duplex scanning as gold standard. 

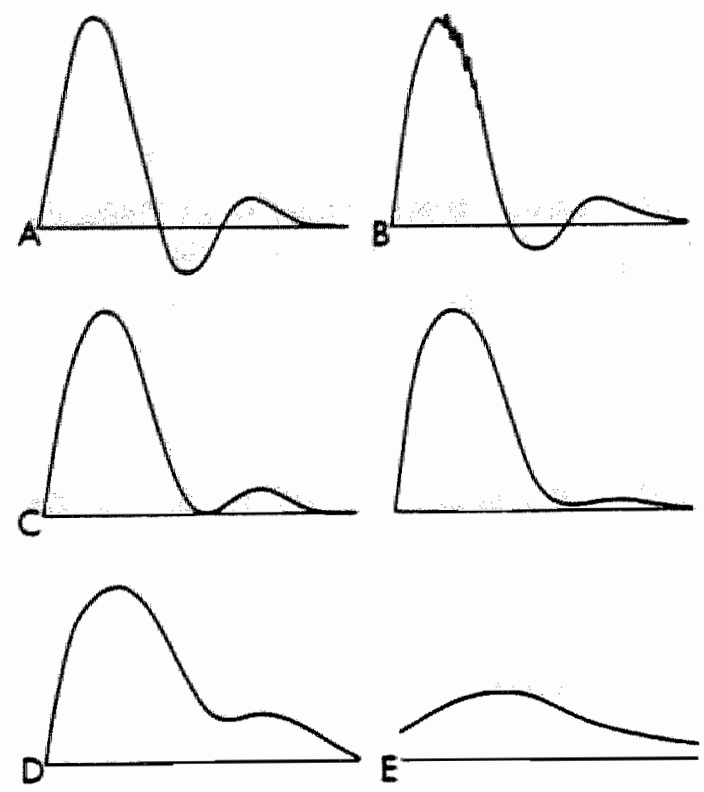

Figure 1. The five categories of common feworal Doppler sonography. For explanation of categories, see text. From Zierler RE et al.

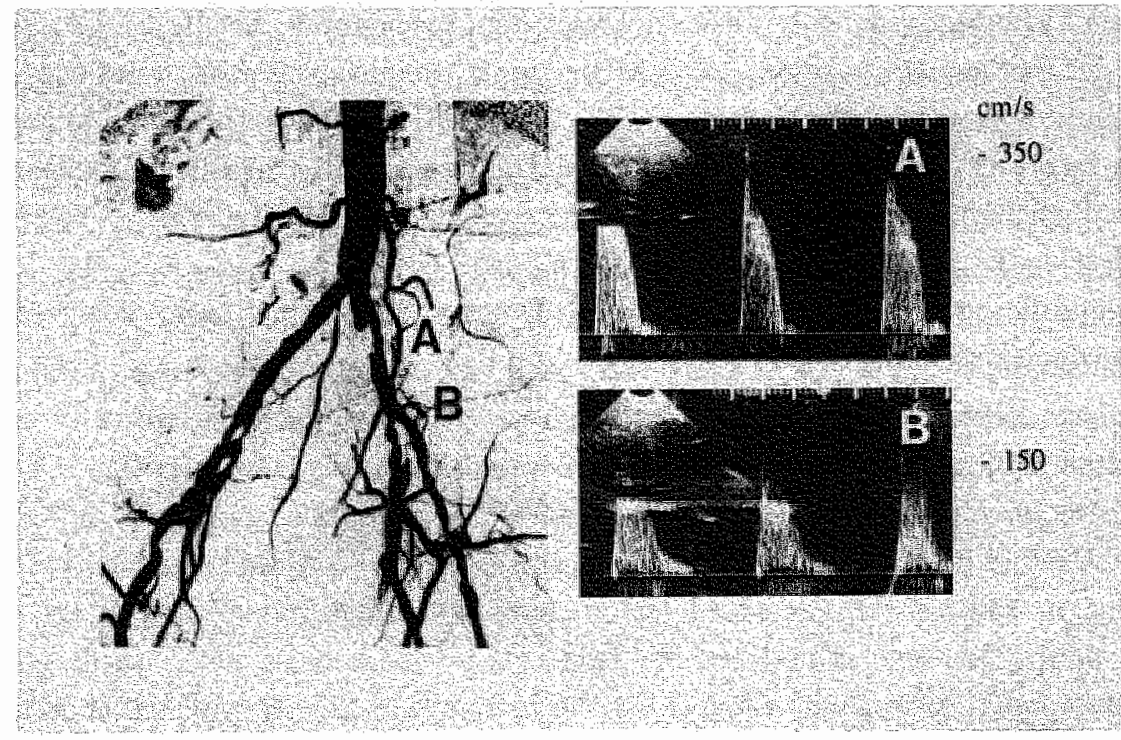

Figure 2. Arteriography and velocity spectra of a stenotic common iliac artery. At the iliac stenosis (A), the PSV is increased to $350 \mathrm{~cm} / \mathrm{sec}$. Distal to the stenosis (B), a turbulent spectrum with a PSV below $150 \mathrm{~cm} / \mathrm{sec}$ is observed. 


\section{Results}

Of the 414 limbs available for examination, 35 duplex examinations were not complete and 2 femoral Doppler sonogram results were not present. Femoral Doppler sonograms and aortoiliac duplex examinations were compared in 379 limbs (Table I).

The prevallence of significant obstructive disease ( = pretest likelihood of disease as assessed by duplex scanning) in the aortoiliac arteries was $39 \%$.

The sensitivity for identifying a $\succ 50 \%$ aortoiliac stenosis by common femoral sonography was $78 \%$, the specificity for excluding a stenosis was $70 \%$. The negative predictive value (NPV) was 83\%, the positive predictive value (PPV) 63\%, and the accuracy $73 \%$ (Table II). Especially the specificity was influenced negatively by an occlusion of the superficial femoral artery.

Table I. Two-way contingency table, results of common femoral CW Doppler sonography and aortoiliac duplex scanning

\begin{tabular}{llccc}
\hline & & \multicolumn{2}{c}{ Duplex scanning } & \\
\cline { 3 - 4 } & & $\alpha 50 \%$ & $\searrow 50 \%$ & $\mathrm{n}$ \\
\hline \multirow{2}{*}{ CW Doppler } & cat A & 108 & 16 & 124 \\
& cat B & 55 & 17 & 72 \\
& cat C-E & 69 & 114 & 183 \\
& & 232 & 147 & 379 \\
\hline
\end{tabular}

cat $=$ Doppler category

Table II. Diagnostic values of common femoral Doppler sonography in differentiating $<50 \%$ or $\pm 50 \%$ diameter reduction as assessed by duplex scanning

\begin{tabular}{lccccc}
\hline CW Doppler & Sensitivity & Specificity & NPV & PPV & Accuracy \\
\hline all & 78 & 70 & 83 & 63 & 73 \\
patent sup fem & 74 & 79 & 81 & 70 & 77 \\
occluded sup fem & 86 & 55 & 89 & 48 & 65 \\
\hline
\end{tabular}

Values are expressed as percentages, sup fem $=$ superficial femoral artery. The cutoff point for an abnormal Doppler sonography is the absence of the reverse flow component in the waveform. 


\section{Discussion}

Nowadays duplex scanning is the best noninvasive method to assess the status of the aortoiliac arteries. The main disadvantage of aortoiliac duplex scanning is that the investigation is time consuming and operator dependent. Despite the fact that femoral Doppler sonography has a low specificity, it is still a commonly used test to assess the hemodynamic status of the aortoiliac vessels indirectly. The method is cheap and quickly to perform. If femoral Doppler sonography has a high NPV, it can be used to identify those patients who need no further investigation. If an investigation requires a high NPV, a test with a high sensitivity should be used, even at expense of a low specificity.

Qualitative and quantitative analysis of the femoral Doppler sonography, such as visual interpretation of the frequency spectrum, pulsatility index, the LaPlace transform damping factor, and the mean power frequency index have yielded sensitivities between $78 \%$ and $100 \%{ }^{7,9-13}$ Several authors have reported that femoral Doppler sonography during postocclusive reactive hyperemia increases the accuracy of the test, but this adds the hyperemia test to the examination. ${ }^{14,15}$ In a comment on waveform analysis, Zierler and Sumner have postulated that many waveform analysis methods, despite the aura of accuracy that numbers convey, are little better than pattern recognition and perhaps not as good. ${ }^{6}$ Recent reports using the approach of simply inspecting the frequency spectrum of the common femoral Doppler sonography mention $>80 \%$ sensitivity. ${ }^{16,17}$ Using this approach, we obtained $78 \%$ sensitivity and $70 \%$ specificity. Thus, if aortoiliac duplex scanning would be limited to the arteries with an abnormal femoral Doppler waveform, $22 \%$ of the $z 50 \%$ aortoiliac lesions would be nissed and consequently not be submitted to further analyses or treatment. This is undesirable and we therefore conclude that femoral Doppler sonography is not longer suitable for the noninwasive evaluation of the aortoiliac arteries.

In clinical practise, an indication of the severity and location of peripheral arterial obstructive disease is given by clinical examination and the determination of ankle-brachial pressure indices at rest and after treadmill exercise. If invasive therapy is considered, noninvasive evaluation of the aortoiliac arteries by duplex scanning is preferred. 


\section{Refierences}

1. Moneta GL, Yeager RA, Lee RW, Porter JM. Noninvasive localization of arterial occlusive disease: A comparison of segmental Doppler pressures and arterial duplex mapping. I Vasc Surg $1993 ; 17: 578-582$.

2. Currie $\mathrm{IC}$, Jones AJ, Wakeley CJ, Tennant WG, Wilson YG, Baird RN, and Lamont PM. Noninvasive aortoiliac assessment. Eur J Vasc Endovase Surg 1995;9:24-28.

3. De Smet AAEA, Ermers EJM, Kitslaar PJEHM. Duplex velocity characteristics of aortoiliac stenoses. J Vasc Surg 1996;23:628-636.

4. Baker JD. Hemodynamic assessment of aortoiliac segment. Surgical Clinics of North America 1990;70:31-40.

5. Thiele BL, Bandyk DF, Zierler RE, Strandness Jr DE. A systematic approach to the assessment of aortoilliacdisease. Arch Surg 1983;118:477-481.

6. Zierler RE, Sumner DS. Physiologic assessment of peripheral arterial occlusive disease. In Rutherford RB ed. Vascular Surgery. Philadelphia: WB Saunders Company 1995;65-117.

7. Persson AV, Gibbons $G$, Griffey $S$. Noninvasive evaluation of the aorto-iliac segment. $J$ Cardiovasc Surg 1981;22:539-542.

8. Legemate DA, Teeuwen $\mathrm{C}$, Hoeneveld $\mathrm{H}$, Eikelboom $\mathrm{BC}$. Value of duplex scanning compared with angiography and pressure measurement in the assessment of aortoiliac arterial lesions. $\mathrm{Br} J$ Surg 1991;78:1003-1008.

9. Walton L, Martin TRP, Collins M. Prospective assessment of the aorto-iliac segment by visual interpretation of frequency analysed Doppler waveforms: A comparison with arteriography. Uiltrasound Med Biol 1984;10:27-32.

10. Junger $\mathrm{M}$, Chapman $\mathrm{BLW}$, Underwood $\mathrm{CJ}$, Charlesworth $\mathrm{D}$. A comparison between two types of waveform analysis in patients with multisegment arterial disease. Br J Surg 19:84;71:345-348.

11. Campbell WB, Cole SEA, Skidmore R, and Baird RN. The clinician and the vascular laboratory in the diagnosis of aortoiliac stenosis. Br J Surg 1984;71:302-306.

12. Baker JD, Machleder HI, Skidmore R. Analysis of femoral artery Doppler signals by LaPlace transform damping method. J Vase Surg 1984;1:520-524.

13. Sawchuk AP, Flanigan DP, Tober JC, Eton D, Schwarcz TH, Eldrup-Jorgensen I, Meyer IP, Durham JR, Schuler JJ. A rapid, accurate, noninvasive technique for diagnosing cirtical and subcritical stenoses in aortoiliac arteries. J Vase Surg 1990;12:158-167.

14. Van Asten WNJC, Beijneveld WJ, Pieters BR, van Lier HJ, Wijn PFF, and Skotnicki SH. Assessment of aortoiliac obstructive disease by Doppler spectrum analysis of blood velocities in the common femoral artery at rest and during reactive lyperaemia. Surgery 1.991;109:633-639.

15. Harward TRS, Bernstein EF, Fronek A. The value of power frequency spectrum analysis in the identification of aortoiliac artery disease. I Vasc Surg 1987;5:803-813.

16. Rosfors S, Eriksson M, Höglund N, Johansson G. Duplex ultrasound in patients with suspected aorto-iliac occlusive disease. Eur I Vasc Surg 1993;7:513-517.

17. Cossman DV, Ellison JE, Wagner WH, Carroll RM, Treiman RL, Foran RF, Levin PM, Cohen JL. Comparison of contrast arteriography to arterial mapping with color-flow duplex imaging in the lower extremities. J Vasc Surg 1989;10:522-529. 
CHAPTER 8

Noninvasive evaluation before and after percutaneous therapy of iliac artery stenoses: The value of the Bernoulli predicted pressure gradient

\author{
A.A.E.A. de Smet, E. Tetteroo, F.L. Moll \\ For the Dutch Iliac Stent Trial Group
}

Submitted 


\section{Abstract}

Purpose. To assess the value of the Bemoull predicted pressure gradient in the noninvasive evaluation of patients undergoing Jiac percutaneous transhuminal angioplasty (PTA) or stent placement, using intraarterial pressure measurements as the standard of reference.

Methods. PTA or stent placement was performed in 261 patients with intermittent claudication caused by iliac artery stenoses ( 333 procedures). Intraarterial translesional pressure gradients were recorded before and after each procedure. Hemodynamic success was defined as a postprocedural mean pressure gradient $\leq 10 \mathrm{mmHg}$. Before and after intervention, the following noninwasive parameters were determined: the Bernoulli predicted pressure gradient, the peak systolic velocity (PSV) ratio, and the ankle-brachial pressure index.

Results. Before treatment, both the intraarterial measured pressure gradients and the Bernoulli predicted gitadients indicated hemodynamic significance of the iliac artery stenoses. After treatment, both methods indicated significant improvement of the translesional pressure gradient $(p<0.0001)$. However, the correlation between the intraarterially measured pressure gradient and the Bemoulli predicted gradient of iliac artery stenoses was low (Pearson's $r=$ 0.27 ). None of the three investigated noninvasive methods could differentiate an optimal PTA or stent result from a suboptimal result, as assessed by intraarterial pressure measurements.

Conclusions. The disappointing correlation between the duplex velocity data, whether expressed as pressure gradient or as PSV ratio, and the actually measured pressure gradient might be caused by errors in pressure or velocity measurements or the different circumstances in which the pressure or velocity measurements were performed. Residual pressure gradients after iliac PTA or stent placement assessed with intraarterial pressure measurements cannot be assessed with noninwasive methods.

\section{Introduction}

Measurement of intraarterial pressure gradients has been advocated for assessment of the hemodynamic significance of iliac artery stenosis and for quantification of the results obtained with percutaneous transluminal angioplasty (PTA) or stenting. ${ }^{-4}$ The pressure gradient of iliac artery stenoses and the result after percutanous therapy may also be estimated by duplex scanning. The peak pressure gradient can be calculated with the velocity data and the modified Bernoulli equation: the pressure gradient $d P^{\prime}=4\left(P S V s^{2}-P S V P\right)$ in units of $\mathrm{mmHg}$, where $P S V_{s}$ is the peak systolic velocity in the stenosis and $P S V_{p}$ the peak systolic velocity proximal to it. ${ }^{5}$ It assumes that part of the kinetic energy of flow in the stenosis calculated from the PSV is converted to heat in the poststenotic region, accounting for the pressure decrease across the stenosis. This noninvasive technique is employed by cardiologists to estimate pressure gradients across cardiac valves, but its usefulness in iliac 
artery stenoses is unclear. ${ }^{6.7}$ If applicable, it may be valuable to determine the hemodynamic significance of iliac artery stenosis and the result of PTA or stenting.

Currently, ankle-brachial pressure index has been recommended as an integral part of the noninvasive evaluation of vascular therapy affecting the lower limb. ${ }^{8}$ Duplex scanning (PSV ratio) is the best noninvasive method to quantify iliac artery stenosis and has been suggested as a follow-up method after PTA or stenting. ${ }^{9.11}$ Bernoulli predicted pressure gradients by means of duplex velocity data might be another method in the noninvasive hemodynamic evaluation of endovascular therapy.

The purpose of this study is to clarify the value of the Bernoulli predicted pressure gradient in the noninvasive hemodynamic assessment of patients undergoing PTA or stenting of iliac artery stenosis.

\section{Patients and methods}

Patients who were seen at the vascular surgery department from November 1993 through August 1996 with intermittent claudication or critical ischemia due to an iliac artery lesion were invited to participate in the Dutch Iliac Stent Trial. Inclusion criteria were as follows: (1) signs and symptoms of intermittent claudication or critical ischemia, and (2) a $\succ 50 \%$ iliac lesion on arteriography ( $\_50 \%$ diameter reduction with visual estimation) or at duplex examination (PSV ratio $\geq 2.5$ ). Grounds for exclusion were stenosis length $\succ 10 \mathrm{~cm}$ and occlusion length $\succ 5 \mathrm{~cm}$, stenosis extending into the distal aorta, or severe comorbidity (e.g. severe cardiac or cerebrovascular pathology, malignant tumors). Two-hundred-and-sixty-one patients enrolled the trial.

Patients were assigned to either primary stent placement or primary PTA, which was immediately followed by secondary stent placement in case of a suboptimal PTA result. A suboptimal PTA result was defined as a residual transstenotic mean pressure gradient of more than $10 \mathrm{mmHg}$ after injection of vasodilators distal to the treated segment. ${ }^{4}$ Randomization was achieved with a computer generated list for each hospital. The study protocol was approved by the institutional review boards of the participating hospitals. All patients were informed about the backgrounds and procedures of the trial, both through oral communication and by means of printed information, and all patients provided written consent.

The length and the arteriographic lumen diameter reduction of the iliac artery stenosis was measured. Bernoulli predicted pressure gradients, intraarterial measured pressure gradients, PSV ratios, and ankle-brachial pressure indexes were measured before and after 333 PTA or stent placement procedures in 261 patients.

Duplex measurements were performed before and the day after therapy with duplex machines equiped with color Doppler. Before therapy, peak systolic velocities (PSV) were recorded at the jet stream within the stenosis and in the adjacent nonstenotic region. After therapy, PSVs were recorded at the treated site and the adjacent region. After stent placement, the reflections of the steel matrix of the Palmaz stent on B-mode indicated the stent site 
clearly; the Doppler velocity spectrum recording was not disturbed by it (Figure 1). Identification of the PTA site was not always easy, because after successful dilatation no change in PSV along the iliac artery is measured. In these circumstances, the duplex examination was done in the region were balloon dilatation had occurred.

The Bernoulli predicted peak pressure gradient was calculated with the modified Bernoulli equation $d P=4\left(P S V^{2}-P S V P\right)$, where $P S V_{S}$ is the peak systolic velocity in the stenosis or treated site and $P S V p$ the velocity proximal to it. ${ }^{5}$ The PSV ratio was obtained by dividing the PSV in the stenosis or treated site by the PSV in the nonstenotic iliac artery.

Mean and systolic intraarterial pressures were measured before and after PTA or stenting of the iliac stenosis: Pressure measurements were performed with a special 5 French doublesensor catheter (Sentron B.V., Roden, the Netherlands) which allows simultaneous recording of intraarterial pressures proximal and distal of the stenosis. The catheter employed a monorail system and was introduced over a 0.025 -inch guide wire. After the initial calibration, the signal from the pressure catheter is both digital and channel recorded by means of a special interface. The endovascular therapy was considered technically successful if the mean pressure gradient across the treated site was equal to or less than $10 \mathrm{mmHg}$ at rest and diring pharmacologically induced vasodilatation.

The significance of a difference in means for paired samples (before and after therapy) was tested by the paired-samples $t$ test. The association between two variables was studied by calculating the Pearson correlation coefficient.

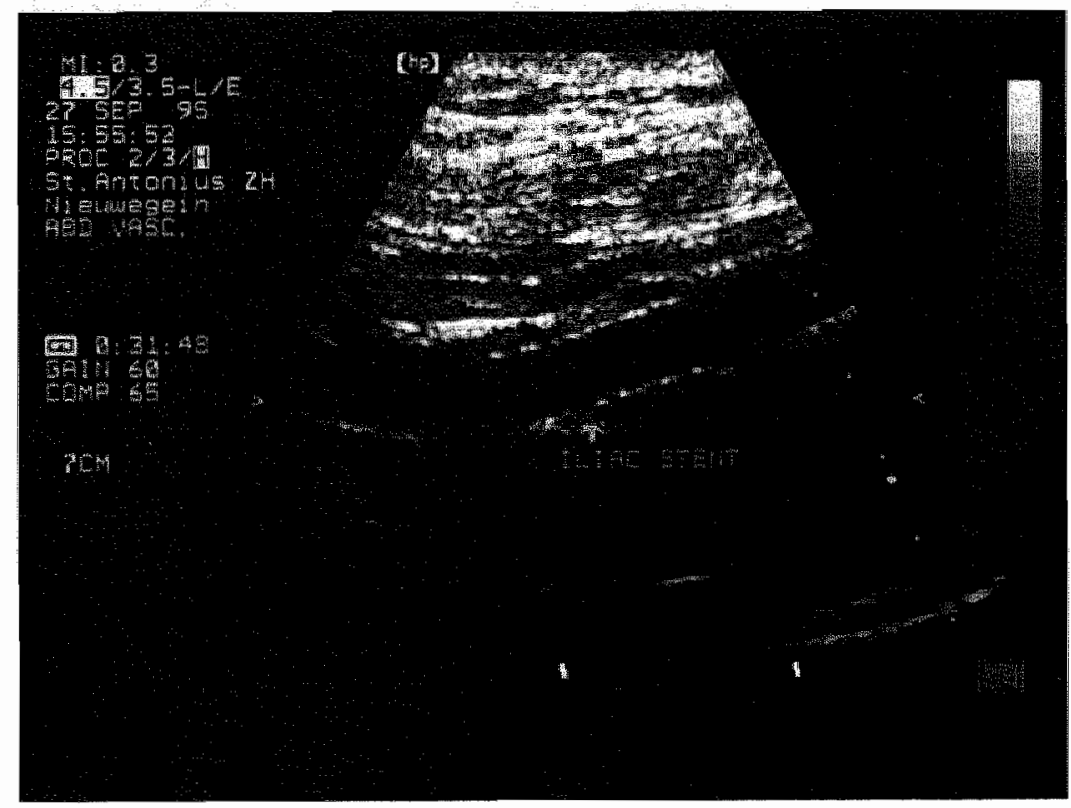

Figure 1. B-mode image of stent in iliac artery, the steel matrix of the stent is clearly visible. 


\section{Results}

The mean pressure gradients, systolic pressure gradients, Bernoulli predicted pressure gradients, PSV ratios, and the ankle-brachial pressure indexes before and after therapy are tabulated (Table I). Both the intraarterial measured and the Bemoulli predicted pressure gradients indicated hemodynamic significant gradients of the iliac stenoses and decreased significantly after therapy (paired-samples $t$ test, $p \prec 0.0001$ ). However, the correlation between the intraarterial measured pressure gradient and the Bernoulli predicted gradient of iliac artery stenoses was low (Pearson's $r=0.27$, Figure 2).

The PSV ratio decreased significantly (paired-samples $t$ test, $p<0.0001$ ) and the anklebrachial pressure index increased significantly after PTA or stenting (paired-samples $t$ test, $p$ $<0.0001$ ). The PSV ratio (Pearson's $r=0.18$ ) and ankle-brachial pressure index (Pearson's $r$ $=-0.23$ ) correlated also poorly with intraarterial measured pressure gradients. The Bernoulli predicted pressure gradients, PSV ratios or ankle-brachial pressure indexes could not differentiate an optimal PTA or stent result assessed by intraarterial pressure measurement from a suboptimal result (Table II). The distribution of the length and arteriographic lumen diameter reduction of the iliac artery stenoses are presented in Table III.

Table I. Mean pressure gradients, systolic pressure gradients, Bernoulli predicted gradients, PSV ratios, and ankle-brachial indexes (mean $\pm S D$, (valid counts)) before and after endovascular therapy of illiac artery stenoses

\begin{tabular}{lcc}
\hline & Before therapy & After therapy \\
\hline Mean pressure gradient & $16.5 \pm 11.3(277)$ & $2.6 \pm 3.1(301)$ \\
Systolic pressure gradient & $40.8 \pm 23.4(278)$ & $7.0 \pm 7.5(303)$ \\
Bernoulli predicted gradient & $59.1 \pm 32.2(175)$ & $3.6 \pm 6.6(197)$ \\
PSV ratio & $5.1 \pm 3.1(175)$ & $1.2 \pm 0.5(197)$ \\
Ankle-brachial index & $0.77 \pm 0.18(313)$ & $0.97 \pm 0.22(182)$ \\
\hline
\end{tabular}

Gradients in $\mathrm{mmHg}$. 


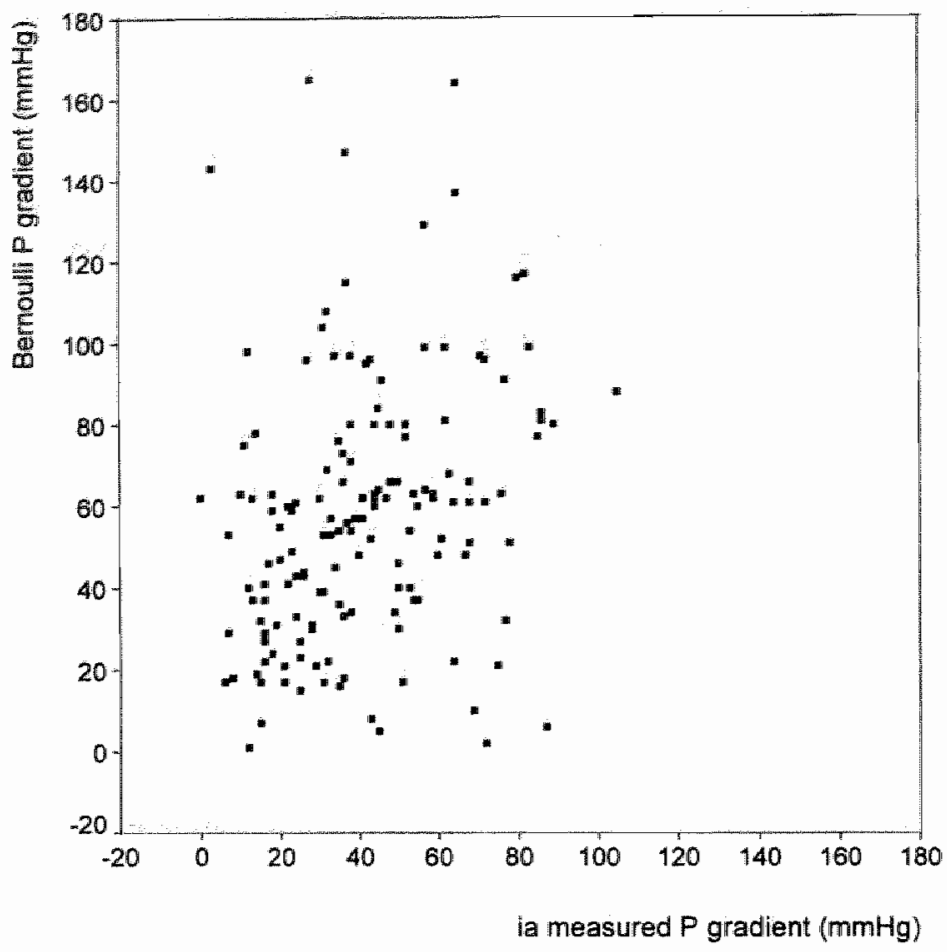

Figure 2. Plot of Bernoulli predicted pressure gradients versus intraarterial measured systolic pressure gradients across iliac artery sienoses.

Table II. Descriptive statistics of Bernoulli predicted pressure gradient, PSV ratio, and ankle brachial pressure index affer an optimal (I) and suboptimal (I) technical result of endovascular illac therapy

\begin{tabular}{lcccccc}
\hline & \multicolumn{2}{c}{ Bernoulli (in mmHg) } & \multicolumn{2}{c}{ PSV ratio } & \multicolumn{2}{c}{ Ankle-brachial index } \\
\cline { 2 - 7 } & I & II & I & II & I & II \\
\hline Mean & 3.6 & 3.7 & 1.15 & 1.16 & 0.99 & 0.98 \\
SD & 6.3 & 9.2 & 0.45 & 0.57 & 0.21 & 0.17 \\
Min & 0 & 0 & 0.33 & 0.72 & 0.38 & 0.62 \\
Max & 39 & 45 & 2.58 & 3.50 & 1.45 & 1.23 \\
Count & 242 & 45 & 242 & 45 & 242 & 45 \\
\hline
\end{tabular}

Tabulated are mean, standard deviation, minimum, maximum, and valid count. 
Table II. Percentual distribution of illac amery sienoses with regard ro arteriogrophic diamerer reduction and length of stenosis

$\%$ Count of stenoses

Diameter reduction

$\begin{array}{lr}<50 \% & 9.3 \% \\ \succ 50 \% & 90.6 \%\end{array}$

Length of stenosis

$$
\leq 2 \mathrm{~cm}
$$

$68 \%$

$>2 \mathrm{~cm}$ and $\leq 5 \mathrm{~cm}$

$30.7 \%$

$>5 \mathrm{~cm}$ and $\leq 10 \mathrm{~cm}$

$1.3 \%$

\section{Discussion}

The hemodynamic significance of iliac artery stenosis and the result after PTA or stenting is preferably assessed by intraarterial measured pressure gradients. ${ }^{1-4} \mathrm{~A}$ possible noninvasive way to assess pressure gradients in iliac arteries before and after PTA or stenting is the peak pressure gradient calculated with the modified Bernoulli equation. ${ }^{5}$ The modified Bernoulli equation calculates the maximum pressure gradient in the iliac artery with the maximum jet PSV and the proximal PSV. Assuming that the kinetic energy in the stenotic jet is completely dissipated beyond the stenosis by viscous losses in turbulence this equation reflects the maximal pressure gradient. Pressure gradients are generally not observed until stenoses exceed $75 \%$ of the lumen area, the point at which turbulence causes energy dissipation. ${ }^{12}$ Below this level the increased velocity causes the Bernoulli equation to predict a pressure gradient when none exists. Consequently, the Bernoulli predicted pressure seems not to be a valid method to identify mild stenosis, such as after a suboptimal PTA or stent result.

In vitro, Doppler derived pressure measurements correlated well with the pressure drop caused by a stenosis, although the peak pressure gradients calculated with the Doppler method were overestimated. ${ }^{13}$ In our study there also was a tendency of overestimation of the pressure gradient by the Bernoulli method. Besides overestimation, our data showed a poor correlation between Bernoulli predicted pressure gradients and intraarterial measured gradients across iliac artery stenoses. The poor correlation in this clinical study may have several causes. First, errors in velocity measurements, which are magnified when the velocity value is squared in the modified Bernoulli equation. Although the Bernoulli relationship works well in echocardiographic measurements, it appears to be less reliable in peripheral vascular measurements. The difference may be that the echocardiographer uses a Doppler examination angle of 0 degrees, whereas the vascular examiner uses angles near 60 degrees. 
For the larger angles, the cosine term in the Doppler equation causes a small uncertainty in the measurement of the angle to result in a large error in velocity estimation. For example, if the estimated examination angle is 60 degrees but the true angle between the Doppler beam and the flow direction is 55 degrees, then the real velocity is $13 \%$ less and the Bernoulli calculated pressure gradient 26\%. Secondly, the modified Bernoulli equations omits the acceleration and viscous resistance terms. The pressure drop caused by viscous resistance can be calculated as described by Poiseuille's law. Omitting viscous resistance leads to an underestimation of the pressure gradient in tight and lengthy stenoses. ${ }^{14}$ Pressure drop by viscous resistance in short stenoses (68\% of the iliac stenoses in this study were less than 2 cms in length) can be neglected. Thirdly, the poor correlation between the Bernoulli calculated and intraarterial measured pressure gradient might be enhanced by variations in flow rates and baseline blood pressures, because the duplex scans were not performed on the same day as the pressure measurements. Fourthly, although intraarterial pressure measurement are valid for pointing out hemodynamically significant stenoses, there are no data available concerning the reproducibillity of this method in the clinical setting. Varying pressure readings might occur due to differences of the intraluminal position of the catheter. ${ }^{3}$ Fifthly, the luminal area reduction of the 5 French double-sensor pressure catheter might lead to an overestimation of the intra-arterial pressure gradients in very tight stenoses. Our results are in contrast with the good correlation between the PSV ratio, which in a way is a relative pressure ratio (see appendix), and the arteriographic diameter reduction of iliac artery stenoses. ${ }^{15}$ We suggest that the above mentioned causes might be responsible for the disappointing correlation between the Bernoulli predicted pressure gradient and the actually measured pressure gradient. The reliability of the Bernouilli relationship in significant iliac artery stenoses is still unclear.

Currently, intraarterial pressure measurements during the procedure and ankle-brachial indexes are validated objective methods in assessing immediate and long term results. The ankle-brachial index measured shortly after the procedure is an objective method to express the PTA or stent result, but is inadequate in patients with near-normal ankle pressures. ${ }^{16}$ Furthermore, it reflects the hemodynamic status of the complete peripheral arterial tree and is therefore not the ideal method to evaluate the long term success of iliac PTA or stenting. Duplex ultrasound has recently been used to predict clinical result after PTA. ${ }^{9-11}$ Patients with a good duplex result (PSV ratio $\prec 2.5$ ) did clinically significantly better than patients with a residual or recurrent stenosis (PSV ratio $\geq 2.5$ ). In our study, none of the 3 investigated noninvasive methods (Bernoulli predicted pressure gradient, PSV ratio, ankle-brachial pressure index) could differentiate an optimal PTA or stent result assessed by intraarterial pressure measurement from a suboptimal result. It seems; that residual pressure gradients after iliac PTA or stenting assessed with intraarterial pressure measurements can not be assessed with noninvasive methods. 


\section{Appendix}

The low correlation between the Bernoulli predicted pressure gradient and the intraarterial measured gradient across iliac artery stenoses is in contrast with the good correlation between the PSV ratio and the arteriographic diameter reduction of iliac artery stenoses. ${ }^{15}$ It raises the question if the Bernoulli predicted pressure gradient correlates good with arteriographic diameter reduction, because - as will be explained below - the PSV ratio and the Bernoulli predicted pressure gradient are related to each other.

If there is steady flow and negligible viscous resistance, Bernoulli gives a pressure drop $\Delta p$, expressed in $\mathrm{mmHg}$, of

$$
\Delta \mathrm{p}=4\left(\mathrm{v}_{\mathrm{s}}^{2}-\mathrm{v}_{\mathrm{p}}^{2}\right)
$$

where $v_{s}$ is peak systolic velocity in the stenosis and $\mathrm{b}$ the nonstenotic peak systolic velocity proximal or distal to the stenosis. At a hemodynamically significant stenosis, the potential. energy in the stenosis is completely converted to kinetic energy and the stenotic pressure can be expressed as

$$
p_{s}=4 v_{s}^{2}
$$

This pressure is also the pressure proximal of the stenosis in the case of negligible viscous resistance. Combining the two equations above, the pressure drop related to the proximal prestenotic pressure p can be written as

$$
\Delta \mathrm{p} / \mathrm{p}=4\left(\mathrm{v}_{\mathrm{s}}^{2}-\mathrm{v}_{\mathrm{p}}^{2}\right) / 4 \mathrm{v}_{\mathrm{s}}^{2} \text { or } \Delta \mathrm{p} / \mathrm{p}=1-\mathrm{v}_{\mathrm{p}}^{2} / \mathrm{v}_{\mathrm{s}}^{2}
$$

Recalling that the PSV ratio (PSV) is defined as

$$
\mathrm{PSV}_{\mathrm{r}}=\mathrm{v}_{\mathrm{s}} / \mathrm{v}_{\mathrm{p}}
$$

the relative systolic pressure drop can be rewritten as

$$
\Delta \mathrm{p} / \mathrm{p}=1-1 / \mathrm{PSV}_{\mathrm{f}}^{2} \text { or } 1-\Delta \mathrm{p} / \mathrm{p}=1 / \mathrm{PSV}_{\mathrm{r}}^{2}
$$

Substituting $\Delta p$ by p (prestenotic pressure) - $p_{d}$ (distal poststenotic pressure), we obtain

$$
\mathrm{p}_{\mathrm{d}} / \mathrm{p}=1 / \mathrm{PSV}_{\mathrm{r}}^{2}
$$

From the last equation we may conclude that:

- The squared PSV ratio is inverse related to the relative pressure drop

- The ankle-brachial pressure index is related to the PSV ratio (by absence of viscous 
differences, pulse wave reflections and multiple significant lesions in the peripheral arteries)

- Recalling that the PSV ratio increases with increasing severity of stenosis, the relative pressure drop also increases with increasing severity of stenosis

The relative systolic pressure drop calculated in this chapter with the above mentioned equation using the velocity data correlated also poorly with the actually measured relative pressure drop (Pearson's $\mathrm{r}=0.20$ ). The disappointing correlation between the duplex velocity data, whether expressed as absolute or relative pressure gradient or as PSV ratio, and the actually measured pressure gradient might be caused by errors in pressure or velocity measurements or the different circumstances in which the pressure or velocity measurements were performed. A favourable correlation between the PSV ratio and the arteriographic diameter reduction has been shown. If the relationship between the relative pressure drop, based on Bernoulli, and the PSV ratio is true, the relative pressure drop should also have a favourable correlation with arteriographic diameter reduction. The dynamic relationship between the relative pressure drop, based on Bernoulli, and the PSV ratios should be further investigated. 


\section{References}

1. Walden R, Siegel $Y$, Rubinstein Z, Morag B, Bass A; Adar R Percutaneous transluminal angioplasty. A suggested method for analysis of clinical, arteriographic, and hemodynamic factors affecting the results of treatment. J Vasc Surg 1986;3:583-590.

2. Rees $C R$, Palmaz JC, Garcia $O$, et al. Angioplasty and stenting of completely occluded iliac arteries. Radiology 1989;1.72:953-959.

3. Palmaz JC, Garcia OJ, Schatz RA, et al. Placement of balloon-expandable intraluminal stents in iliac arteries: First 171 procedures. Radiology 1990;174:969-975.

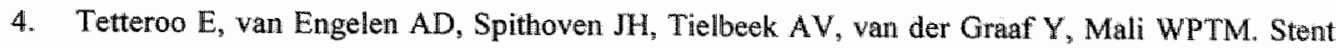
placement after illiac angioplasty: Comparison of hemodynamic and angiographic criteria. Radliology 1996;201:155-159.

5. Legemate DA, Teeuwen $\mathrm{C}$, Hoeneveld $\mathrm{H}$, Eikelboom $\mathrm{BC}$. How can the assessment of the haemodynamic significance of aortoiliac arterial stenosis by duplex scanning be improved? A comparative study with intra-arterial pressure measurement. J Vase Surg 1993;17:676-684.

6. Hatle L, Brubakk A, Tromsdal A, Angelsen B. Noninvasive assessment of pressure drop in mitralis stenosis by Doppler ultrasound. $\mathrm{Br}$ Heart J 1987;40:131-140.

7. Rijsterborgh $\mathbb{H}$, Roelandt J. Estimation of transvalvular pressure drops by the Doppler echocardiography: The Bemouilli equation revisited. In: Roelandt J, ed. Color Doppler flow imaging and other advances in Doppler echocardiography. Dordrecht: Martinus-Niehoff, 1986:19. 28.

8. Rutherford RB, Flanigan DP, Gupta SK, et al. Suggested standards for reports dealing with lower extremity ischemia. J Vase Surg 1986;4:80-94.

9. Spijkerboer AM, Nass PC, de Valois JC, Eikelboom BC, Overtoom TThC, Beek FJA, Moll FL, Mali WPThM. Iliac artery stenoses after percutaneous angioplasty: Follow-up with duplex ultrasonography. J Vasc Surg 1996;23:691-697.

10. Mewissen MW, Kinney EV, Bandyk DF, Reifsnyder T, Seabrook GR, Lipchik EO, Towne IB. The role of duplex scanning versus angiography in predicting the outcme after balloon angioplasty in the femoropopliteal artery. J Vasc Surg 1992;15:860-866.

11. Miller BV, Scharp WJ, Shamma AR, Kresowik TF, Petrone S, Corson JD. Surveillance for recurrent stenosis after endovascular procedures. Arch Surg 1991;126:867-872.

12. Kohler TR, Nicholls SC, Zierler RE, Beach KW, Schubert PJ, Strandness DE Jr. Assessment of pressure gradient by Doppler ultrasound: Experimental and clinical observations. J Vasc Surg $1987 ; 6 ; 460-469$.

13. Weber G, Strauss AL, Rieger $\mathrm{H}$, Scheffler A, Eisenhoffer J. Validation of Doppler measurements of pressure gradients across peripheral model arterial stenosis. J Vasc Surg 1992;16:10-16.

14. Teirstein PS, Yock PG, Popp RL. The accuracy of Doppler ultrasound measurement of pressure gradients across irregular, dual, and tunnellike obstructions to blood flow. Circulation $1985 ; 72.577-584$

15. de Smet AAEA, Ermers EJM, Kitslaar PJEHM. Duplex velocity characteristics of aortailiac stenoses. J Vasc Surg 1996;23:628-636.

16. Salles-Cunha SX, Andros G, Dulawa LB, Harris RW, Oblath RW. Changes in peripheral hemodynamics after percutaneous transluminal angioplasty. J Vasc Surg 1989;10:338-342. 
CHAPTER 9

General discussion and conclusions 
Patients with symptoms of lower extremity atherosclerotic occlusive disease commonly have involved several arterial segments in the disease process. Planning of the therapy of the patient requires determination of the relative contribution of each level of obstructive disease to the hemodynamic behaviour and the patient's overall clinical status. Accurate hemodynamic assessment of stenoses in aortodiac segments is a difficult clinical problem. A general impression of the severity and location of peripheral arterial occlusive disease is given by clinical examination and the determination of ankle-brachial pressure indices, but this is inadequate if endowascular or surgical therapy is considered. Standard methods for determining the severity of aortoiliac obstructive disease are arteriography and intraarterial pressure measurements. Arteriography is considered the gold standard in the assessment of the morphology of the aortoiliac arteries, whereas intraarterial pressure measurements are considered the gold standard to assess the haemodynamics.' Different aspects of aortoiliac obstructive disease, such as lumen or area reduction of stenotic regions, pressure gradients or blood flow velocity characteristics across stenotic regions, are assessed by different diagnostic methods (Table).

Table. Different aspects of aortoiliac obstructive disease examined by different diagnastic methods. $+=$ aspect examined by the diagnostic method

\begin{tabular}{lcccc}
\hline Aspect & Arteriography & FAP & Duplex & $\begin{array}{l}\text { Femoral } \\
\text { Doppler }\end{array}$ \\
\hline $\begin{array}{l}\text { Diameter/Area } \\
\text { Reduction }\end{array}$ & + & + & \\
$\begin{array}{l}\text { Pressure Gradient/Ratio } \\
\text { Flow velocity }\end{array}$ & + & + & \\
\hline
\end{tabular}

Noninvasive ultrasonic methods, such as Doppler analysis of common femoral blood flow velocity waveforms and aortoiliac duplex scanning, have been used to assess aortoiliac obstructive disease. As discussed in chapter 3, none of the historically developed qualitative and quantitative methods of femoral Doppler waveform analysis for indirect hemodynamic assessment of aortoiliac obstructive disease has gained widespread clinical acceptance. An inherent problem with the indirect methods is their reliance on velocity events downstream from the stenotic aortoiliac segment. Disturbed Doppler femoral waveforms indicate presence of aortoiliac pressure gradients, but femoral waveform disturbances may also result from local, or more distal, atherosclerotic obstructive disease. A pressure reducing aortoiliac artery stenosis or occlusion cannot be unambiguously quantified nor can the morphology of the aortoiliac region be assessed by this method.

Combining B-mode ultrasound imaging with a pulsed Doppler flow detector and 
spectrum analyzer in a so-called duplex scanner allows acquisition of Doppler information directly from areas suspect of a stenosis. The clinical application of duplex scanning to aortoilliac arteries was stimulated by dissatisfaction with the indirect Doppler methods discussed above. Duplex scanning enables the assessment of both morphology and hemodynamics of stenotic regions by providing arterial cross-sections and velocity characteristics along the complete aortoiliac pathway, where its interpretation is adapted to the site of measurement. The velocity data may be used to assess the area reduction of the stenosis and to estimate arterial pressure gradients. The main goal of this thesis was to investigate whether aortoiliac duplex scanning might replace invasive methods like arteriography and intraarterial pressure measurements without sacrificing accuracy.

Arteriography provides detailed anatomic information about aortoiliac occlusive disease. Single-plane arteriography provides a two-dimensional portrayal of a three-plane structure. The degree of stenosis usually is determined as the percentage of narrowing of the normal lumen diameter. The actual degree of narrowing reported varies with the image plane used. Eccentric lesions are either under- or overestimated, depending on the projection used. For reduction of errors, at least two or three projections are recommended. ${ }^{2.3}$

Duplex scanning provides morphologic and hemodynamic information. The B-mode allows direct visualization of the aortoiliac arteries, giving an impression of the presence of calcifications in the arterial wall and allowing for positioning of the Doppler sample volume in the artery. From the B-mode image also the Doppler angle of observation can be determined, which allows measurement of absolute blood flow velocities. The degree of stenosis expressed as area reduction is estimated from velocity data rather than from B-mode. The use of area reduction rather than diameter reduction will probably improve accuracy. Duplex scanning has been shown to differentiate between $<50 \%$ and $\geq 50 \%$ arteriographic diameter reduction in the aortoiliac arteries by means of the ratio of peak systolic velocity (PSV) at the site of the stenosis and its immediate normal vicinity. ${ }^{4.6}$ Substitution of arteriography by duplex scanning is only recommended when the aortoiliac arteries can be visualized along their whole course and the arterial stenoses can be classified more precisely than simply as $<50 \%$ or $\succ 50 \%$ diameter reduction. In chapter 5 , we assessed the value of duplex velocity characteristics for improved grading of aortoiliac stenoses. From this study and other recently published data, ${ }^{5,6}$ the following criteria for aortoiliac stenoses were proposed: a PSV ratio $<1.5$ combined with reverse flow and a clear systolic window in the Doppler spectrum predicted a diameter reduction $\prec 20 \%$; a PSV $\prec 200 \mathrm{~cm} / \mathrm{sec}$ and $/$ or a PSV ratio $\prec 2.5$ indicated a diameter reduction $\prec 50 \%$; a PSV ratio $\succeq 2.5$ identified a diameter reduction $\succeq 50 \%$; and a PSV ratio $\succeq 5.0$ and an enddiastolic velocity (EDV) $\succeq 40 \mathrm{~cm} / \mathrm{sec}$ indicated a diameter reduction $\geq 75 \%$. Currently, aortoiliac stenoses can be quantified accurately with these duplex velocity characteristics.

Duplex ultrasound may also be used to estimate absolute and relative pressure gradients across iliac artery stenoses by measuring both the stenotic velocity and the velocity proximal to the stenosis, and use of the modified Bernoulli equation. Only few endeavours of this approach in peripheral vascular diagnosis have been published. ${ }^{7,8}$ The low correlation 
between the Bernoulli predicted pressure gradients and the intraarterial measured gradients across iliac artery stenoses (see chapter 8 ) is in contrast with the good correlation between the PSV ratio, which in a way is a relative pressure gradient, and the arteriographic diameter reduction of iliac artery stenoses (see chapter 5). It raises the question if the Bernoulli predicted pressure gradient correlates favourable with arteriographic diameter reduction, because - as has been explained in chapter 8 - the PSV ratio and the Bernoulli predicted pressure gradient are related to each other. The dynamic relationship between the relative pressure drop, based on Bernoulli, and the PSV ratios should be further investigated.

Intraarterial pressure measurements, such as directly measured systolic femoral artery pressures (FAP) under resting and hyperemic conditions, were considered to be the gold standard for determining the hemodynamic significance of aortoiliac stenosis. ${ }^{9}$ To determine a duplex criterion for hemodynamically significant aortoiliac stenosis, aortoiliac duplex scanning was compared to FAP measurements as described in chapter 4 . The optimum cutoff value for hemodynamically significant aortoiliac stenosis, as assessed by FAP measurements, was between a $100 \%$ and $200 \%$ increase of the PSV at the site of the stenosis in respect to the PSV in the immediate normal vicinity (equivalent to a PSV ratio between 2.0 and 3.0 ). From another study described in chapter 6 , we concluded that an EDV $>0 \mathrm{~cm} / \mathrm{sec}$ at the stenotic site indicated a significant pressure gradient. We observed that the sensitivity of duplex scanning if compared to the FAP test as gold standard was disappointingly low. Because of these observations and the fact that there is little clinical evidence that decisions based on FAP measurements are of value, ${ }^{10,11}$ we had doubts about the clinical diagnostic value of FAP measurements as the gold standard for determining the hemodynamic significance of iliac stenosis. To clarify this uncertainty, we examined prospectively the value of the FAP test compared to duplex scanning and arteriography on clinical decisions (see chapter 6). We observed only a moderate agreement between FAP measurements on the one hand and duplex scanning or arteriography on the other hand. The low number of endovascular or operative procedures on limbs with an abnormal FAP test in this study indicated that the FAP test seemed to overestimate the severity of disease. This overestimation was mainly due to the pressure measurements under hyperemic conditions. The hyperemic pressure ratios are probably not as reliable as the resting pressure ratios; the papaverine induced hyperemic response causes a variable and unpredictable increase in the femoral artery blood flow. A better accuracy of pressure measurements under hyperemic conditions might be obtained by quantifying the hyperemic response and correcting for the magnitude of it, for example by the measurement of the blood flow rate through the entire cross-section of the leg with a blood flow scanner. ${ }^{12}$ The use of resting pressure ratios only is not the solution, because resting pressure ratios underestimate the severity of disease. For determination of the femorobrachial systolic pressure ratios, we used the technique described by Flanigan et al. ${ }^{10,11}$. However, the use of two independent methods for pressure measurement, a brachial oscillometric and femoral artery manometric, may induce errors. Our results raise questions concerning the value of the FAP test as gold standard for determining the haemodynamic significance of iliac artery stenosis. Maybe that other techniques can improve the reliability of pressure gradient or 
pressure ratio assessment of aortoiliac obstructive disease in the clinical setting.

Due to the diagnostic reliability of aortoiliac duplex scanning, the abundant requests for aortoiliac duplex scanning has become a burden for the vascular laboratory. We were interested to find out if the number of patients submitted for aortoiliac duplex scanning could be diminished by selecting the patients with a more simple noninvasive method. It has been postulated that femoral Doppler sonography, if normal, reliably confirms the absence of aortoiliac obstructive disease. If this is true, duplex scanning might be reserved for patients with an abnormal femoral Doppler sonogram. However, as described in chapter 7, we observed that common femoral Doppler sonography missed one out of five aortoiliac stenoses of $\succeq 50 \%$ diameter reduction. This is undesirable and we concluded that there is no place for common femoral Doppler sonography in the noninvasive evaluation of aortoiliac obstructive arterial disease and that aortoiliac duplex scanning is preferred.

In conclusion, the following answers can be given to the questions underlying the investigations reported in this thesis:

- Common femoral Doppler sonography is no longer suitable for noninvasive evaluation of aortoiliac arteries

- Aortoiliac obstructive disease can be quantified accurately by duplex scanning using several Doppler parameters such as the PSV ratio, the absolute PSV value, EDV, and the presence or absence of reverse flow and spectral broadening in the Doppler spectrum

- Duplex scanning can replace arteriography as a screening tool for the detection of treatable aortoiliac lesions

- The value of FAP measurements in clinical practice is limited

- The reliability of pressure gradients based on Bernoulli in iliac artery stenoses is still unclear

- The relative pressure drop is inverse related to the squared PSV ratio

Arteriography should be reserved for use in complicated cases and as a preliminary to surgical treatment. This policy reduces the number of patients exposed to an invasive diagnostic procedure. ${ }^{13}$ Patients without significant aortoiliac atherosclerotic disease according to duplex scanning need no further evaluation of the aortoiliac arteries. Patients with aortoiliac disease suitable for transcutaneous endovascular therapy can be identified and scheduled for treatment without antecedent arteriography. To date, this is increasingly becoming routine clinical practice. Surgical therapy of the aortoiliac arteries based on noninvasive work-up alone has been performed in selected cases. If any surgeon decides to operate only on the basis of duplex scan information, the accuracy of the laboratory must be carefully and scientifically established. The ultimate goal of ultrasonic assessment of aortoiliac occlusive disease will be achieved if operative or endovascular therapy is performed on the basis of ultrasonic data alone. 


\section{The future}

Color-flow maging provides another method of displaying the Doppler information but it is not anticipated that it will supplant the need for Doppler spectral analysis. It is likely that color Doppler imaging of the residual arterial lumen will be used increasingly for direct visual measurement of arterial stenoses, and that the use of spectral Doppler analysis will decrease somewhat. Ultrasound image enhancement by microbubble agents, e.g. Levovist (Schering $\mathrm{AO}$, Germany), may aid Doppler ultrasound investigation in patients whose unenhanced scans are suboptimal or non-diagnostic. Three-dimensional imaging may lessen problems associated with measuring tortuous or irregular stenotic lumens, enhancing the value of direct color Doppler stenosis measurement. Power Doppler imaging may have a role in direct stenosis measurement (length and cross-sectional area) because this method is less angle dependent than standard color Doppler imaging. ${ }^{1 / 4}$

A new method of noninvasive evaluation of peripheral arterial occlusive disease is magnetic resonance angiography (MRA). ${ }^{15}$ Unlike conventional angiography, MRA does not require ionizing radiation, injection of contrast material, and arterial catheterization. It is a promising method which may have a major impact on noninvasive evaluation of aortoiliac obstructive disease. 


\section{References}

1. Baker AR, Macpherson DS, Evans DH, Bell PRF. Pressure studies in arterial surgery. Eur I Vasc Surg 1987;1:273-283.

2. Berne FA, Lawrence WP, Carlton WH. Roentgenographic measurements of arterial narrowing. AJR 1970;110:757-759.

3. Clifford PC, Cole SEA, Rhys Davies E, Baird $\mathbb{R N}$. Detection of arterial stenosis: Increased accuracy using biplanar angiography and Doppler signal analysis. I Cardiovasc Surg $1985 ; 25: 554-557$.

4. Jager KA, Phillips DJ, Martin RL. Noninvasive mapping of lower-limb arterial lesions. Ultrasound Med Biol 1985;11:515-521.

5. Ranke $\mathrm{C}$, Creutzig A, Alexander K. Duplex scanning of the peripheral arteries: correlation of peak systolic velocity with angiographic diameter reduction. Ultrasound Med Biol 1992;18:433-440.

6. Legemate DA, Teeuwen $C$, Hoeneveld H, Ackerstaff RGA, Eikelboom BC. Spectral analysis criteria in duplex scanning of aortoiliac and femoropopliteal arterial disease. Ultrasound Med Biol 1991;17:769-776.

7. Kohler TR, Nicholls SC, Zierler RE, Beach KW, Schubert PJ, Strandness Jr DE Assessment of pressure gradient by Doppler ultrasound: Experimental and clinical observations, $\mathrm{J}$ Vasc Surg $1987 ; 6: 460-469$.

8. Legemate DA, Teeuwen $C$, Hoeneveld $H$, Eikelboom $B C$. How can the assessment of the haemodynamic significance of aortoiliac arterial stenosis by duplex scanning be improved? A comparative study with intra-arterial pressure measurement. J Vasc Surg 1993;17:676-684.

9. Kinney TB, Rose SC. Intraarterial pressure measurements during angiographic evaluation of peripheral vascular disease: techniques, applications, and limitations. AJR 1996;166:277-284.

10. Flanigan DP, Williams LR, Scwartz JA, et al. Hemodynamic evaluation of the aortoiliac system based on pharmacologic vasodilatation. Surgery 1983;93:709-714.

11. Flanigan DP, Ryan TJ, Williams LR, et al, Aortofemoral or femoropopliteal revascularization? $A$ prospective evaluation of the papaverine test. J Vasc Surg 1984;1:215-223.

12. Salles-Cunha SX, Andros G, Dulawa LB, Harris RW, Oblath RW. Changes in peripheral hemodynamics after percutaneous transiuminal angioplasty. J Vasc Surg 1989:10:338-342.

13. Elsman BHP, Legemate DA, van der Heyden FHWM, de Vos HJ, Mali WPThM, Eikelboon BC. Impact of ultrasonographic duplex scanning on therapeutic decision making in lower limb arterial disease. Br J Surg 1995;482:630-633.

14. Zwiebel WJ. Vascular sonography: where do we go from here? J Vasc Technol 1995;19:221-226.

15. Douek PC, Revel D, Chazel S, Falise B, Villard J, Amiel M. Fast MR angiography of the aortoiliac arteries and arteries of the lower extremity: value of bolus-enhanced, whole-volume subtraction technique. AJR 1995;165:431-437. 
CHAPTER 10

Summary 
Chapter 1 gives a general introduction and the goals of this thesis. The main goal of the thesis was to investigate whether aortoiliac duplex scanning might replace invasive methods, such as arteriography and intratrerial pressure measurements, in the assessment of aortoiliac obstructive disease without sacrificing accuracy.

Chapter 2 discusses the Doppler frequency shift in ultrasonic waves and its application in the detection of blood flow. The development of ultrasonic flowmeters and duplex scanners, a combination of B-mode and pulsed Doppler ultrasound, is described.

Chapter 3 reviews the development of uitrasound techniques for the assessment of aortoiliac obstructive disease. It started with the indirect assessment of aortoiliac obstructive disease by audible interpretation of the Doppler ultrasound signal obtained from the common femoral artery and evolved into the direct assessment of aortoiliac obstructive disease by color-flow duplex scanning.

In chapter 4 a duplex criterion to assess hemodynamically significant aortoiliac stenoses is investigated. The usual duplex criterion for an arterial stenosis is the relative increase of peak systolic velocity (PSV) at the stenosis. The results of duplex scanning of 97 aortoiliac segments were compared with intraarterial pressure measurements in the common femoral artery (FAP test). It is found, that the optimum cutoff value for assessment of hemodynamically significant aortoiliac stenosis has to be selected between a $100 \%$ and $200 \%$ increase of PSV at the site of the stenosis in respect to the PSV in the immediate normal vicinity.

Chapter 5 deals with the duplex velocity characteristics of aortoiliac stenoses. It is now possible to grade aortoiliac stenoses in broad categories based on PSV changes. We investigated whether additional simple Doppler parameters would improve the grading of aortoiliac obstructive disease. It is concluded that the PSV ratio is the most important parameter to grade aortoiliac stenoses into $\varangle 20 \%, 20 \%$ to $49 \%, 50 \%$ to $74 \%$, and $75 \%$ to $99 \%$ diameter reduction. Additional parameters such as absolute PSV value, end-diastolic velocity, and the presence or absence of reverse flow and spectral broadening in the Doppler spectrum have additional value in the gradation.

Chapter 6 deals with the value of duplex scanning in grading aortoiliac obstructive disease and in selecting patients for interventional therapy. The results of duplex scanning of 153 aortoiliac segments in 87 patients were compared with arteriography and FAP test, which are considered the gold standards for assessment of aortoiliac obstructive disease. It is shown, that duplex scanning can replace arteriography as a screening tool for the detection of treatable aortoiliac lesions, wheras the value of FAP measurements in the decision making process is limited. 
Chapter 7 discusses the place for common femoral Doppler sonography in the noninvasive evaluation of aortoiliac obstructive arterial disease. It is shown, that common femoral Doppler sonography misses one out of five $z 50 \%$ aortoiliac stenoses. This number is unacceptably high, and therefore femoral Doppler sonography is not longer suitable for the noninvasive evaluation of the aortoiliac arteries and preference should be given to aortoiliac duplex scanning.

Chapter $\mathbf{8}$ discusses the value of the Bernoulli predicted pressure gradients in iliac stenoses before and after endovascular therapy. The pressure gradient is calculated with the modified Bernoulli equation using velocity data obtained by duplex scanning. The Bernoulli predicted gradients correlated poorly with the intraarterial measured pressure gradients. Several possible explanations for the disappointing correlation are discussed. The underlying relationship between the relative pressure drop based on Bernoulli and the PSV ratio is discussed in an appendix.

Chapter 9 gives the general discussion and the conclusions. 
CHAPTER 10

Samenvatting 
Hoofdstuk 1 geeft een algemene inleiding en de doelstellingen van het proefschrift. De belangrijkste doelstelling was om te onderzoeken of duplex scanning de invasieve diagnostiek zoals angiografie en invasieve drukmetingen bij de diagnose van aorto-iliacale vernauwingen of obstructies kan vervangen.

Hoofdstuk 2 bespreekt de ultrageluidstoepassing van het Doppler principe in de bloedstroom snelheidsmetingen. De ontwikkeling van uitrageluid flowmeters en duplex scanners, een combinatie van B-mode en pulsed Doppler ultrageluid, wordt beschreven.

Hoofdstuk 3 beschrijft de ontwikkelingen van ultrageluidstechnieken voor de vaststelling van aorto-iliacale obstructieve afwijkingen. Vroeger werd de functionele status van het aortoiliacale segment op een indirecte wijze bepaald door te luisteren naar het geluid van het Doppler signaal van de polsgolf van de arteria femoralis communis. Momenteel kan de bloedstroom in de aorto-iliacale arterieên met kleuren duplex scanning direct onderzocht worden. Duplex scanning blijkt de beste ultrageluidsmethode te zijn om aorto-iliacale obstructieve afwijkingen te onderzoeken.

In hoofdstuk 4 werd een duplex criterium onderzocht om hemodynamisch belangrijke aortoiliacale vernauwingen aan te tonen. Het onderzochte criterium was de toename van piek systolische snelheid (PSV) in de vernauwing ten opzichte van de PSV voor of na de vernauwing. De duplex resultaten van 97 aorto-iliacale segmenten werden vergeleken met intra-arteriele drukmetingen in de arteria femoralis communis (FAP test). Het blijkt dat het optimale duplex criterium om een hemodynamische significante aorto-iliacale vernauwing aan te tonen is gelegen tussen de $100 \%$ en $200 \%$ toename van de PSV ter plaatse van de vernauwing.

Hoofdstuk 5 behandelt de duplex snelheidskarakteristieken van aorto-iliacale vernauwingen. Op basis van piek systolische snelheidsveranderingen was het reeds mogelijk om vernauwingen met $<50 \%$ diameter reductie te onderscheiden van stenosen met $>50 \%$ diameter reductie. Onderzocht werd met welke Doppler parameters een meer gedetailleerde classificatie van aorto-iliacale vernauwingen verkregen kon worden. Het blijkt dat de PSV ratio de belangrijkste parameter is om aorto-iliacale vernauwingen in te delen in $<20 \%, 20 \%$ tot $50 \%, 50 \%$ tot $75 \%$, en $75 \%$ tot $99 \%$ diameter reductie. Andere parameters zoals de absolute PSV waarde, de einddiastolische snelheid, en de aan- of afwezigheid van terugstroom of spectrale verbreding in het Doppler spectrum zijn ook van belang voor deze indeling.

Hoofdstuk 6 handelt over de waarde van duplex scanning om de ernst van aorto-iliacale obstructieve afwijkingen te graderen en om patienten voor interventies te selecteren. Daartoe werden de resultaten van duplex scanning van 153 aortoiliacale segmenten bij 87 patienten vergeleken met arteriografie en FAP test. Beide methoden worden beschouwd als de gouden 
standaard voor het vaststellen van aorto-iliacale obstructieve afwijkingen. In tegenstelling tot de FAP test correspondeerde de uitkomst van arteriografie of duplex scanning uitstekend met de behandelingskeuze. Aangetoond werd dat arteriografie als selectie methode voor te behandelen aorto-iliacale obstructieve afwijkingen vervangen kan worden door duplex scanning en dat de waarde van de FAP test in de klinische bestuitvorming beperkt is.

Hoofdstuk 7 gaat in op de plaats van. Doppler signaal analyse van de polsgolf van de arteria femoralis communis bij de noninvasieve evaluatie van aorto-iliacale arterieên. 379 femoralis Doppler analyses bij 207 patienten werden vergeleken met aorto-iliacale duplex scanning. $20 \%$ van de $\geq 50 \%$ aorto-iliacale vernauwingen werden gemist door de femoralis Doppler analyse. Dit is onacceptabel en daarom is deze methode niet langer geschikt voor noninvasieve evaluatie van de aorto-iliacale arterieên en heeft duplex scanning de voorkeur.

Hoofdstuk 8 bespreekt de waarde van de met de gemodificeerde Bernoulli vergelijking berekende drukgradient over iliacale vernauwingen voor en na endovasculaire therapie. De snelheden nodig voor de berekening werden met duplex scanning verkregen. De berekende gradienten correleren slecht met de werkelijk gemeten drukgradienten. Enkele mogelijke verklaringen voor deze teleurstellende correlatie worden besproken. In een appendix wordt de relatie tussen de relatieve drukgradient berekend met behulp van de Bernoulli vergelijking en de PSV ratio besproken.

Hoofdstuk 9 geeft een algemene discussie en de conclusies. 
List of abbreviations 

AIOD
aortoiliac obstructive disease
CFA
common femoral artery
CW
continuous wave
EDV
end diastolic velocity
FAP test
invasive common femoral artery pressure measurements
FBI
LT
femorobrachial systolic pressure index
NPV
Laplace transform
negative predictive value
PCA
PFSA
principal component analysis
PI
power frequency spectrum analysis
PPV
pulsatility index
PSV
positive predictive value
peak systolic velocity
PSV ratio
stenotic PSV divided by nonstenotic PSV
PSV difference
difference between stenotic PSV and nonstenotic PSV 
Dankwoord 
Graag wil ik hier een kort woord van dank richten aan hen die mij hebben geholpen bij het tot stand komen wan dit proefschrift.

Mijn promotor, Prof. Dr. P.J.E.H.M. Kitslaar, die mij overtuigde dat diagnostiek van aortoiliacale vernauwingen of obstructies nader klinisch onderzoek verdiende en dat $\mathrm{ik}$ op dit onderwerp kon promoveren.

Mijn promotor, Prof. Dr. Ir. A.P.G. Hoeks, die mij met enkele vragen betreffende haemodynamiek aan het denken zette en hielp een antwoord op deze vragen te vinden.

Mijn opleider valatchirurgie, Dr F.L. Moll, die de mogelijkheid schiep om met gegevens van de Dutch Iliac Stent Trial het proefschrift meer inhoud te geven.

Eric Tetteroo, die mij hielp met het rangschikken van deze gegevens.

De dames van het vaatlaboratorium, René Dresens-Penders, Edith Ermers, Yvonne Reijnders en Inge Zwiers. Zij verrichtten deskundig de Doppler en duplex onderzoekingen en hielpen met de registratie van de gegevens.

Mijn moeder, die mij een hart onder de riem stak met herinneringen over het tot stand komen van het proefschrift van mijn vader. Ook hij had momenten dat hij er mee wilde kappen.

Mijn vader, die mij altijd aanspoorde.

Gijs en Mees, mijn zoontjes, die voor het slapen nog even naar de visjes op de computer kwamen kijken.

Hanneke en Roosje, mijn vrouw en dochtertje, die met de jongens blij zullen zijn dat dit boekje eindelijk klaar is. 
Curriculum vitae 
André Aloysius Eugène Augustinus de Smet werd geboren op 15 december 1960 te Tilburg. Hij volgde de middelbare schoolopleiding atheneurn $\beta$ aan het St. Thomas College te Venlo en studeerde geneeskunde aan de Rijksuniversiteit Gent (België) en aan de Rijksuniversiteit Groningen. Hij behaalde het artsdiploma in 1988.

De eerste helft van de algemeen chirurgische opleiding (januari 1989 - december 1991) genoot hij in het Academisch Ziekenhuis Maastricht (opleider: Prof Dr G. Kootstra), de tweede helft in het Catharina Ziekenhuis te Eindhoven (januari 1992 - september 1994, opleider: Dr J.G. Prins),

In 1989 is hij getrouwd met Hanneke Mattousch en samen hebben zij 3 kinderen, Gijs, Mees en Roos.

$\mathrm{Na}$ de algemeen chirurgische opleiding en een korte vasculaire stage te Los Angelos en te Stanford volgde hij gedurende 2 jaar (januari 1995 - december 1996) de vervolgopleiding vaatchirurgie in het St Antonius Ziekenhuis te Nieuwegein (opleider: Dr F.L. Moll). Sinds januari 1997 werkt hij als algemeen chirurg met aandachtsgebied vaatchirurgie in het St. Clara Ziekenhuis te Rotterdam. 